\title{
Saccharomyces cerevisiae DNA helicases Mph1, Srs2 and Sgs 1 collaborate for the reinitiation of stalled or collapsed replication forks
}

\author{
Dissertation \\ Zur Erlangung des Doktorgrades \\ der Mathematisch-Naturwissenschaftlichen Fakultäten \\ Der Georg-August-Universität zu Göttingen
}

Vorgelegt von

Evandro Rocco Panico

Aus Casarano

ITALIEN

Göttingen 2006 
D 7

Referent: PD Dr. Wilfried Kramer

Korreferent: PD Dr. Andreas Schwienhorst

Tag der mündlichen Prüfung: 6 Juli 2006 
Replication fork arrest or collapse and the DNA damage checkpoint response

Error-free and error-prone rescue of stalled replication

forks by the post replicative repair pathway

Mechanisms of DNA damage tolerance

Post replicative repair pathway and PCNA modifications

Interrelationships between PCNA modifications

Homologous recombination as alternative to PRR for resolution of stalled/collapsed replication forks

Mechanisms of Homologous Recombination

Models for error-free resolution of stalled or collapsed replication forks via homologous recombination

The RecQ family of helicases contribute to resolution of recombinogenic structures arising after impediment of replication fork progression

The Saccharomyces cerevisiae MPH1 gene 20

$\begin{array}{ll}\text { MPH1 Human homolog FANCM } & 21\end{array}$

$\begin{array}{ll}\text { MATHERIALS AND METHODS } & 24\end{array}$

$\begin{array}{ll}\text { Media } & 24\end{array}$

Chemicals inducing DNA damage 25

$\begin{array}{ll}S \text {. Cerevisiae strains used in this study } & 26\end{array}$

Plasmids 31

Tetrad analysis $\quad 31$

Drop dilution assay (DNA damage sensitivity test) 32

$\begin{array}{ll}\text { Spontaneous mutation rate determination } & 32\end{array}$

$\begin{array}{ll}\text { RESULTS } & 34\end{array}$

RAD52 epistasis group and strand invasion process $\quad 34$

Genetic interactions between S. Cerevisiae MPH1 and SRS2 genes 38

The SRS2 gene and its role in homologous recombination 38

mph1 srs2 synthetic lethality in the CEN.PK2 strain background 39

$m p h 1$ and srs2 genetic interaction in other strain backgrounds 44

Homologous recombination causes lethality in the double mutant mph1 srs $2 \quad 47$ 
Deletion of the genes involved in the DNA damage checkpoint pathway suppresses the $m p h 1$ srs 2 synthetic lethality

$M P H 1$ and the RAD54 gene $\quad 58$

SRS2 and PCNA SUMOylation $\quad 59$

Investigations on the viable mph1 srs2 spores $\quad 62$

$\begin{array}{ll}\text { Extension of the genetic analysis to the S. cerevisiae SGS1 gene } & 64\end{array}$

The Sgs1 helicase and its activities in DNA methabolism 64

Multicopy $S G S 1$ can partially rescue the genotoxic sensitivities
of mph1 and srs 2 single mutants and $m p h 1$ srs 2 double mutants

REV3 dependence of the sgs1 mutator phenotype $\quad 69$

$\begin{array}{ll}\text { DISCUSSION } & 70\end{array}$

$\begin{array}{ll}\text { A likely function for Mph1 is D-loop formation or processing } & 70\end{array}$

$\begin{array}{ll}\text { mph1 srs2 Synthetic growth defect } & 71\end{array}$

The importance of Srs2, Sgs1, Rad54 and Mph1 proteins during replication 72

Replication fork arrest as one of the causes of the $m p h 1$ srs 2 synthetic growth defect

Replication fork restart after collapse is defective in the $m p h 1 s r s 2$

double mutant

$\begin{array}{ll}\text { REFERENCES } & 79\end{array}$

$\begin{array}{ll}\text { ABBREVIATIONS } & 95\end{array}$ 


\section{INTRODUCTION}

DNA replication is one of the fundamental processes in all living cells. It has to be a very accurate and processive process in order to produce two identical copies of the genetic material thus ensuring genome stability over many generations. DNA lesions such as base modifications, template strand breaks, a protein bound to DNA or other barriers are examples of obstacles preventing progression of DNA replication. Cellular responses to these obstacles are represented by DNA repair, DNA damage tolerance and DNA damage checkpoint mechanisms. DNA damage arising during replication activates the intra-S-phase DNA damage checkpoint; the DNA replication process will slow down and it will be tightly coordinated with the repair process. In case of a DNA lesion stalling the replication fork translesion synthesis may be a rescue pathway allowing DNA replication to proceed past the damaged base. Alternatively, homologous recombination may represent an error-free repair pathway restoring stalled or collapsed replication forks. As illustrated by the genome instability and cancer predisposing human diseases like Bloom syndrome, Ataxia telangiectasia, Fanconi Anemia and Rothmund-Thomson syndrome the cooperation between DNA replication and DNA damage response is of vital importance in order to assure the accurate replication of the genome (Rouse and Jackson 2002; Cobb et al 2002; Oakley and Hickson 2002; Prakash et al 2004; Rudolph et al 2006).

\section{REPLICATION FORK ARREST OR COLLAPSE AND THE DNA DAMAGE CHECKPOINT RESPONSE}

Exogenous agents such as UV light and ionizing radiation or endogenous agents such as water and reactive oxygen species, generated during respiration, are responsible for the generation of DNA damages. They are mainly represented by strand breaks, base modification and bulky adducts (Oakley and Hickson 2002) and they may provoke the arrest of replication forks since the tight binding pocket of the replicative polymerases prevents the copying of damaged nucleotides in the template strand (Friedberg et al 2001; Kool et al 2002). Furthermore, secondary lesions such as DNA double strand ends may arise when the replication fork runs into unrepaired nicks or gaps in the template strand thus causing fork collapse (Kuzminov 1995). 
Damage arising during S-phase is problematic to the cell since replication of the genome must be completed and should proceed without replicating the DNA damage. Functional S-phase checkpoint mechanisms are essential for cell survival in the presence of replicative stress (Nyberg et al 2002) and they constitute a complex signaling pathway to halt genome duplication and to promote DNA repair (Branzei and Foiani 2005). This signaling pathway can be divided into factors, as illustrated in the table 1, acting as sensors which recognize and bind to sites of DNA damage and mediators which facilitate the transmission of the checkpoint signal between sensors and effector proteins (Gottifredi and Prives, 2005). Yeast and human responses to DNA damage during replication are similar and the proteins involved are also well conserved between the two species (see also table 1) (Elledge et al 1996). An overview of mechanisms and proteins allowing cells to cope with obstacles preventing replication completion is presented. Proteins belonging to human or yeast cells will be discussed and distinguished by a prefix (h, human; sc, S. cerevisiae); more details about yeast factors playing a key role in the DNA damage checkpoint can be found in the Result section.

Table 1. Checkpoint homologs in S. cerevisiae and Humans

\begin{tabular}{llll}
\hline Group & S. cerevisiae & Humans & Function \\
\hline Sensors & Rad24 & RAD17 & RCF like lamp loader \\
& Ddc1 & RAD9 & PCNA like clamp \\
& Mec3 & HUS1 & PCNA like clamp \\
& Rad17 & RAD1 & PCNA like clamp \\
& Mec1 & ATR & PI3 like kinase \\
& Ded2/Pie1/Lcd1 & ATRIP & Interaction with Mec1 and ATR \\
& & & \\
& Tel1 & ATM & PI3 like kinase \\
& & & \\
& Rad9 & BRCA1 & Mediates activation of effectors \\
& Mrc1 & Claspin & Mediates activation of effectors \\
& & & \\
\hline \multirow{5}{*}{ Effectors } & Rad53 & CHK2 & S/T kinase \\
& Chk1 & CHK1 & Kinase \\
\hline
\end{tabular}

It is suggested that the DNA damage checkpoint response during replication is triggered through the recognition of DNA abnormalities common to all DNA lesions. 
Single stranded DNA (ssDNA) is one candidate, as structure, for recognition and recruitment of checkpoint molecules (Costanzo and Gautier 2003). Proteins related to the family of the phospatidylinositol 3-kinases (PI-3 kinase) are, in yeast and human, important for activation of the DNA damage checkpoint response. In particular, scMec1 and the homolog hATR (Ataxia Telangiectasia and rad-related) are the primary S phase checkpoint kinases responding to polymerase blocking DNA lesions and stalled replication forks. hATM (Ataxia Telangiectasia mutated) plays a key role in responding to double strand breaks (DSBs) in humans whereas the homolog scTel1 seems to play a secondary role in such circumstances (Ellege 1996; Usui at al 2001; Shiloh 2003; Gottifredi and Prives 2005). scMec1 and hATR respectively in complex with scDdc2 (also called scLcd1 or scPie1) and hATRIP (ATR-interacting protein) show ability to associate with DNA replication forks even in the absence of DNA damage. The recruitment, concomitant with origin of replication firing, might indicate a direct role of scMec1 and hATR in sensing signals of replicative stress such as changes in the speed and processivity of polymerases or in the extent of ssDNA during the replication process (Paciotti et al 2000; Cortez et al 2001; Melo et al 2001; Rouse and Jackson 2002; Unsal-Kakmaz and Sancar 2004; Gottifredi and Prives 2005).

DNA replication requires loading of the proliferating cell nuclear antigene factor (PCNA) onto DNA. PCNA, coded by the essential gene POL30, is a homotrimeric DNA clamp functioning at multiple levels in directing DNA metabolic pathways like replication, repair, DNA modification or chromatin remodelling. PCNA encircles double strand DNA (dsDNA) and slides across it functioning as processivity factor for replicative polymerases. Loading of PCNA onto DNA template-primer junctions is performed in an ATP-dependent process by replication factor C (RFC) (Tsurimoto 1999, Jónsson and Hübscher 1997; Majka et al 2004). PCNA-like structures, required in case of DNA damage, are found in yeast and humans and they are formed by the heterotrimeric complexes $\mathrm{scDdc} 1 / \mathrm{scRad} 17 / \mathrm{scMec} 3$ and hRAD9/hRAD1/hHUS1 respectively. They are loaded onto DNA by RFC-like complexes composed of the four small subunits of RFC (Rfc2-5) and scRad24 or hRAD17 proteins sharing homology to the large subunit of RFC, Rfc1 (Green et al 2000; Melo et al 2001; Zou et al 2002; Bermudez et al 2003). Loading of PCNA-like complexes onto DNA, in case of damage, is thought to allow recruitment of specific DNA polymerases such as translesion polymerases capable of bypassing lesions 
impeding replication fork progression (Rouse and Jackson 2002 a; Majka and Burgers 2004). PCNA and RFC-like structures are also required for effective checkpoint activation since in their absence the scMec1/hATR-dependent phosphorylation of downstream targets like the mediators proteins scRad9, scMrc1, hBRCA1 and Claspin is severely reduced (de la Torre Ruiz et al 1998; Emili 1998; Bao et al 2001; Zou et al 2002; Bao et al 2004). In yeast, phosphorylation of Rad9 is required for activation of scRad53 and scChk1 kinases after DNA damage whereas phosphorylation of scMrc1 is required for activation of scRad53 in response to stalled replication fork. Once activated, scRad53 and scChk1 phosphorylate downstream targets as Dun1 and Pds1 leading to cell cycle arrest, induction of repair genes, inhibition of late replication origin firing and stabilization of stalled replication forks (Santocanale and Diffley 1998; Lopes et al 2001; Tercero and Diffley 2001). In human hClaspin is an highly conserved mediator protein related to the scMrc1 protein. It is responsible for activation of the downstream effectors CHK1 and CHK2 kinases in S-Phase (Lin et al 2004). hBRCA1 with hBRCA2 are the so called breast cancer susceptibility genes products identified some years ago through the analysis of families at high risk from breast and ovarian cancer (Venkitaraman 2002). Homologs of hBRCA1 and hBRCA2 are not found in yeast but hBRCA1 is grouped together with the scRad9 protein based on their possible functional similarity. Once phosphorylated by hATM or hATR hBRCA1 forms nuclear repair foci together with other repair proteins during stalled replication and facilitates the ability of hATM or hATR to phosphorylate downstream effectors including hChk2 and the tumor suppressor p53 (Gatei et al 2000; Tibbets et al 2000; Foray et al 2003).

\section{ERROR-FREE AND ERROR-PRONE RESCUE OF STALLED REPLICATION FORKS BY THE POST REPLICATIVE REPAIR PATHWAY}

Cells developed a repertoire of repair systems for the maintenance of DNA. Most of these mechanisms operate within dsDNA. They rely on the excision and resynthesis of damaged stretch of ssDNA using the complementary strand to restore the original sequence information. In contrast, they can not operate on ssDNA arising 
during replication because the two parental strands are separated (Friedberg 2003). Alternative mechanisms are required during replication to cope with DNA lesions that may impede fork progression. The cell can adopt DNA-damage-tolerance mechanisms able to bypass the lesion without removing the DNA damage or errorfree repair mechanisms certainly preferred in order to ensure genome stability. The post replicative repair pathway (PRR) is one pathway responsible for both errorprone or error-free rescue of stalled replication forks (Ulrich 2005).

\section{MECHANISMS OF DNA DAMAGE TOLERANCE}

A way to continue DNA replication in the presence of a lesion blocking the replication machinery is to polymerize across the lesion. This process called translesion DNA synthesis (TLS) requires the recruitment of specialized polymerases (Prakash and Prakash 2002). In contrast to replicative polymerase, which synthesize DNA with a high degree of accuracy and are easily blocked by lesions in DNA, TLS polymerases synthesize undamaged DNA with much higher error rates and they have a more spacious catalytic centre which can insert nucleotides opposite a variety of abnormal structures. They are also characterized by a very low processivity so that they fall off the template after insertion of few nucleotides. Most of them belong to a class of enzymes called the $\mathrm{Y}$ family containing a large number of polymerases specialized for different type of lesions. Specialization and tight control over their activity allows to minimize the danger of inducing mutations during TLS (Prakash et al 2005). A TLS polymerase in budding yeast is Pol $\eta$. It is encoded by the gene $R A D 30$, can replicate through cis-syn thymine dimers inserting two adenines (Washington et al 1999; Washington et 2000). Loss of the human homolog Poln leads to the xeroderma pigmentosum variant (XP-V) syndrome, in which individuals have reduced ability to replicate past UV damage and suffer a vastly increased incidence of skin cancer (Masutani et al 1999; Masutani et al 2000). Another translesion polymerase in budding yeast is Pol $\zeta$ which consists of the two subunits Rev3 and Rev7. It works together in TLS with the Rev1 protein, a deoxycytidyl transferase able to incorporate a cytosine opposite guanine and also opposite an abasic site. Pol $\zeta$ was shown to be efficient in the extension of mismatched primer termini at a variety of damages like UV lesions and abasic sites (Lawrence and Christensen 1976; Morrison et al 1989; Nelson et al 1996). 


\section{POST REPLICATIVE REPAIR PATHWAY AND PCNA MODIFICATIONS}

In budding yeast the principal member of the PRR pathway is Rad6. It is a ubiquitin conjugation enzyme (UBC) able to transfer the small protein ubiquitin to a target protein (Jentsch et al 1987). rad6 mutations confer a high degree of sensitivity towards DNA damaging agents, an enhanced spontaneous mutation rate but a defect in damage-induced mutagenesis (Montelone et al 1981; Prakash 1974). Rad6 exists in a complex with Rad18; a RING finger protein which binds ssDNA. The RAD18 gene belongs to the PRR pathway and the phenotype of rad18 mutants resembles that of rad6 mutants. Thus, a role for Rad18 could be targeting of Rad6 to ssDNA produced by the stalling of replication forks at a lesion site (Bailly et al 1994; Bailly et al 1997). The Rad6-Rad18 complex is responsible for monoubiquitination of PCNA in response to DNA damage at a highly conserved lysine residue K164 (Hoege et al 2002). Rad6-Rad18-mediated monoubiquitination of PCNA is necessary for TLS mediated by Pol $\zeta$ and Pol $\eta$. In fact, PCNA mutants that can not be ubiquitinated at K164 have the same DNA damage sensitivity as rev3 rad30 double mutants (Stelter and Ulrich 2003). Once PCNA is monoubiquitinated by the Rad6Rad18 complex a multiubiquitin chain can be assembled by the Rad5-Ubc13-Mms2 complex. Rad5, another RING finger protein within the RAD6 group, possesses DNA-binding capacity, an ATPase activity stimulated by ssDNA and interacts with Rad18 (Johnson et al 1994; Ulrich and Jentsch 2000). Rad5 interacts with Ubc13 by means of its RING finger domain. Ubc13 is a UBC enzyme that, in cooperation with Mms2 (non-canonical UBC enzyme), forms the complex Ubc13-Mms2 able to assemble multiubiquitin chain at the monoubiquitinated lysine residue K164 of PCNA. In the multiubiquitin chain the ubiquitin moieties are linked through the lysine residue K63 of ubiquitin (Hofmann and Pickart 1999). Such modification defines an error-free Rad5-dependent pathway where the undamaged complementary sister chromatid is used as template to accomplish replication past the damaged site (Li et al 2002; Hoege et al 2002). Such mechanism is thought to be responsible for repair of UV-induced DNA damage and is also known as template switch or copy choice type of damage bypass (figure 2 II b, e, h) (Higgins et 1976, Haracska et al 2004). Yeast PCNA can be also modified by the small ubiquitin-related modifier SUMO. PCNA SUMOylation targets primarily the lysine residue K164 and to a 
lesser extent K127. SUMO modification of PCNA requires the Ubc9 SUMO conjugating enzyme and the Siz1 SUMO ligase. Ubc9 interacts with PCNA, Rad18 and Rad5 indicating its involvement in the PRR pathway (Hoege et al 2002).

\section{INTERRELATIONSHIPS BETWEEN PCNA MODIFICATIONS}

The effect of PCNA SUMOylation and its relations with PCNA mono- and polyubiquitination has been subject to intense study. PCNA SUMOylation was shown to have an inhibitory effect on DNA damage tolerance since pol30(K127/K164), a mutant lacking both lysine residues, was found to be more tolerant to DNA damage than pol30(K164). pol30(K164) can not be ubiquitilated but can still be modified by SUMO at the K127 residue (Hoege et al 2002). After deletion of the SIZ1 gene abolishing PCNA SUMOylation, the single and the doublelysine mutants exhibited the same sensitivity towards UV light irradiation and chemically induced DNA damage. This finding indicates that the enhanced sensitivity previously observed in the pol30(K164) single mutant, compared to the pol30(K127/K164), can be ascribed to SUMO modification at K127 (Stelter and Ulrich 2003).

Monoubiquitination of PCNA was demonstrated to be required for translesion synthesis by Pol $\zeta$ and Pol $\eta$. Indeed, in a mutant where deletion of the genes coding for both translesion polymerases is combined with pol30(K164) and sizl mutations, the DNA damage sensitivity is the same as in the double mutant pol30(K164) sizl (Stelter and Ulrich 2003). Furthermore, in rad6 and rad18 single mutants damage induced mutagenesis is inhibited at the same level as in the rev3 mutant. On the contrary, it is not affected in a sizl single mutant or in a sizl ubcl3 double mutants. These results clearly indicate that monoubiquitination of PCNA is a prerequisite for Polל-dependent damage-induced mutagenesis (Cassier-Chauvat and Fabre 1991; Stelter and Ulrich 2003). Evidences that error-prone and error-free branches of PRR operate independently results from additive or synergistic relationship between mutations that inactivate the individual systems. For example, deletion of MMS2 gene results in a significant increase in spontaneous mutagenesis and this increase is dependent on the functional REV3 gene (Broomfield S. et al 1998). Furthermore, although $m m s 2$ and rev3 single mutants display only moderately increased sensitivity to various DNA damaging agents, the $m m s 2$ rev3 double mutant is very sensitive to 
these agents and the effect is clearly synergistic (Xiao et al 1999). When considering the spontaneous mutator phenotype, PCNA SUMOylation seems to play a role in this process as well. Since Pol $\zeta$ is responsible for $50-70 \%$ of all spontaneous mutations it is surprising that the rad6 and rad18 mutants display a spontaneous Pol $\zeta$-dependent hypermutator phenotype (Quah et al 1980; Roche et al 1995). Furthermore the same phenotype was observed in the $u b c 13$ mutant. A possible explanation came from the findings that high spontaneous mutagenesis can be reduced in the $u b c 13$ or rad18 mutants introducing the pol30(K164) or to an even lower extent with the pol30(K164/K127) mutation. This results imply that SUMO modification of PCNA is responsible for elevated spontaneous mutagenesis in $u b c 13$ and rad18. Indeed, a sizl deletion is also able to reduce the rad18 spontaneous mutagenesis to the pol30(K164/K127) mutant level, whereas in the $u b c 13$ mutant the reduction observed is only partial. Probably reduced mutation rates are seen when neither SUMO nor ubiquitin can be attached to PCNA (as in pol30(K164/K127) mutant). These data suggest that Pol $\zeta$-dependent spontaneous mutagenesis can be stimulated by either mono-ubiquitination or SUMO modification of PCNA. Sizl deletion can not completely abolish the spontaneous mutator phenotype in the $u b c 13$ mutant because mono-ubiquitination is still possible (Stelter and Ulrich 2003).

The ability of the sizl mutation to suppress the UV sensitivity of rad6 and rad18 mutants resembles that of $s r s 2$ deletion. In both cases the suppressor effect requires a functional RAD52 pathway responsible for DSBs repair and for genetic recombination (Lawrence and Christensen 1979; Schiestl et al 1990; Symington 2002; Pfander et al 2005). The SRS2 gene codes for a DNA helicase that appears to exert mainly anti-recombinogenic functions (Aboussekhra et al 1989; Krejci et al 2003; Veaute et al 2003) and recently it was found to directly interact with the SUMO modified form of PCNA (Pfander et al 2005). This findings indicates that PCNA SUMOylation specifically blocks a recombination pathway which might be an alternative to PRR. A more detailed description of Srs2 in this context is given in the Results section. 


\section{HOMOLOGOUS RECOMBINATION AS AN ALTERNATIVE TO PRR FOR RESOLUTION OF STALLED/COLLAPSED REPLICATION FORKS}

Recombination is the cellular process of exchange or transfer of information between DNA molecules. Homologous recombination (HR) process involves DNA molecules with perfect or near-perfect homology over several hundreds of base pairs. HR plays an essential role in the maintenance of genome stability in prokaryotic and eukaryotic organisms. Its primary role in mitotic cells is to repair DSBs and also DNA double strand ends formed after replication fork collapse due to the presence of unrepaired gaps in the template strand. It is also required for telomere maintenance and proliferation in the absence of telomerase. During meiosis it establishes a physical connection between homologous chromosomes ensuring their correct disjunction at the meiotic division. Much of the understanding of the recombination processes is based on works from $S$. cerevisiae where genetic screens allowed the identification of more than 30 genes involved in recombination (Paques and Haber 1999; Symington 2002; Krogh and Sygmington 2004).

\section{MECHANISMS OF HOMOLOGOUS RECOMBINATION}

Two types of HR, crossing-over and gene conversion, were identified in budding yeast based on the meiotic segregation of heterozygous markers. In this organism the products of a single meiosis can be recovered for analysis in the form of an ascus containing four haploid spores. A crossing-over between linked heterozygous markers produces a new arrangement of the two markers but they are still recovered in a Mendelian ratios in the four spores of the asci (Symington 2002). Gene conversion is defined as a nonreciprocal transfer of genetic information from one molecule to its homologue. Usually it involves two alleles of one gene; however this process can comprise many contiguous genes, including for example the entire distal part of a chromosome. The gene conversion between two alleles of one gene will produce the duplication of one of the two alleles with corresponding loss of the other giving rise to a non-Mendelian segregation in the four spores of the ascus (Fogel and Mortimer 1969; Hurst et al 1972). 
The double-strand-break repair (DSBR) model is one of those proposed to explain the molecular mechanism of recombination. As shown in figure $1(a, b, c, d)$, in the DSBR model the ends of a DSB are resected to form 3'-ssDNA tails which are suitable for the invasion of an homologous duplex and, after invasion occurred, they can act as primer for initiation of new DNA synthesis. The invasion and subsequent elongation will form a D-loop structure which can pair with the 3 '-ssDNA tail of the other DSB allowing also the elongation by DNA synthesis of the 3'-end of the non invading strand. After ligation, a double-Holliday-junction ( $\mathrm{dHJ}$ ) intermediate can be formed and this structure can than be cleaved by a resolvase (Orr-Weaver et al 1981; Orr-Weaver and Szostak 1983; Szostak et al 1983).

A variant of the DSBR model is the synthesis-dependent strand-annealing (SDSA) model. As shown in figure 1 (a, e, f), in the SDSA model the strand invasion occurs as proposed before but after DNA synthesis the D-loop is disrupted and the elongated invading strand is displaced from the template. It can now pair with the 3'-ssDNA tail from the other side of the break. DNA synthesis can now be initiated by the non invading 3'-end in order to fill the gap. It is also possible that both 3 '-ssDNA tails invade the donor and initiate DNA synthesis, in this case both invading strands are displaced and able to anneal through the newly synthesized complementary regions. (Nassif et al 1994; Ferguson and Holloman 1996).

In circumstances where one of the ends of a DBS is not avilable the break induced replication (BIR) model has been suggetsed. The theoretical feature of BIR (figure 1 $\mathrm{a}, \mathrm{g}, \mathrm{h}$ ) is that after strand invasion of the 3 '-end there is no possible stabilization of the displaced strand by annealing with the second DSB end. As consequence a replication fork is established and DNA synthesis can proceed to the end of the chromosome (Davis and Symington 2004; Morrow et al 1997). This model could account for the long tracts of gene conversion reported in mitosis (Golin and Esposito 1984; Golin and Tampe 1988; Malkova et al 1996).

Another model for repair of a DSB occurring between two flanking homologous regions is referred to as single-strand annealing (SSA, figure $1 \mathrm{i}, \mathrm{j}, \mathrm{k}$ ). In this model, after formation of the DSB, the ends are resected and the 3 '-ssDNA tails can anneal together if resection is sufficient to reveal complementary regions and ssDNA tails are still present can be removed by nucleases and the gaps filled by DNA synthesis (Symington 2002; Krogh and Sygmington 2004). In this model the repair of the chromosome results in a deletion containing a single copy of the repeated sequence. 
Such events were detected in yeast and animal cells using artificial direct repeats (Maryon and Carrol 1991; Fishman et al 1992).

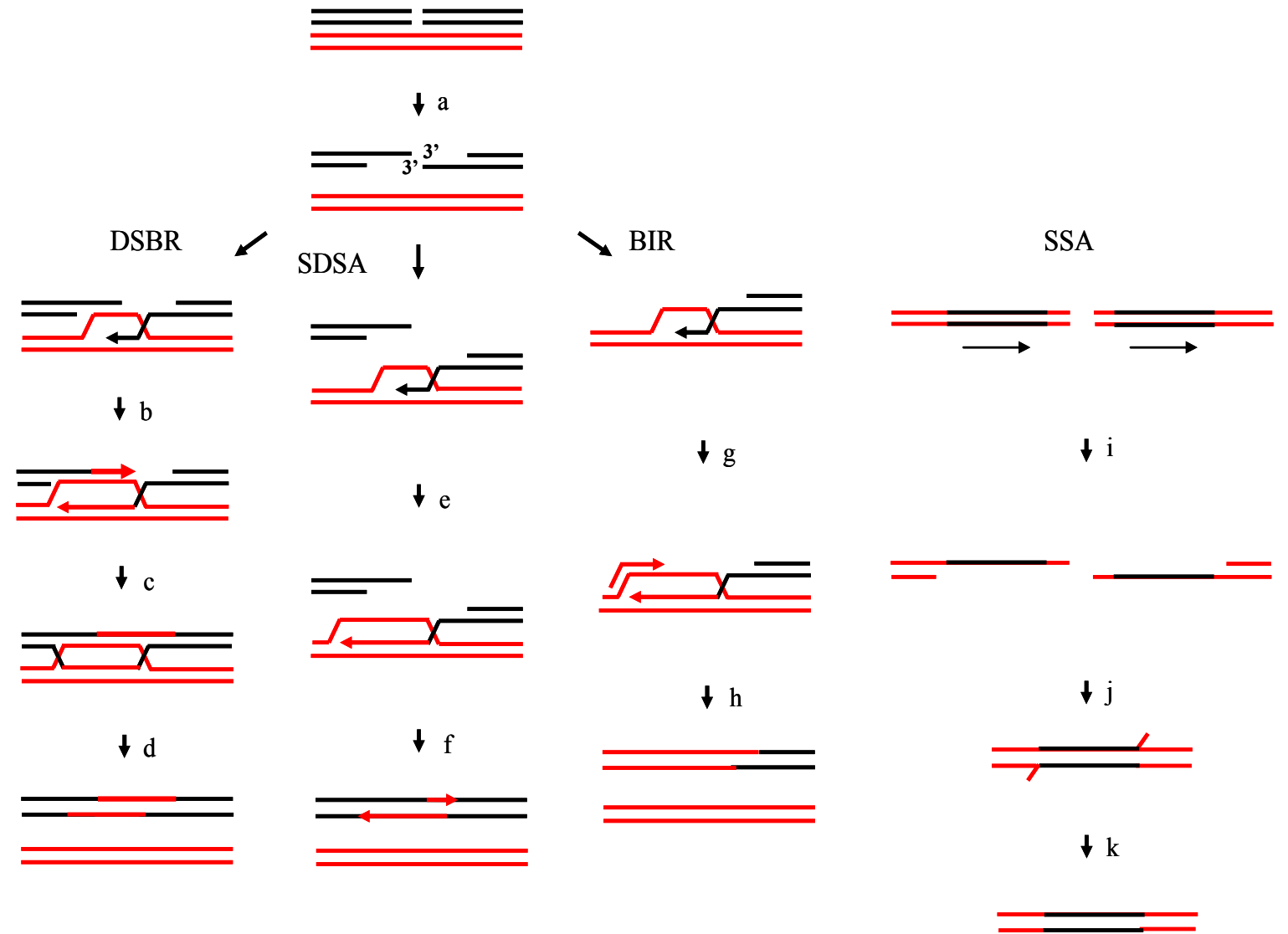

Figure 1. Models of homologous recombination. DSBR: in the double strand break repair model the ends are processed to form 3'-ssDNA tails. One 3'-ssDNA tail invade the homologous duplex forming the D-loop and priming DNA synthesis. The D-loop can pair with the 3'-ssDNA tail of the other DSB allowing elongation of the 3 '-end of the non invading strand. After ligation, a double-Holliday-junction (dHJ) intermediate can be formed and this structure can than be resolved. SDSA: in the synthesis dependent strand annealing model the ends are processed to form 3'-ssDNA tails one of which invade the homologous duplex forming the D-loop and priming DNA synthesis. After DNA synthesis the D-loop is disrupted and the elongated invading strand is displaced from the template. It can now pair with the 3'-ssDNA tail from the other side of the break. DNA synthesis can now be initiated by the non invading 3'-end in order to fill the gap. BIR: in the break induced replication model the 3'end invades the homologous duplex and DNA synthesis proceeds to the end of the chromosome. SSA: in the single strand annealing model a DSB between two direct repeats is made and the ends are resected. The 3'ssDNA tails can anneal together if resection is sufficient to reveal complementary regions. ssDNA tails that are still present can be removed by nucleases and the gaps filled by DNA synthesis 


\section{MODELS FOR ERROR-FREE RESOLUTION OF STALLED OR COLLAPSED REPLICATION FORKS VIA HOMOLOGOUS RECOMBINATION}

Homologous recombination may represent an alternative to PRR pathway for the rescue of stalled or collapsed replication forks. The DNA lesion arresting the replication machinery may produce different consequences depending on which parental strand contain the lesion. A DNA lesion encountered by the lagging strand blocks the synthesis of the Okazaki fragment extending towards the lesion but should not affect the progression of the replication fork. Lagging strand synthesis can proceed by elongating the primer for the next Okazaki fragment leaving a gap in the nascent lagging strand. The free 3' end of the incomplete lagging strand could be utilized by the homologous recombination machinery to invade the homologous sequence in the sister-chromatid allowing DNA synthesis beyond the lesion or, as an alternative, TLS may also be utilized to directly bypass the DNA lesion (Oakley and Hickson 2002). On the other end, a DNA lesion blocking the leading strand may block the replication machinery but not the lagging stand synthesis. It can continue for a while producing a lagging strand longer than the leading strand (Svoboda et al 1995; Cordeiro-Stone et al 1999; Pagés and Fuchs 2003; Higuchi et al 2003). In such circumstances a possible way to bypass a DNA lesion blocking the replication fork is represented by the formation of a "chicken-foot" structure (figure 2 II b). A "chicken-foot" structure is a four-way junction structurally equivalent to the Holliday junction recombination intermediate (Oakley and Hickson 2002). It is formed by the backward movement of the fork and subsequent base pairing of the parental and nascent DNA strands. Development of torsional stress ahead of the replication fork could account for the backward movement of the fork in this model (Postow et al 2001a; Postow et al 2001b). If the DNA lesion blocks the synthesis of the leading strand as depicted in figure 1 and the lagging strand is elongated beyond the lesion, the base pairing of the nascent DNA strands in the chicken-foot structure could provide the right information for elongation of the leading strand (template switch type of damage bypass, see also page 11). The fork might than be reset by "reverse" branch migration in the direction of replication allowing the reassembly of a new replication machinery (figure $2 \mathrm{II}$ e and $\mathrm{h}$ ). 
In this case the lesion has to be repaired at a later time. Another possibility would be the cleavage of the four-way structure by resolving enzymes which may also act directly at the stalled replication fork (figure 2 II e f and III c f). In both cases one of the replicated arms would be released and might undergo a strand invasion process into the sister duplex assisted by the recombination machinery (figure $2 \mathrm{f}$ and $\mathrm{j}$ ). The D-loop structure formed after the strand invasion can be further processed by a specific endonuclease in order to restart replication. In particular, the heterodimeric endonuclease Mms4/Mus81 is thought to cleave three branched DNA structures in order to restore replication forks (Kaliraman et al 2001). The same model, as depicted above, could also account for replication fork restart after collapse due to unrepaired nicks or gaps in the template strand since in this case a double strand end would be formed. The leading strand blocked at a DNA lesion may also be subject to a direct strand invasion process into the sister chromatid duplex resulting in the formation of a D-loop structure so that the 3' end may be elongated beyond the lesion (figure $2 \mathrm{I}$ a and d). The intermediate that is formed (figure 2 II d) might be resolved by disruption of the D-loop by an helicase followed by the restoration of a replication fork (figure $2 \mathrm{I} \mathrm{d}$ and $\mathrm{h}$ ). It might also be that the leading strand is elongated toward the end of the lagging strand producing a chicken foot structure that can be resolved as previously proposed (figure $1 \mathrm{I} \mathrm{d}$ and e). If during D-loop extension the displaced strand hybridize with the complementary strand of the sister chromatid a Holliday junction will be formed. It would than became a double Holliday junction if the invading strand is at a certain point placed back on its original template (Rudolph et al 2006). 


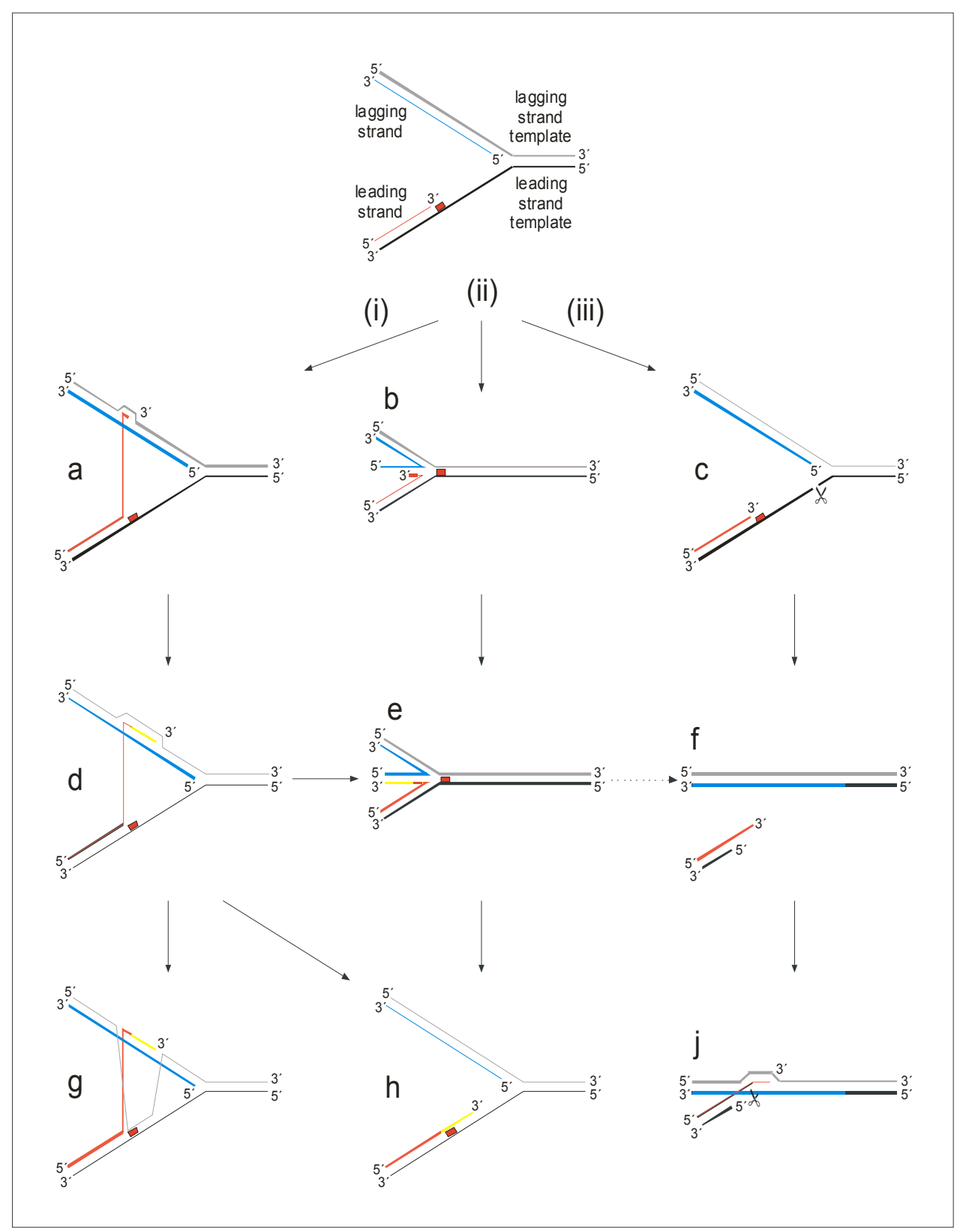

Figure 2. Models for error-free rescue of replication forks stalled at a damage (orange rectangle) on the leading strand template. The newly synthesized DNA is represented by a yellow line. (i) The terminated leading strand can invade the sister chromatid forming the intermediate a where elongation of the 3 '-end of the leading strand leads to intermediate $\mathrm{d}$. This could be converted into the intermediate $\mathrm{g}$ if the displaced lagging strand template hybridize with the leading strand template or into the intermediate e if the elongation of the 3 '-end reaches the end of the lagging strand. Another possibility could be the formation of the intermediate $\mathrm{h}$ if the D-loop is disrupted by an helicase. (ii) A fork regression, after replication arrest at the leading strand, would yield the intermediate $b$ where the base pairing of the nascent DNA strands allows the elongation of the leading strand with formation of the intermediate e. This can be converted into the intermediate $h$ by reverse branch migration. The intermediate e could also be cleaved and processed to form the intermediate f. (iii) Cleavage of the intermediate $\mathrm{c}$ at the leading strand template and resection of the resulting 5'-end to create a 3' overhang will lead to the intermediate $\mathrm{f}$ and after the strand invasion process with the sister chromatid the intermediate $\mathrm{j}$ will be formed which could be further cleaved in order to restart replication. 


\section{THE RECQ FAMILY OF HELICASES CONTRIBUTE TO RESOLUTION OF RECOMBINOGENIC STRUCTURES ARISING AFTER IMPEDIMENT OF REPLICATION FORK PROGRESSION}

The proteins of the RecQ family are DNA helicases with homologues in several prokaryotic and eukaryotic species. They all share a central region of 350-400 residues also found in other DNA and RNA helicases. RecQ helicases are required for ensuring that structural abnormalities arising after replication fork blocks are properly corrected. In mutants defective in these proteins, abnormal replication was observed and cells display aberrant responses to DNA-damaging agents or inhibitors of DNA synthesis (Chakraverty and Hickson 1999; Karow et al 2000). In humans five members of the RecQ family were identified and three of them $B L M, W R N$ and RECQ4 are associated with a genetic disorder. Mutation in the $B L M$ gene lead to the Bloom's syndrome which features are immunodeficiency, dwarfism and predisposition to a wide range of cancers (Ellis et al 1995). Cells from patients affected by the Bloom's syndrome display elevated levels of sister-chromatid exchanges (SCEs), chromosome breakage and chromosomal rearrangement (Chaganti et al 1974). One biochemical activity of BLM is branch migration of Holliday junctions (Karow et al 2000). Moving each junction of the double Holliday junction towards the other, the double Holliday junction would be converted into a hemicatenane which could than be resolved by Topoisomerase III (Wu and Hickson 2003).

Mutation in the $W R N$ gene gives rise to the Werner's syndrome characterized by premature ageing related disorders (Shen and Loeb 2000). In the case of the Werner's syndrome the cells do not show elevated SCEs but illegitimate recombination and large chromosomal deletion (Shen and Loeb 2000). Mutations in the RECQ4 gene are associated with the Rothmund-Thomson syndrome (RTS). Individual with RTS display growth deficiency, skin pigmentation abnormalities, and predisposition to osteogenic sarcomas amongst other cancers. RTS cells have an increased frequency of chromosomal aberrations (Vennos and James 1995).

Budding yeast has a single RecQ family member encoded by the SGS1 gene. High levels of mitotic homologous recombination and illegitimate recombination were 
reported also in S. cerevisiae strains lacking the Sgs1 helicase (Gangloff et al 1994; Watt et al 1996; Yamagata et al 1998). Sgs1 interacts with topoisomerases Top3 and Top2 (Gangloff et al 1994; Watt et al 1995). This interaction is thought to be essential for the resolution of recombinogenic structures arising at paused forks, such as the four-way chickenfoot structure which formation is catalyzed by Rad51 and the other members of the HR pathway (Bjergbaek et al 2005).

\section{THE SACCHAROMYCES CEREVISIAE MPH1 GENE}

The subject of this $\mathrm{PhD}$ thesis is the MPH1 (mutator phenotype 1) gene from Saccharomyces Cerevisiae coding a nuclear protein with homology to the super family 2 (SF2) class of helicase enzymes since it contains all the seven characteristic motifs (Entian et al 1999; Scheller et al 2000). mphl deletion mutants shown an increased spontaneous mutation rate in a forward mutation assay to canavanine resistance and in a reversion assay of the amber mutation trp1-289 (Entian et al 1999). The $m p h 1$ spontaneous mutator phenotype was found to be REV3 dependent since it is abolished by the introduction of a rev3 mutation inactivating the errorprone DNA polymerase $\zeta$. Cells lacking Mph1 are also hypersensitive to the genotoxic agents like MMS, ethyl methanesulfonate (EMS), 4-NQO and to camptothecin (Scheller et al 2000). Purified Mph1 protein shown in an in vitro assay ATP hydrolytic function dependent on ssDNA for activation. A large increase in the ATPase activity when the ssDNA length reaches 40 residues was observed. Further increase in the DNA length had only a minor stimulatory effect on the ATPase activity. In the assay for DNA helicase activity Mph1 was able to unwind DNA duplex substrate having a 3 '-single strand overhang. Its in vitro helicase activity requires ATP and $\mathrm{Mg}^{2++}$ and shown a modest processivity. In fact, unwinding of a 100 bp DNA duplex was observed only in the presence of the heterotrimeric ssDNA binding factor Rpa. Rpa is thought to prevent DNA re-annealing by sequestering ssDNA produced as a result of strand separation (Prakash et al 2005). Genetic analysis revealed that the mphl mutation is synergistic, in terms of spontaneous mutator phenotype, with mutants defective in the Nucleotide Excision Repair (NER) and Base Excision Repair (BER) pathways. The synergistic effect is strong when the mph1 mutation is combined to deletions of APN1 and APN2 genes coding two AP endonucleases of the BER pathway. Since the apn1 apn2 double mutant shown a 
spontaneous mutator phenotype comparable to wild type level, the strong increase observed in the apn1 apn2 mph1 triple mutant indicates a possible MPH1 involvement in processing of spontaneous AP sites in an error-free manner (Schürer et al 2004). rad51, rad52 and rad55 deletions were found epistatic to $m p h 1$ with respect to spontaneous mutation rates and DNA damage sensitivity. This epistatic genetic relation with the HR pathway indicates that the error-free bypass of DNA lesions involving Mph1 requires the HR pathway (Schürer et al 2004). mph1 mutants are proficient in mitotic and meiotic recombination. Therefore Mph1 seems to work in error-free bypass of DNA lesions and not general recombination (Scheller et al 2000; Schürer et al 2004).

\section{MPH1 HUMAN HOMOLOG FANCM}

A digression about the MPH1 human homolog FANCM is presented since it is also involved in mechanisms ensuring genome stability. FANCM is one of the components of the Fanconi Anemia (FA) pathway (Meetei et al 2005). The FA pathway, through the cooperation of multiple proteins, regulates a cellular response to DNA cross-linking agents and other genotoxic stresses that may stall a replication fork (Kennedy and D'Andrea 2005). In this pathway are involved as well the BRCA1 and BRCA2 gene products. Defect in this pathway produces an autosomal recessive and $\mathrm{X}$-linked disorder. It is characterized by congenital abnormalities, bone marrow failure and predisposition to develop cancers (Joenje and Patel 2001; D'Andrea and Grompe 2003). To date twelve genes (FANCA/B/C/D1/D2/E/F/G/I/J/L/M) belonging to this pathway are identified. At least eight of them (A, B, C, E, F, G, L, M) code for proteins interacting in a large nuclear complex also called "core complex" (Kennedy and D'Andrea 2005). Such complex, in particular the ubiquitin ligase subunit $\mathrm{L}$, is required for the monoubiquitination of FANCD2 during S phase of a normal cell cycle and is also required for inducible FANCD2 monoubiquitination following cellular exposure to DNA damaging agents. Deficiency in one of the proteins forming the core complex prevents FANCD2 monoubiquitination. The ubiquitinated form of FANCD2 (FANCD2-ub) migrate from a soluble nuclear compartment to the chromatin fraction. It colocalizes in nuclear foci with other DNA damage response proteins. In particular with the FANCD1/BRCA2, BRCA1, the RAD51 recombinase, PCNA and 
NBS1. NSB1 is a component of the MRE11/RAD50/NBS1 (MRN) complex that has 3'-5' exonuclease activity and is required for DNA processing prior to repair through HR. (Garcia-Higuera et al 2001; Nakanishi et al 2002; Taniguchi et al 2002; Gregory et al 2003; Meetei et al 2003; Hussain et al 2004; Wang et al 2004). Disruption of the FA pathway results in the absence of FANCD2 nuclear foci, leading to cellular and clinical abnormalities. In FA the chromosomal aberrations originate during replication and affect the newly replicated DNA and are microscopically visible as broken chromatids. The breakpoints are often misrepaired to generate a chromatid interchange figure such as a quadriradial, where two chromosome are fused together (Joenje and Patel 2001). FANCM was recently identified as a 250-KDa polypeptide of the FA core complex. Depletion of FANCM by short interfering RNA (siRNA) strongly reduced the levels of monoubiquitinated FANCD2 under basal condition and after induction with DNA damaging agents. Furthermore the cells showed increased DNA damage sensitivity. These results underline that FANCM has probably an essential function in the FA pathway where it is necessary for FA core complex assembly and FANCD2 monoubiquitination. FANCM contains an helicaseATPase domain highly conserved in the seven motifs present in the SF2 family of helicases. It contains also another domain homologous to the endonuclease domain of the human ERCC4, and the yeast Mus81 endonuclease (Meetei et al 2005). FANCM is closely related to the archeal protein Hef which posses both helicase and endonuclease activities and is involved in resolving stalled forks during DNA replication (Komori et al 2002). The homology with the yeast Mph1 protein is restricted to the DNA helicase domain since an endonuclease domain is absent in the yeast homolog. Intriguingly the endonuclease domain of FANCM, even if retained during evolution, seems to be degenerated and non-functional. Indeed, mutation of the nuclease domain of the chicken FANCM homolog in DT40 cells does not affect the sensitivity to cross-linker agents. These proteins may have derived from the same ancestor and experienced the loss of the nuclease domain during evolution. FANCM showed in vitro DNA-dependent ATPase function with affinity for ssDNA and forked structure. Mutation in the helicase domain causes loss of ATPase function and cell sensitivity to cross-linker agents (Mosedale et al 2005; Meetei et al 2005). Furthermore FANCM did not show in vitro helicase activity but translocase activity in the triple-helix displacement assay thus suggesting a possible role in dissociation of DNA triplex. FANCM and the recently identified FANCJ, a DNA helicase, are the 
two subunits of the core complex having DNA-related enzymatic domains or activities. Therefore a model is proposed for FANCM where the protein moves the FA core complex along the DNA probably in association with the replication fork. Thus FANCM might be involved in the detection of a cross-link stalling a replication fork and could participate in the activation of the FA pathway (Meetei et al 2005; Levitus et al 2005). 


\section{MATERIALS AND METHODS}

\section{MEDIA}

All media were autoclaved for $20 \mathrm{~min}$ at $121^{\circ} \mathrm{C}$. For plates, 1,6\% agar (Agar Bacteriological No. 1; Oxoid, Basingstoke, Great Britain) was added in addition before autoclaving.

YPD: 2\% D-glucose (Merck, Darmstadt, Germany or Roth, Karlsruhe, Germany), 2\% Bacto peptone (Difco Becton Dickinson, Sparks, MD, USA), 1\% Yeast Extract (Oxoid, Basingstoke, Great Britain) in water purified with a Milli-Q water purification system (Millipore, Bedford, MA, USA);

Synthetic complete medium: 2\% D-glucose (autoclaved separately or together with agar, if preparing plates), 0,17\% Difco Yeast Nitrogen Base without amino acids and without ammonium sulfate, $0,51 \%$ ammonium sulfate and $680 \mathrm{mg} / 1$ synthetic complete mixture. Synthetic complete mixture contains the following components weighed in as powder and added before autoclaving (indicated are final concentrations): adenine $40 \mathrm{mg} / \mathrm{l}$, L-arginine 30mg/l, L-histidine $20 \mathrm{mg} / \mathrm{l}$, Lisoleucine $20 \mathrm{mg} / \mathrm{l}$, L-leucine $30 \mathrm{mg} / \mathrm{l}$, L-lysine-HCL $30 \mathrm{mg} / \mathrm{l}$, L-methionine 20 $\mathrm{mg} / \mathrm{l}$, L-phenylalanine $50 \mathrm{mg} / \mathrm{l}$, L-serine $100 \mathrm{mg} / \mathrm{l}$, L-threonine $150 \mathrm{mg} / \mathrm{l}$, Ltryptophane $30 \mathrm{mg} / \mathrm{l}$, L-tyrosine $30 \mathrm{mg} / 1$, uracil $20 \mathrm{mg} / \mathrm{l}$, L-valine $100 \mathrm{mg} / \mathrm{l}$.

Drop out media: Synthetic complete medium lacking nutrilite supplements. For example, "uracilless" medium is without uracil (SC-uracil).

Canavanine plates: SC-arginine containing $40 \mathrm{mg} / 1 \mathrm{~L}$-canavanine (Sigma) filtersterilized $2 \%$ stock solution in water after autoclaving when medium was partially cooled.

G418 plates: YPD plates containing $200 \mu \mathrm{g} / \mathrm{ml}$ G418 (Calbiochem, San Diego), added as a powder after autoclaving when medium was partially cooled.

5-FOA plates: SC plates containing in addition $50 \mathrm{mg} / 1$ uracil and $1 \mathrm{~g} / 1 \mathrm{~s}$ fluoroorotic acid (Toronto Research) added after autoclaving as powder when medium was partially cooled).

Sporulation plates: 0,05 \% D-glucose, 0,23\% Yeast Extract, 2\% Potassium Acetate (MERCK, Darmstadt, Germany). 
Dissection plates: $2 \%$ D-glucose, $0,5 \%$ bacto peptone, $1 \%$ yeast extract, $0,3 \%$ beef extract (Difco Becton Dickinson, Sparks, MD), aminoacids synthetic complete mixture and 2,5\% Agar.

For sterile filtered liquid media, all components were dissolved in water and filtered through Vacuflo PV 050/3 disposable sterile filter units $(0,2 \mu \mathrm{m}$ pore size; Schleicher \& Schuell, Dassel, Germany).

\section{CHEMICALS INDUCING DNA DAMAGE}

Methyl methane-sulfonate (Fulka Chemie GmbH, Buchs, Switzerland) (MMS): MMS is an alkylating agent able to transfer methyl groups to nucleophilic centers in DNA forming a variety of different adducts. The most frequent MMS adducts are $N^{7}$-methylguanine and $N^{3}$-alkyladenine and they may block replication fork progression (Pegg 1984).

4-nitroquinoline-1-oxide (Fulka Chemie GmbH, Buchs, Switzerland) (4-NQO): after metabolic activation 4-NQO forms bulky adducts with nucleobases (Turesky 1994). Therefore, 4-NQO is also referred as UV mimeticum, although it produces a significant amount of oxidative damage as well (Ramotar et al 1998).

Camptothecin (Sigma, Deisenhofen, Germany): camptothecin is not a DNAdamaging agent by itself. It inhibits topoisomerase I (topo I) (Pommier et al 1998) by blocking the rejoining step of the cleavage/relegation reaction of topo-I, resulting in accumulation of a covalent reaction intermediates which could lead to formation of a DNA double strand end when the replication runs into them (Liu et al 1996). 


\section{S. CEREVISIAE STRAINS USED IN THIS STUDY}

Most of the $S$. cerevisiae mutant strains used in this study were already constructed during previous studies (Scheller et al 2000; Schürer 2003; Schürer et al. 2004). They were constructed by one-step gene disruption procedure (Rothstein, 1991) and all mutants are null alleles. Transformations were carried out as described (Gietz et al 1992) DNA fragments for deletion mutant construction were obtained by either cleavage of plasmid listed in table 2 or PCR (Wach et al 1994, 1997). PCR primers utilized for the disruptions were about 60 nucleotides long and contained 40 nucleotide tails from the 5'- or 3'- flanking regions, respectively, of the gene to be deleted and about 20 nucleotide termini from the 5'- or 3'- flanking regions, respectively, of the plasmid cassette expressing the selectable markers (KanMX4 or HIS3MX6, Wach et al 1994, 1997) replacing the deleted gene. Transformants were streaked for single cells on selective medium and single-cell colonies were tested by PCR for correct construction of the deletion. As illustrated in figure 3, 5'- and 3'flanks of the deletion were verified using primer pairs, where one primer was located in the selective marker and one primer in the flanking region of the deleted gene, but outside of the DNA fragment used for transformation. Primers pairs located into the gene were also used as control. Primer combinations, for each deletion presented in this study, and the sequences of the primers used to verify the deletions are listed in tables 3 and 4.

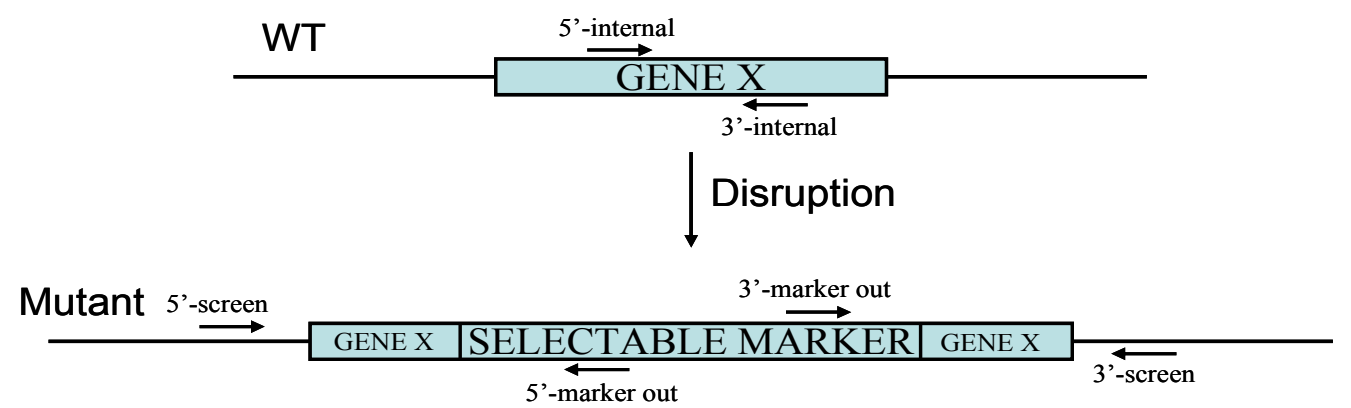

Figure 3. Scheme illustrating the result of the gene disruption and the position of the primers utilized to verify the deletions.

The isogenic derivatives of the S.cerevisiae strain CEN.PK2 (MATa/MATa, ura 352, leu 2-3, 112, his3 $\triangle 1$, trp1-289, MAL-2-8c, SUC2, from Peter Kötter, Entian et al 1999) presented in this study are listed in table 2. The mph1 (mph1::URA3), mph1 
YIplac 211 MPH1 (mph1::hisG/MPH1::URA3) and siz1 (siz1::HISMX6) strains were constructed in the course of this study and the deletions verified by PCR. The $m p h 1:$ :hisG deletion was previously constructed (Scheller et al 2000) using the hisG::URA3::hisG cassette (Alani et al 1987) and ura3 recombinants were selected on 5-fluoroorotic acid (Sikorski and Boeke 1991).

Table 2. Isogenic derivatives of $S$. cerevisiae strain CEN.PK2

\begin{tabular}{|c|c|c|}
\hline Strains & Disruption & Disruption construction and references \\
\hline mphl & mph1::URA3 & $\begin{array}{c}\mathrm{pHI} 2(m p h 1: \because U R A 3) \text { cut with } P v u \mathrm{II} \\
\text { Source: A. Hinnen }\end{array}$ \\
\hline $\operatorname{srs} 2$ & $\operatorname{srs} 2:: H I S 3 M X 6$ & (Schürer 2003) \\
\hline & & PCR based \\
\hline sizl & siz1::HIS3MX6 & (Wach et al 1997) \\
\hline & & For primers see table 4 \\
\hline $\operatorname{rad} 51$ & $\operatorname{rad} 51:: L E U 2$ & (Schürer et al. 2004) \\
\hline rad52 & $\operatorname{rad} 52:: k a n M X 4$ & (Schürer et al. 2004) \\
\hline rad55 & $\operatorname{rad} 55:: L E U 2$ & (Schürer et al. 2004) \\
\hline $\operatorname{rad} 57$ & rad57::LEU2 & (Schürer 2003) \\
\hline tel1 & tell::kanMX4 & (Schürer 2003) \\
\hline smll mecl & smll::HIS mec $1:: T R P 1$ & (Schürer 2003) \\
\hline sml1 rad53 & rad53::kanMX4 in sml1::HIS & (Schürer 2003) \\
\hline rad17 mph1 & $\operatorname{rad} 17:: U R A 3$ in $m p h 1$ & (Schürer 2003) \\
\hline $\operatorname{rad} 9$ & $\operatorname{rad} 9:: k a n M X 4$ & (Schürer 2003) \\
\hline $\operatorname{rad} 24$ & $\operatorname{rad} 24:: K a n M X 4$ & (Schürer 2003) \\
\hline rad6 & $\operatorname{rad} 6:: K a n M X 4$ & (Scheller et al 2000) \\
\hline rad5 & $\operatorname{rad} 5:: K a n M X 4$ & (Schürer et al. 2004) \\
\hline $\operatorname{sgs} 1$ & $\operatorname{sgs} 1:: L E U 2$ & (Schürer 2003) \\
\hline rev3 & rev3::KanMX4 & (Scheller et al 2000) \\
\hline mph1 YIplac 211 MPH1 & $m p h 1:: h i s G$, YIplac $211 M P H 1$ & YIplac $211 M P H 1$ cut with ApaI in $m p h 1$ \\
\hline
\end{tabular}

The isogenic srs2 ( $\operatorname{srs} 2:: H I S 3 M X 6$ deletion) derivative of the $S$. cerevisiae strain MW 3317-21A (MATa Atrp1 ura3-52 ade2A ade8 hom3-10 his3-KpnI met4 met13, Kramer et al 1989) was constructed in this study using a PCR based method (Wach et al 1997) and the deletion was verified by PCR. The sequences of the primers utilized for the disruption are listed in table 4 (5'/3'SRS2 disrupt-HIS).

The isogenic mphl (mph1::kanMX4 deletion) derivative of the $S$. cerevisiae strain

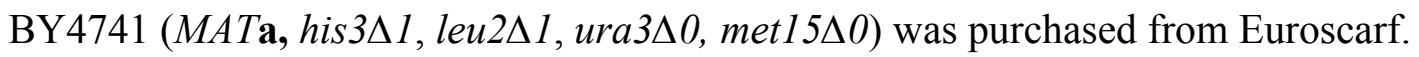

The isogenic mph1 (mph1::kanMX4 deletion) derivative of the $S$. cerevisiae strain DF5 (MATa, his3-4200, leu2-3,2-112, lys2-801, trp1-1(am), ura3-52) was previously constructed using a PCR based method (Wach et al 1994) and the deletion was verified. The sequences of the primers utilized for the disruption are listed in table 4 (5'/3'MPH1 disrupt-Kan). 
Table 3. Combination of primers used to verify the deletion mutants.

\begin{tabular}{|c|c|c|c|}
\hline Disruption & Combination of primers & PCR product wt (bp) & PCR product mutant (bp) \\
\hline \multirow[t]{3}{*}{ mec1::TRP1 } & 5' screen \& 3' TRP1 & - & 650 \\
\hline & 3' screen \& 5' TRP1 & - & 900 \\
\hline & 5' screen \& 3' internal & 430 & - \\
\hline \multirow[t]{3}{*}{ mphl::hisG } & 5' screen \& hisG2 & - & 1500 \\
\hline & 3' screen \& hisG1 & - & 1300 \\
\hline & 5' \& 3' internal & 970 & - \\
\hline \multirow[t]{3}{*}{$m p h 1:: U R A 3$} & 5' screen \& 5' URA3 & - & 1645 \\
\hline & 3' screen \& 3' URA3 & - & 1327 \\
\hline & 5' \& 3' internal & 970 & - \\
\hline \multirow[t]{3}{*}{ mph1::kanMX4 } & 5' screen \& 5' KAN out & - & 1600 \\
\hline & 3' screen \& 3' KAN out & - & 1000 \\
\hline & $5, \& 3$ ' internal & 970 & - \\
\hline \multirow{3}{*}{$\operatorname{rad} 51:: L E U 2$} & 5' screen \& 5' LEU2 out 2 & - & 900 \\
\hline & 3' screen \& 3' LEU2 out & - & 1100 \\
\hline & 5 ' \& 3' internal & 470 & - \\
\hline \multirow{3}{*}{$\operatorname{rad} 52:: k a n M X 4$} & $5^{\prime}$ screen \& 5' KAN out & - & 685 \\
\hline & 3' screen \& 3' KAN out & - & 470 \\
\hline & $5^{\prime} \& 3^{\prime}$ internal & 214 & - \\
\hline \multirow[t]{3}{*}{$\operatorname{rad} 55:: L E U 2$} & 5' screen \& 5' LEU2 out & - & 1500 \\
\hline & 3' screen \& 3' LEU2 out & - & 2400 \\
\hline & $5 ' \& 3$ ' internal & 200 & 2500 \\
\hline \multirow[t]{3}{*}{$\operatorname{rad} 57:: L E U 2$} & 5' screen \& 3' LEU2 out & - & 1400 \\
\hline & 3' screen \& 5' LEU2 out & - & 2800 \\
\hline & $5 ' \& 3$ ' internal & 480 & - \\
\hline \multirow[t]{3}{*}{$\operatorname{rad53::kanMX4}$} & 5' screen \& 3' screen & 2800 & 1700 \\
\hline & 3' screen \& 3' $K A N$ out & - & 800 \\
\hline & 5' screen \& 5' KAN out & & 800 \\
\hline \multirow[t]{3}{*}{$\operatorname{rad} 17:: U R A 3$} & 5' screen \& 3' screen & 1100 & 2600 \\
\hline & 5' screen \& 3' URA3 out & - & 1500 \\
\hline & 5' \& 3' internal & 757 & - \\
\hline \multirow[t]{3}{*}{$\operatorname{rad} 9:: \operatorname{kan} M X 4$} & 5' screen \& 5' KAN out & - & 809 \\
\hline & 3' screen \& 3' KAN out & - & 842 \\
\hline & 5' \& 3' internal & 1009 & - \\
\hline \multirow[t]{3}{*}{$\operatorname{rad} 24:: K a n M X 4$} & 5' screen \& 5' KAN out & - & 1000 \\
\hline & 3' screen \& 3' $K A N$ out & - & 900 \\
\hline & 5' \& 3' internal & 650 & - \\
\hline \multirow[t]{3}{*}{$\operatorname{rad} 6:: K a n M X 4$} & $5^{\prime}$ screen \& 5' KAN out & - & 1000 \\
\hline & 3' screen \& 3' $K A N$ out & - & 1200 \\
\hline & 5' \& 3' screen & 1100 & 2000 \\
\hline \multirow{3}{*}{$\operatorname{rad} 5:: K a n M X 4$} & $5^{\prime}$ screen \& 5' KAN out & - & 1100 \\
\hline & 3' screen \& 3' KAN out & - & 1000 \\
\hline & $5^{\prime} \& 3^{\prime}$ internal & 1000 & - \\
\hline \multirow[t]{3}{*}{ siz1::HISMX6 } & 5' screen \& 5' HIS out & - & 906 \\
\hline & 3' screen \& 3' HIS out & - & 844 \\
\hline & 5' \& 3' internal & 1328 & - \\
\hline \multirow[t]{3}{*}{ srs $2:: H I S M X 6$} & $5^{\prime}$ screen \& 5' HIS out & - & 900 \\
\hline & 3' screen \& 3' HIS out & - & 950 \\
\hline & $5^{\prime} \& 3^{\prime}$ internal & 500 & - \\
\hline \multirow[t]{2}{*}{$\operatorname{smll::HIS}$} & 5' screen \& 3' screen & 900 & 1900 \\
\hline & 5' screen \& 3' internal & - & 1000 \\
\hline \multirow[t]{3}{*}{ tell::kanMX4 } & 5' screen \& 5' KAN out & - & 1000 \\
\hline & 3' screen \& 3' KAN out & - & 900 \\
\hline & 5' \& 3' internal & 800 & - \\
\hline
\end{tabular}


Table 4. Sequences of the primers used to verify the deletions.

\begin{tabular}{|c|c|c|}
\hline Primer & $\begin{array}{l}\text { Number in } \\
\text { the lab list }\end{array}$ & Sequence \\
\hline 5' URA3 & 224 & 5'-GTC GAA AGC TAC ATA TAA GG \\
\hline 3' URA3 & 151 & 5'-CAC ACC GTG TGC ATT CGT AAT G \\
\hline 5'URA3_2 & 446 & 5'-AGG TAG AGG GTG AAC GTT ACA G \\
\hline 5'LEU2_2 & 448 & 5'-GGTAAGGCCATTGAAGATGCAG \\
\hline 5' LEU2 & 321 & 5'-GCC CCT AAG AAG ATC GTC GTT T \\
\hline 3' LEU2 & 153 & 5'-TAC CTC CCA CTA ATT CTC TGA C \\
\hline 5' TRP1 & 292 & 5'-TGA AAG TTT GCG GCT TGC AGA G \\
\hline 3' TRP1 & 152 & 5'-GTC TTG GTA TTC TTG CCA CGA C \\
\hline 5' kan out & 11 & 5'-CGT GAG TCT TTT CCT TAC CCA TGG \\
\hline 3' kan out & 12 & 5'-ATG TTG GAC GAG TCG GAA TCG CAG \\
\hline 5 ' his out & 282 & 5'-GTA AAG TCG TAA GCT CCA GCC T \\
\hline $3^{\prime}$ his out & 283 & 5'-GAC GAA GCT CTT TCT AGA AGC G \\
\hline his G1 & 88 & 5'-CCT TTC TGG TCG AGG TAG CGT TTG \\
\hline his G2 & 89 & 5'-GCT ATC TGC GAT TTG GTC TCT ACC \\
\hline 5' MEC1 screen & 304 & 5'-GGA ACG CAC GCT CCA AAA CTA G \\
\hline 3' MEC1 screen & 305 & 5'-TTA ACT CCG CCG GAG AAA AGC A \\
\hline 3' MEC1 internal & 306 & 5'-CTC AAA GTT CCC GTT GGA ATC C \\
\hline 5' MPH1 disrupt-Kan & 342 & $\begin{array}{l}\text { 5'-ATG GCT AGT GCA GAT GAT TAC TTT AGT GAT TTC } \\
\text { GAA GAT GCA GCT GAA GCT TCG TAC GC }\end{array}$ \\
\hline 3' MPH1 disrupt-Kan & 343 & $\begin{array}{l}\text { 5'-AAA ATC AGA ATC TGA GCC CAG TAT GTC ATC TAA } \\
\text { TTC TGC GGC ATA GGC CAC TAG TGG ATC TG }\end{array}$ \\
\hline 5' MPH1 screen & 378 & 5’-AGT AGT GGA GCG TCT AAC TGG CCT \\
\hline 3' MPH1 screen & 377 & 5'-TGC TTA GCT TTT GCG ACA CCT GTG \\
\hline 3' MPH1 internal & 92 & 5'-CGC TCT CTT AGT TCG TTC AGC TCC \\
\hline 5' MPH1 internal & 93 & 5'-TCT TGT CAT CGA TGA AGC TCA CAG \\
\hline 5' YIR002domain 1 & 2 & 5'-GAC ACC TTC CAG GT CAG AGG CTG G \\
\hline 5' RAD51 screen & 248 & 5'-TCT CACCATATCCCA CGA CTA G \\
\hline 3' RAD51 screen & 249 & 5'-GAG GAA GTA GTC ATC GGG AAG A \\
\hline 5' RAD51 internal & 487 & 5'-CAG ATC CAA AGA AGC CTA TCG G \\
\hline 3' RAD51 internal & 488 & 5'-GCTTAGTTCACCACGACCAGAA \\
\hline 5' RAD52 screen & 177 & 5'-ATCGGGTCTTGCACACGTCGCTAA \\
\hline 3' RAD52 screen & 176 & 5'-TTAATACGACACATGGAGGAAAGAA \\
\hline 5' RAD52 internal & 531 & 5'-AAGGTGAAGTTCGATCCGCCAG \\
\hline 3' RAD52 internal & 225 & 5'-GGG TAC CTC GAC TTA CTG TA \\
\hline 5' RAD55 screen & 334 & 5'-GCT CCG CTA TCA AAG ATG TCA AGT \\
\hline 3' RAD55 screen & 335 & 5'-TGT ATG GAA GGT AGA CCT CGG GGC \\
\hline 5' RAD55 internal & 336 & 5'-ATT AGT CTG CGA TCA TCT GTG TAC \\
\hline 5' RAD55 internal & 337 & 5'-TCT TCC AAG GAT TCG AAT TCG TTT \\
\hline 5' RAD57 screen & 338 & 5'-AAC CAC TGG GAA TTC ACC ATT T \\
\hline 3' RAD57 screen & 339 & 5'-GTC TCG AAT TAC GAT TCT GGC T \\
\hline 5' RAD57 internal & 340 & 5'-GTT GCC TAT TTT ATT AGA GAG A \\
\hline 3' RAD57 internal & 341 & 5'-TTC GCT CAA CGG TTT TAT TCT C \\
\hline 5' RAD53 screen & 299 & 5'-GGT TGA GAA GAT AAA GGG TAC C \\
\hline 3' RAD53 screen & 300 & 5'-CGT ATC AAA ACG TCA CTC TAT A \\
\hline 5' RAD17 screen & 131 & 5'-TAT GGT GTG CCT GAA GAT GAA C \\
\hline 3' RAD17 screen & 132 & 5'-TAA GGC TGA ATG AAG GGC TTC G \\
\hline 5' RAD17 internal & 529 & 5'-GATGGGCTGTCATTTGTCAGGG \\
\hline 3' RAD17 internal & 530 & 5'-GCAGTTGGCGAATACTACCTGG \\
\hline
\end{tabular}




\begin{tabular}{|c|c|c|}
\hline 5' RAD9 screen & 115 & 5'-CGG CCT TGT TAG CGT TAG ATA C \\
\hline 3' RAD9 screen & 110 & 5'-TCA TCT CAC CCA TTG GGG TGA A \\
\hline 5' RAD9 internal & 113 & 5'-TAA TAG TGC TGT GTC TGG CAC C \\
\hline 3' RAD9 internal & 114 & 5'-CTG AAG TTC TGA GCTCTG TCC T \\
\hline 5' RAD24-screen & 121 & 5'-GGC CTT ATC CTT CGT TTC ATG C \\
\hline 3' RAD24-screen & 122 & 5'-TCA ATG GGG AGT TCC AGG G \\
\hline 5' RAD24-internal & 119 & 5'-AGT TCG GAG CCT CTA TTA CCT C \\
\hline 3' RAD24-internal & 120 & 5'-AGG TTT TGC GCA CTT CTC GTA A \\
\hline 5' RAD6 screen & 187 & 5'-TGG TGA CTA CAT TTC CCG GAT TAG \\
\hline 3' RAD6 screen & 188 & 5'-CGG GTA TCG GCA GTT ATA ACC GAT \\
\hline 5' RAD5 screen & 109 & 5'-GAG GCG AGC TAG CTG CTA TTA A \\
\hline 3' RAD5 screen & 110 & 5'-ACC CAC CTT GTA TGG GTT CGT A \\
\hline 5' RAD5 internal & 107 & 5'-GCT CGA AAA GAC TGG CTC TAC T \\
\hline 3' RAD5 internal & 108 & 5’-GAC GTC CTCATC TGT CAT CCT \\
\hline 5' SIZ1 disrupt-HIS & & $\begin{array}{l}\text { 5'-ATG ATA AAT TTA GAG GAT TAC TGG GAA GAT } \\
\text { GAA ACG CCT GCA GCT GAA GCT TCG TAC GC }\end{array}$ \\
\hline 3' SIZ1 disrupt-HIS & & $\begin{array}{l}\text { 5'-AAT TGG TGA CAA CAT AAA GAA AGG TAT TAG } \\
\text { AAC GCA AAA GGC ATA GGC CAC TAG TGG ATC TG }\end{array}$ \\
\hline 5' SIZ1 screen & 618 & 5’-CAC CGC ACC AGA TAG TAA GTT G \\
\hline 3' SIZ1 screen & 619 & 5'-GCT AGG GGA ATG CAA ACA GT \\
\hline 5' SIZ1 internal & 616 & 5'-GAT CCC GAG GTA ATG AAC CCA \\
\hline 3' SIZ1 internal & 617 & 5'-CGT TGG GGA TGA TAC GCT AAC \\
\hline 5' SRS2 disrupt-HIS & 309 & $\begin{array}{l}\text { 5'-TTC CAA TTT GAT CTT TCT TCT ACC GGT ACT } \\
\text { TAG GGA TAG CAA ATG TCG CAG CTG AAG CTT CGT } \\
\text { ACG CTG C }\end{array}$ \\
\hline 3' SRS2 disrupt-HIS & 310 & $\begin{array}{l}\text { 5'-ATA AAC CGC CTC CAA TAG TTG ACG TAG TCA } \\
\text { GGC ATG AAA GTG CTA CTA GCA TAG GCC ACT AGT } \\
\text { GGA TCT G }\end{array}$ \\
\hline 5' SRS2 screen & 253 & 5'-GTA ACG AGA CGC GAA TGC GAA A \\
\hline 3' SRS2 screen & 254 & 5'-TTG ACT GGG TAC TGC TTG ACT G \\
\hline 5' SRS2 internal & 255 & 5'-CAG TCG CTT ACG TCG AGT GAA T \\
\hline 3' SRS2 internal & 417 & 5'-GAT GCA GGT TCA TTC TTC ACC TT \\
\hline 5' SML1 screen & 294 & 5'-TTT TTG TTA CCT CGC GCT GAG C \\
\hline 3' SML1 screen & 295 & 5'-AGC ATT GAT CAA GAG AGG GGG A \\
\hline 3' SML1 internal & 298 & 5'-CAT AGG TGG CAA AGG CAC CCT T \\
\hline 5' TEL1 screen & 214 & 5'-GGC CAA GAG TTG CAT CTA ACT C \\
\hline 3' TEL1 screen & 215 & 5'-TGC GTA GTG AGT CTT TAC GGC A \\
\hline 5' TEL1 internal & 216 & 5'-TCC CCT ACC GAC CAG TAA TTTTAC \\
\hline 3' TEL1 internal & 217 & 5'-GCG TAA ACT CTT TCA CAA CTC CGC \\
\hline
\end{tabular}




\section{PLASMIDS}

YIplac211-MPH1 is a derivate of YIplac211 (Gietz and Sugino, 1988). MPH1 gene (YIR002c) including promoter and terminator was cut released from pRS316 MPH1 (A. Schürer) with PstI and XbaI and cloned into YIplac211 cut with the same enzymes. For integration into the ura3-52 locus the vector was linearised with ApaI. The integrated vector complements the mutator phenotype of $m p h l$ mutants. This plasmid has been constructed and kindly provided by Anke Schürer, Leibniz Institute for Age Research-Fritz Lipman Institute, Jena, Germany.

pYES2 SGS1 is a pYES2 derivates (Invitrogene), where between the Bam HI and NotI sites the open reading frame of $S G S 1$ is cloned under control of the galactose inducible GAL1 promotor. This plasmid was kindly provided by Ian Hickson, Weatherall Institute of Molecular Medicine, Oxford, UK.

\section{TETRAD ANALYSIS}

The single and double null mutants constructed in the S. cerevisiae strains listed above were crossed by simultaneous inoculation of two fresh cultures, of strains with different mating type, in $5 \mathrm{ml}$ of liquid YPD. An o/n incubation at $30^{\circ} \mathrm{C}$ was performed in a rotating incubator and the next morning an aliquot of the culture was plated on selective media in order to isolate zygotes.

For instance, when the $m p h 1$ mutant (disruption $m p h 1:: U R A 3)$ with mating type "a" was crossed with the $\operatorname{srs} 2$ mutant (disruption $\operatorname{srs} 2:: H I S 3 M X 6$ ) with mating type " $\alpha$ ", the cells were plated on drop out solid medium lacking simultaneously uracil and histidine. When one of the selectable markers in the zygote was kanMX4 and the other a marker selectable on drop out media the selection was performed in two steps since the aliquot was first plated on drop out media and than some of the cell forming colonies were streaked on G418 solid medium in order to select zygotes. If selective media could not be used for isolation of zygotes the two strains to be crossed where mixed together on a YPD plate and the plate was incubated for about three hours at $30^{\circ} \mathrm{C}$. Same cells were than picked from the YPD plate and disposed on a dissection plate and zygotes where isolated by micromanipulation. The isolated zigotes were grown on YPD plates at $30^{\circ} \mathrm{C}$ for two days and than replica plated on sporulation plates and incubated at $30^{\circ} \mathrm{C}$. Spore formation needed 1 or 2 weeks of incubation. Sporulated colture directly picked from the sporulation plates were resuspended in $50 \mu \mathrm{l}$ of Milli-Q water and $50 \mu \mathrm{l}$ of Zymolyase solution $(0,7 \mathrm{mg} / \mathrm{ml}$ 
Zymolyase-100CT, ICN Immunobiologicals, in $1 \mathrm{M}$ Sorbitol) was added. The cells were incubated for $5 \mathrm{~min}$ at $30{ }^{\circ} \mathrm{C}$ to partially digest the cell wall of the ascospores and than $800 \mu \mathrm{l}$ of Milli-Q water was added. Few microliters of the cell suspension were disposed on a dissection plate where the asci were subject to dissection using the microscope Wild Heerbrugg (Switzerland) provided with a micromanipulator of microneedles. The four-spored asci were subject to dissection and each of the four ascospores were relocated to separate positions where they could form isolated spore colonies. The dissection plate was incubated at $30{ }^{\circ} \mathrm{C}$ for 1 week or longer and than replica plated on selective media in order to determine the genotype of the spores. The mating type of triple and quadruple null mutant spores identified after replica plating on selective media was determined. For each cross presented in this study one spore of mating type a and one of mating type $\alpha$ were further characterized by PCR in order to verify the structure of the deletions (for combinations of primers see table 3 ) and they have been stored at $-80{ }^{\circ} \mathrm{C}$.

\section{DROP DILUTION ASSAY (DNA DAMAGE SENSITIVITY TEST)}

For sensitivity test, the yeast strains were grown overnight in liquid YPD at $30{ }^{\circ} \mathrm{C}$. The next morning strains were diluted 1:10 in fresh YPD and grown at $30{ }^{\circ} \mathrm{Cfor}$ about 4 hours. In the meantime, YPD plates containing the respective chemicals were prepared. Chemicals were not added before the medium had cooled below 60 ${ }^{\circ} \mathrm{C}$. Cell density was determined with a hematocytometer and adjusted to $1 \times 10^{7}$ cells $/ \mathrm{ml}$. Three serial dilutions were prepared $\left(1 \times 10^{6}, 1 \times 10^{5}\right.$ and $1 \times 10^{4}$ cells $\left./ \mathrm{ml}\right)$ and $10 \mu \mathrm{l}$ of the adjusted cell suspension and of the serial dilutions were spotted onto YPD plates without added chemicals as control and onto YPD plates containing MMS, 4-NQO and Camptothecin. Plates were incubated for 3 days at $30^{\circ} \mathrm{C}$.

\section{SPONTANEOUS MUTATION RATE DETERMINATION}

Cells undergoing unperturbed growth may acquire spontaneous DNA mutations at any stage of the cell cycle. In a cell culture, cultured until stationary phase, the number of mutated cells may vary significantly depending on when the mutation has been acquired. For instance, if cells acquire the DNA mutation at an early stage of the culturing period the number of mutated cells will be higher than if cells acquire the mutation at a later time. The number of mutations observed in a cell culture is named mutation frequency and can be distinguished from the mutation rate 
indicating the probability of appearance of a mutation. The mutation rate can be determined with statistical methods and the one utilized in this study is the method of the median (Lea and Coulson 1948). In particular, the system of forward mutation to canavanine resistance was used. The CAN1 gene, coding for an arginine permease, is responsible for uptake of L-arginine and also of the L-Canavanine structural analog. Integration of L-Canavanine instead of arginine into the proteins can lead to aberrant proteins and can be toxic for the cell. An arginine phototrophic cell, having a forward mutation of the CAN1 gene, will be resistant because the uptake of L-canavanine and L-arginine is no longer possible but the latter can be synthesized by the cell.

The mutation rates determinations presented in this study were performed following this procedure: eleven parallel $7 \mathrm{ml}$ cultures (YPD or drop out media), for each strain object of the investigation, were inoculated with 20 cells $/ \mathrm{ml}$ using an o/n culture. The cultures were grown until they reached the stationary face (three or four days for slower growing strains) and the incubation was performed at $30{ }^{\circ} \mathrm{C}$ in a rotating incubator. Aliquots of all the cultures were plated on canavanine plates for determination of the number of mutated cells. For the living title determination two randomly chosen cultures, between the 11 cultures relative to each strain investigated, were plated on SC-ARG plates in serial dilutions. It is assumed that the total cell number in the stationary phase of all the 11 parallel cultures is more or less the same. The plates were incubated at $30{ }^{\circ} \mathrm{C}$ until formation of colonies was observed. For each strain, the value of the median plate (the seventh canavanine plate in order of number of resistant colonies) was used in the calculation of the mutation rate. The living title was calculated by the average of the value of the two randomly chosen cultures. The experiments where performed using the same batch of media, the wt strain was also included as control and all the values were referred to the wt value for comparison. 


\section{RESULTS}

In this study newly discovered genetic interactions between the $S$. cerevisiae $M P H 1, S R S 2$ and SGS1 genes are presented. These genes encode DNA helicases fueled by ATP hydrolysis and showing a 3'-5' polarity in vitro. They are implicated in DNA repair as well as homologous recombination. (Rong and Klein 1993, Bennett et al 1998; Spell and Jinks-Robertson 2004; Praskash et al 2005). The MPH1 gene was recently implicated in an error-free DNA damage bypass pathway that requires genes from homologous recombination (Schürer et al 2004). This section will begin with a digression on the RAD52 epistasis group of genes and proteins responsible for mediating the strand invasion process during homologous recombination (Paques and Haber 1999; Symington 2002; Krogh and Sygmington 2004).

\section{RAD52 EPISTASIS GROUP AND STRAND INVASION PROCESS}

Genes important for the repair of DSBs were identified in yeast as mutations sensitive to ionizing radiation. These genes are classified as the RAD52 epistatis group (Game and Mortimer 1974). In this group the RAD52 gene is the one basically required for all homologous recombination events. The RAD51, RAD54, RAD55 and $R A D 57$ genes are required for some recombination events but less for others. Moreover the RAD50, MRE11 and XRS2 genes form another family of interacting proteins whose deletions have similar phenotypes (Paques and Haber 1999). The Rad50, Mre11 and Xrs2 proteins form a complex (MRX complex) required for the nucleolytic processing of DNA double ends in 3'-ssDNA tails (Johzuka and Ogawa 1995; Usui et al 1998). The Mre11 protein has in vitro endonuclease activity on circular and linear ssDNA, on harpin structures and 3'-ssDNA tails at the single/double stranded transition. It shows also a weak 3' -5 ' exonuclease activity on blunt and 3' recessed ends contrasting with the exonuclease activity needed to produce 3'-ssDNA tails. However, Rad50 and Xrs2 proteins influence MRX substrate binding and nuclease activity of Mre11 in order to process DNA double ends in 3'-ssDNA tails in vivo as depicted in figure 4 (1) (Paull and Gellert 1998; Trujillo and Sung 2001; Trujillo et al 2003). The 3'-ssDNA tail formed by resection is the substrate for binding by the Rad51. Rad51 forms right handed helical filaments 
on ssDNA with structural similarity to those formed by the homologous RecA protein in E.coli. Rad51 is a 43-KDa protein having Walker A and Walker B motifs for nucleotide binding and ATP hydrolysis. It binds with higher affinity to DNA duplex with single stranded tails than to duplex or ssDNA (Aboussekhra et al 1992; Basile et al 1992; Shinohara et al 1992; Ogawa et al 1993; Mazin et al 2000). Binding to ssDNA activates the Rad51 ATPase and mutation of a conserved lysine to alanine (Rad51-K191A) in the Walker box A abolishes DNA binding and ATPase activity of this protein. The same conserved lysine residue, when mutated to arginine (Rad51-K191R), produces a protein with ATP-dependent DNA binding but no ATP hydrolysis activities. In vivo, the rad51-K191A mutation confers a null phenotype, the $\operatorname{rad51-K191R}$ mutant is partially functional in repair and recombination (Sung and Stratton 1996; Morgan et al 2002). In vitro experiments shown that formation of the Rad51 nucleoprotein filament is stimulated in the presence of the heterotrimeric DNA binding protein Rpa. This effect was observed only when Rad51 is added to the reaction prior Rpa (Sung 1997). The Rpa protein, as illustrated in figure 4 (2 and 3), is thought to remove secondary structures from ssDNA thus allowing formation of a continuous ssDNA filament (McIlwraith et al 2000) and has an higher affinity for ssDNA than Rad51. Furthermore, it is very abundant in cells and probably binds ssDNA before Rad51 (Sung 1997). Therefore Rpa has to be displaced in order to form the Rad51 nucleoprotein filament and, as depicted in figure 4 (4), the Rad52 protein, which directly interacts with Rpa and Rad51, is supposed to mediate the assembly of the nucleoprotein filament by simultaneously displacing Rpa and favouring binding of Rad51 to ssDNA (Song and Sung 2000; Sugiyama and Kowalczykowski 2002). In an in vitro reaction the addition of Rad52 allows the formation of Rad51 nucleoprotein filament and strand exchange even if Rpa is added before Rad51 (New et al 1998; Shinoara and Ogawa 1998). Two more proteins, Rad55 and Rad57, are involved in the nucleoprotein filament formation and strand invasion process. They are referred to as paralogs of Rad51 since they share $20 \%$ $30 \%$ of sequence identity (Kans and Mortimer 1991; Lovett 1994). Rad55 and Rad57 form a heterodimer thought to mediate the assembly and stabilization of the Rad51 nucleoprotein filament (figure 4, 5). Similarly to what is observed for Rad52, the inhibition of the in vitro strand exchange reaction, when Rpa and Rad51 are added simultaneously, is partially overcome in the presence of Rad55 and Rad57 (Sung 1997). 


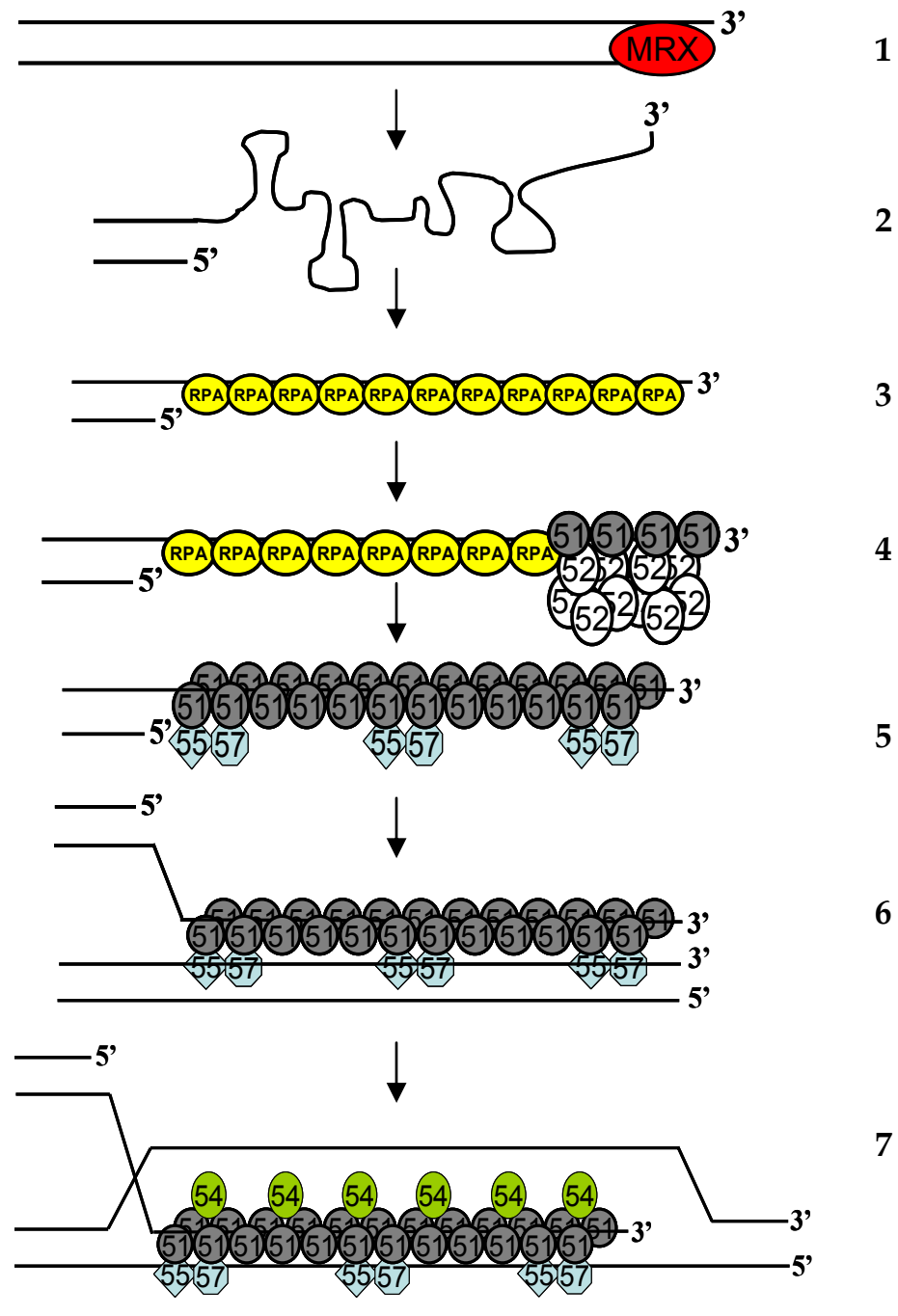

Figure 4. Model describing the strand invasion process. The double strand end is resected by the MRX complex (1) to produce a 3'-ssDNA tail (2) which is coated by the Rpa protein to eliminate secondary structures (3). The Rad52 protein mediate the assembly of the Rad51 nucleoprotein filament by simultaneously displacing Rpa and favouring binding of Rad51 to ssDNA (4). The extension of the Rad51 nucleoprotein filament is mediated by the Rad55/Rad57 complex (5). The Rad51 nucleoprotein filament locate an homologous DNA sequence (6) and the strand invasion process take place with formation of the D-loop structure (7). The Rad54 protein, interacting with Rad51, favourites the extension of the D-loop and the search for homology.

Rad55 interacts with Rad51 but not with Rpa. This suggests a role as mediator in the assembly of the nucleoprotein filament different from the one exerted by Rad52 (Hays et al 1995; Johnson and Symington 1995). The Rad51 nucleoprotein filament, once assembled, interacts with a second double stranded DNA molecule in order to initiate the strand exchange reaction involving homologous sequences (figure 4, 7). An important role is played at this stage by the $\operatorname{Rad} 54$ protein. Rad54 is a dsDNA- 
dependent ATPase without helicase activity belonging to the Swi/Snf2 family of chromatin-remodelling proteins. It interacts with Rad51 (Jiang et al 1996; Clever et al 1997) and facilitates the Rad51 in vitro binding to ssDNA in the presence of Rpa (Mazin et al 2003).

In vitro D-loop assays show that Rad51 and Rpa inefficiently promote D-loop formation. The same reaction is greatly stimulated by the addition of Rad54 (figure 4, 7) (Petukova at al 1998). Furthermore, Rad54 dsDNA-dependent ATPase activity is associated with its capability to translocate on duplex DNA generating negative and positive supercoils (Petukhova et al 1999 a; Petukhova et al 1999 b; Van Komen et al 2000). Both Rad54 enzymatic activities are stimulated by Rad51 or by Rad51ssDNA complexes (Mazin et al 2000; Van Komen et al 2000). The ATP-dependent translocation activity of Rad54 on duplex DNA also functions to displace nucleosomes or other protein that could represent an obstacle to strand invasion (Alexeev et al 2003; Jaskelioff et al 2003). Rad54 was also shown to promote heteroduplex DNA extension during strand exchange reactions and to displace Rad51 from duplex DNA (Solinger et al 2001; Solinger et al 2002). The displacement of Rad51 from duplex DNA could be important for its turnover at the end of recombination (Krogh and Symington 2004). All this findings indicate a function for Rad54 in facilitating search for homology between duplex DNA and incoming Rad51 nucleoprotein filament. It may also promote formation of the joint once homology is located.

Studies in E. coli with the Rad51-homolog RecA protein suggest that the homology search is rapid. It involves random collisions of the two DNA molecules and once the homology is found the strand exchange occurs. The exchange proceeds with a 5 ' to 3' polarity in the case of Rad51 that is opposite to the polarity observed for RecA (Sung and Robberson 1995).

The yeast Srs2 DNA helicase, described in the next paragraph, seems to negatively regulate homologous recombination by disrupting the Rad51 filament (Ira et al 2003; Krejci et al 2003; Veaute et al 2003). 
Results

\section{GENETIC INTERACTIONS BETWEEN S. CEREVISIAE MPHI AND SRS 2 GENES}

\section{THE SRS2 GENE AND ITS ROLE IN HOMOLOGOUS RECOMBINATION}

The SRS2 gene (suppressor of $\underline{\operatorname{rad}} \underline{\text { six mutant }} \underline{2}$ ) was identified as a suppressor of the DNA repair defect produced by inactivation of the RAD6 and RAD18 genes responsible for initiating the PRR pathway (see also page 10) (Lawrence and Christensen 1979). The Srs2 protein, related to nucleic acid helicases belonging to the SF1 family (Aboussekhra et al 1989), shows ssDNA-dependent ATPase and DNA 3'-5' helicase activities (Rong and Klein 1993; Van Komen et al 2003). Srs2 is linked to the DNA damage checkpoint. It is phosphorylated in response to intra Sphase DNA damage in a Mec1- and Cdk1-dependent manner and somehow influences checkpoint activation during S-phase (Liberi et al 2000). Yeast srs 2 null mutants exhibit an hyper-recombination phenotype (Aguilera and Klein 1988; Aboussekhra et al 1989). Srs2 physically interact with the Rad51 recombinase (Krejci et al 2003) and it suppresses in vitro recombination reactions mediated by Rad51. In particular, it was shown that Srs2 disrupts the preformed Rad51 presynaptic filament releasing the ssDNA. Furthermore, the presence of Rpa enhances the reaction since, once released by the action of Srs2, the ssDNA is sequestered by Rpa preventing the Rad51 re-nucleation reaction (Krejci et al 2003; Veaute et al 2003). Interestingly, the presence of Rad52 in the recombination reaction can partially overcome the inhibitory effect of Srs 2 facilitating the loading of Rad51 on an RPA-coated ssDNA template (Krejci et al 2003). This result indicates that Srs2 and Rad52 may antagonize each other in the regulation of the homologous recombination pathway. The Srs2 ATPase activity was shown to be required in order to prevent recombination reactions. In fact, ATPase defective srs 2 mutants exhibit a hyper-recombination phenotype (Krejci et al 2004).

Another interesting aspect of the $S R S 2$ gene is the synthetic lethality or sickness observed when the srs 2 deletion is combined with deletions in genes affecting DNA metabolism. For instance, the srs 2 is lethal in combination with the $s g s 1$ and the rad54 deletions (Palladino and Klein 1992; Lee et al 1999; Gangloff et al 2000). The SGS1 gene, coding for a RecQ helicase (see also page 19), is thought to function at 
later recombination steps with respect to Srs2 (Gangloff et al 1994; Liberi et al 2005). Srs 2 is also connected with replication since it physically interacts with the SUMOylated form of PCNA during an unperturbed S-phase. Therefore it is thought to act as a guarding mechanism, at the replication fork, in order to prevent $\operatorname{Rad} 51$ filament formation and avoiding unwanted recombination during DNA replication (Pfander et al 2005; Papouli et al 2005).

Even though Srs2 seems to be involved in the suppression of spontaneous recombination events, it participates as well in DSB repair by homologous recombination where it probably plays an important role. It is shown that repair of site-specific DSBs made by the $\mathrm{HO}$ endonuclease is greatly diminished in the srs 2 mutants (Aylon et al 2003). Furthermore, Srs2 promotes SDSA during the processing of DSB preventing resolution by cross-over (Ira et al 2003).

\section{mph1 srs2 SYNTHETIC LETHALITY IN THE CEN.PK2 STRAIN BACKGROUND}

From the involvement of the MPH1 gene in DNA metabolism and, in particular, in a recombinogenic pathway for error-free DNA damage avoidance (Scheller et al 2000; Schürer et al 2004) a further analysis on a possible genetic interaction between the $M P H 1$ and the $S R S 2$ genes was certainly attractive. A classical genetic approach was used, haploid null mutants mph1 (mph1::URA3 deletion) and srs2 ( $\operatorname{srs} 2:: H I S 3 M X 6$ deletion), isogenic derivatives of the $S$. cerevisiae strain CEN.PK2, having opposite mating type (a and $\alpha$ ), were crossed. The zygotes mph1/MPH1 $s r s 2 / S R S 2$, isolated after the cross, were subjected to sporulation and tetrad analysis. The dissection plates, containing the isolated spores forming colonies (some of them can be observed in figure 5), were replica plated onto SC-URA and SC-HIS drop out plates in order to determine the genotype of the spores. As shown in figure 5, the mph1 deletion resulted to be lethal if combined with the $\operatorname{srs} 2$ deletion. No spore colonies could be recovered where the genotype, inferred from the genotype of the other spores forming the same tetrad, would have been an mph1 srs 2 double mutant. Very rarely the $m p h 1$ srs 2 spores were able to form visible tiny colonies; one of these examples can be observed at the left bottom of figure 5 . 
Since the conclusion of the mph1 srs 2 synthetic lethality was based on a negative evidence (non-growth of inferred double mutants), it was also verified with a different experimental system where the need of the two genes, MPH1 and SRS2 for cell viability, was demonstrated in vegetative cells undergoing normal cell growth. The strains utilized were a double mutant $m p h 1 s r s 2$ and a single mutant $s r s 2$ both provided with an ectopic functional $M P H 1$ gene. For construction of these two strains the ectopic $M P H 1$ gene was introduced into an mphl (mph1::his G deletion) mutant by integration of the YIplac211 MPH1 plasmid at the ura3-52 locus. The mph1 mutant, provided with the ectopic $M P H 1$ gene, was than crossed with an srs 2 ( $\operatorname{srs} 2:: H I S 3 M X 6)$ mutant. After sporulation of the isolated zygotes and subsequent tetrad analysis, two different spores, one with genotype mph1 srs 2 MPH1 and the other with srs2 MPH1 genotype, were recovered and the deletions further verified by PCR. The idea was to compare the ability of the two strains to survive the loss of the ectopic $M P H 1$ gene.

$m p h 1 \Delta \mathrm{x} \operatorname{srs} 2 \Delta$ in CEN PK2

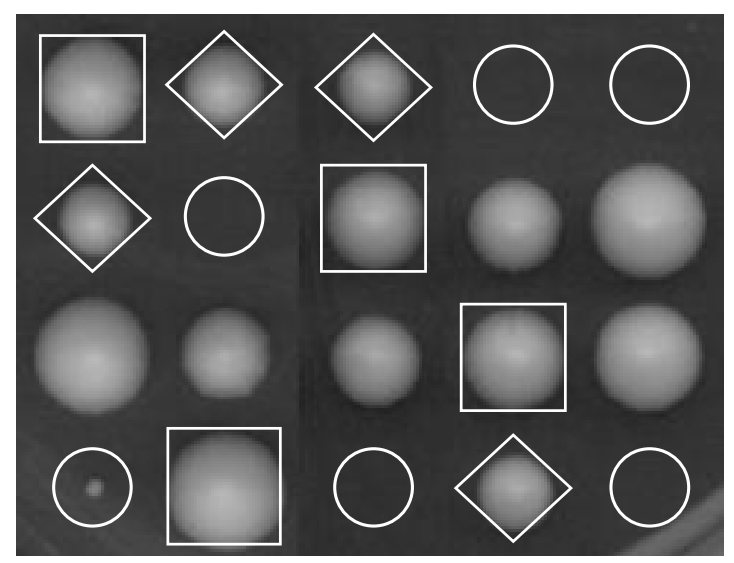

Figure 5. $m p h 1$ srs 2 synthetic lethality in the CEN.PK2 genetic background. Five dissected tetrads obtained from the cross of $m p h 1$ ( $m p h 1:: U R A 3$ deletion) null mutants to $\operatorname{srs} 2$ ( $\operatorname{srs} 2:: H I S 3$ deletion) null mutants are shown. The genotype of the spores forming colonies was determined by replica plating on SC-URA and SC-HIS drop out plates. The $m p h 1 \Delta \operatorname{srs} 2 \Delta$ double mutants are indicated with circles, they are unviable and were inferred from the genotype of the other spores forming the same tetrad. In particular, the $m p h 1$ mutants are indicated with squares, the srs 2 mutants with rhombus and the wt spores are not indicated. One exception, where a tiny spore colony with $m p h 1 \Delta \operatorname{srs} 2 \Delta$ genotype was recovered, can be observed at the left bottom of this picture. 
As depicted in figure 6, the integration of the YIplac211 MPH1 plasmid is the consequence of a recombination event between the URA3 gene harboured by the plasmid and the chromosomal ura3-52 gene of the CEN.PK2 strain.

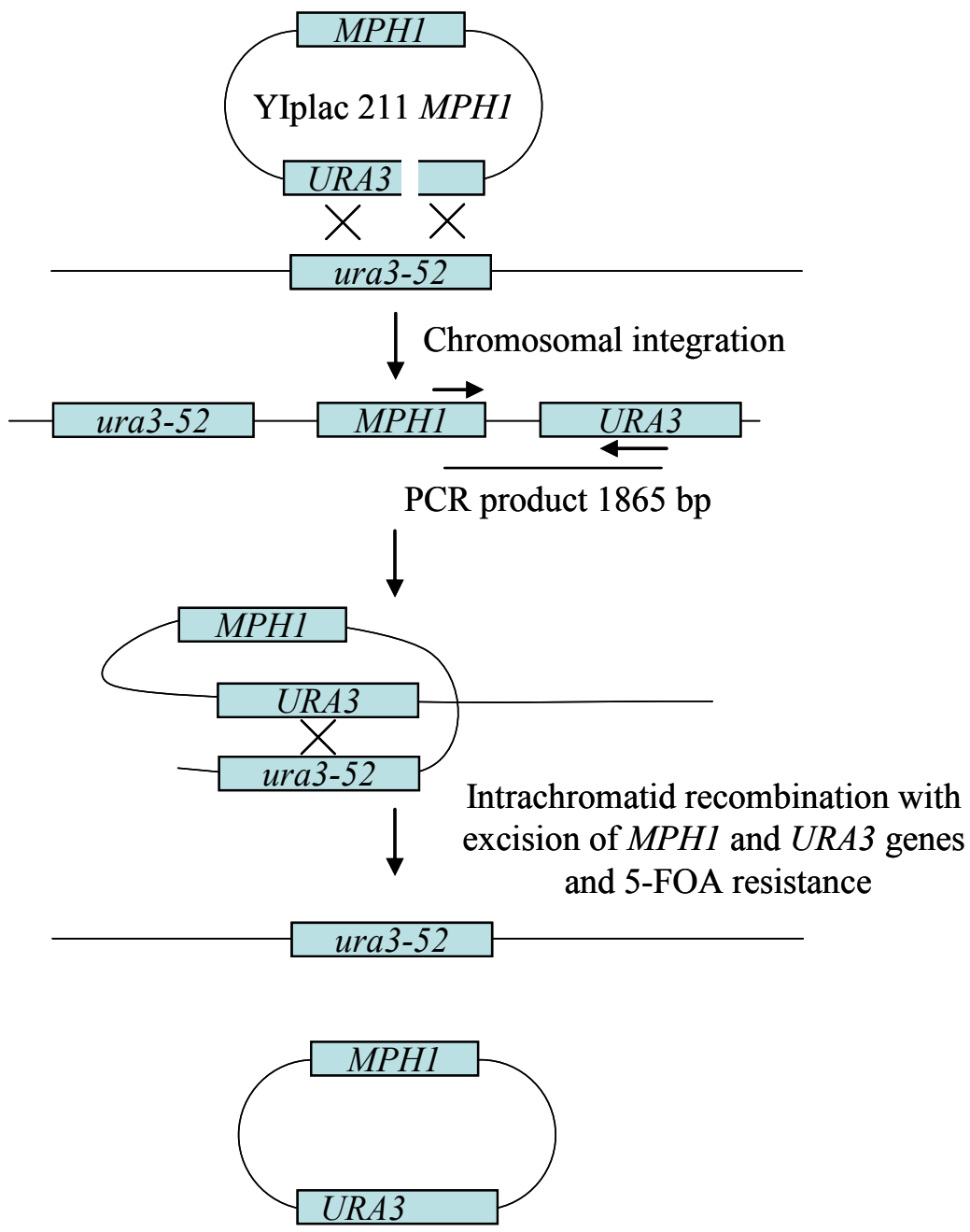

Figure 6. Model describing the integration of the YIplac211 MPH1 plasmid at the ura3-52 locus and the 5FOA resistance following excision of MPH1 and URA3 genes as circular extrachromosomal product. Location of primers utilized to verify the integration is also shown.

This integration produces a chromosomal $M P H 1$ gene flanked by the two alleles URA3 and ura3-52 (Orr-Weaver et al 1981). A yeast strain, with a functional URA3 gene, is sensitive to the 5-Fluoroorotic acid (5-FOA). URA3 gene codes an orotidine decarboxylase converting the 5-FOA in 5-fluoro-deoxyuridine-monophosphate that poisons the cell forming covalent adduct with the thymidylate synthetase. The cell 
can survive on 5-FOA plates after loss of the URA3 gene function that, in this experimental system, should occur by recombination between the two alleles URA3 and ura3-52 and excision of the MPH1 and URA3 genes as circular extrachromosomal product. It might as well be, even if with a considerably lower frequency (due to the high fidelity of the replication machinery and DNA repair mechanisms), that the URA3 gene inactivation is not due to excision but to a mutation inactivating the gene. Taking into account that the probability of having an intrachromatid recombination over a simple inactivation of the URA3 function should be the same for the two strains used in this experiment, they were compared for the rate of forming 5-FOA resistant colonies using the method of the median (Lea and Coulson 1948). As shown in table 5, the srs 2 mutant had a 327 fold increased rate of 5-FOA resistance compared to the mph1 srs 2 double mutant. Furthermore, eight 5-FOA resistant colonies for each of the two strains were picked and the chromosomal DNA was isolated and subjected to PCR analysis in order to check for the presence of the integrated MPHI gene. The two primers utilized (5'_YIR002domain1 and 5'-URA3_2; for sequences see Materials and Methods section) were located on the URA3 gene and the MPHI genes allowing detection of a 1865 bp DNA fragment, as shown in figure 6. The PCR analysis (figure 7) revealed that the fragment was still detectable in all the $m p h 1$ srs 2 mutants after the acquired 5-FOA resistance but it was not detectable in the 5-FOA resistant srs 2 mutants. This result indicates that the 5-FOA resistance in $m p h 1$ srs 2 mutants was probably due to mutational inactivation of the URA3 gene and not loss of MPH1 and URA3 genes as circular extrachromosomal product.

Table 5. Rate 5-FOA resistance determinate by method of the median (Lea and Coulson, 1948). The ectopic MPH1 was integrated between the ura3-52 and URA3 loci by integration of the plasmid YIplac $211 \mathrm{MPH1}$.

\begin{tabular}{lll}
\hline Strain (Haploids) & Rate of 5-FOA resistance & Ratio \\
\hline$m p h 1$ srs $2 M P H 1$ & $9,44 \times 10^{-8} \pm 1.6 \times 10^{-8}$ & 1 \\
\hline srs $2 M P H 1$ & $3,09 \times 10^{-5} \pm 0.27 \times 10^{-5}$ & 327 \\
\hline
\end{tabular}




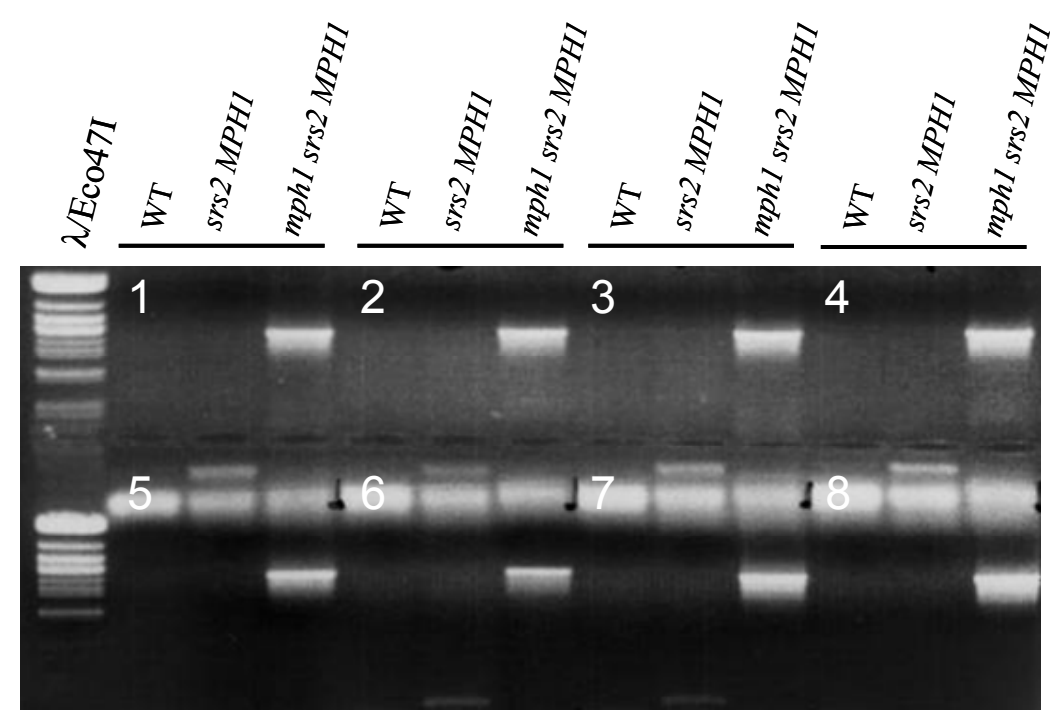

Figure 7. PCR analysis on chromosomal DNA extracted from eight srs 2 MPH1 and eight mph1 srs 2 MPH1 single cells colonies picked from 5-FOA plates. Eight independent PCR reactions (product $1865 \mathrm{bp}$ ) were performed and in each of them the wt chromosomal DNA was included The $\lambda /$ Eco47I (MBI Fermentas) marker was used where the size of the DNA fragments range from $8126 \mathrm{bp}$ to $23 \mathrm{bp}$.

Furthermore, as shown in table 6, a microscopic inspection of 9 dissected tetrads, obtained from a cross between mph1 (mph1::URA3) and $\operatorname{srs} 2$ ( $\operatorname{srs} 2:: H I S 3 M X 6)$ mutants, revealed that haploids spores $m p h 1$ srs 2 , which position on the plate was inferred after replica plating of the dissection plate on selective media, undergo few cell division before arresting and in one case the formation of a microcolony was observed. Taken together all these data clearly suggest that the combined deletion of $M P H 1$ and $S R S 2$ genes in the CEN.PK2 yeast strain results in a severe synthetic growth defect.

Table 6. Microscopic inspection of 9 dissected tetrads obtained from the cross between an mph1 (mph1::URA3) and $\operatorname{srs} 2(\operatorname{srs} 2:: H I S 3 M X 6)$ mutants.

\begin{tabular}{|c|c|c|c|c|c|c|c|c|}
\hline 1 & 2 & 3 & 4 & 5 & 6 & 7 & 8 & 9 \\
\hline srs 2 & srs 2 & $\begin{array}{c}\text { mph1 srs } 2 \\
\text { microcolony }\end{array}$ & WT & srs 2 & WT & mphl & $\begin{array}{c}\text { mph1 srs } 2 \\
6 \text { cells }\end{array}$ & $s r s 2$ \\
\hline $\begin{array}{c}\text { mph1 srs } 2 \\
3 \text { cells }\end{array}$ & mphl & WT & WT & $\begin{array}{c}\text { mph1 srs } 2 \\
4 \text { cells }\end{array}$ & $s r s 2$ & WT & srs 2 & $\begin{array}{c}\text { mph1 srs2 } \\
1 \text { cell } \\
\end{array}$ \\
\hline WT & WT & mph1 & $\begin{array}{l}\text { mph1 srs } 2 \\
2 \text { cells }\end{array}$ & $\begin{array}{l}\text { no marker } \\
\text { colony }\end{array}$ & mphl & srs 2 & $m p h l y$ & $m p h 1$ \\
\hline mph1 & $\begin{array}{l}\text { mph1 srs } 2 \\
8 \text { cells }\end{array}$ & $s r s 2$ & $\begin{array}{c}\text { mph1 srs } 2 \\
5 \text { cells }\end{array}$ & colony & $\begin{array}{c}\text { mph1 srs } 2 \\
8 \text { cells }\end{array}$ & $\begin{array}{c}\text { mph1 srs } 2 \\
1 \text { cell }\end{array}$ & WT & WT \\
\hline
\end{tabular}


$m p h 1$ and $s r s 2$ GENETIC INTERACTION IN OTHER STRAIN BACKGROUNDS

The genetic interaction between the MPH1 and SRS2 genes was also investigated in other yeast strains since other labs reported the construction of viable double null mutants $m p h 1 s r s 2$ in yeast strains different from the CEN.PK2. Therefore an $m p h 1$ mutant (mph1::KanMX4 deletion), isogenic derivative of the $S$. cerevisiae strain BY4741, was crossed with an srs 2 null mutant (srs2::HIS3MX6 deletion) isogenic derivative of the $S$. cerevisiae strain MW3317-21A (Kramer et al 1989). A total number of eighteen tetrads was dissected. The 64 spore colonies were replica plated onto G418 and SC-HIS plates. The total number of spores having the mph1 srs 2 genotype was 15 . Of them, 10 were viable whereas the remaining 5 were unviable and they were inferred from the genotype of the other spores forming the tetrads. Six tetrads, obtained from this cross, are shown in figure 8 where three viable and three unviable mph 1 srs 2 double mutant spores are indicated. It can be observed that the three viable $m p h 1$ srs 2 spores formed colonies of smaller size compared to the other spores.

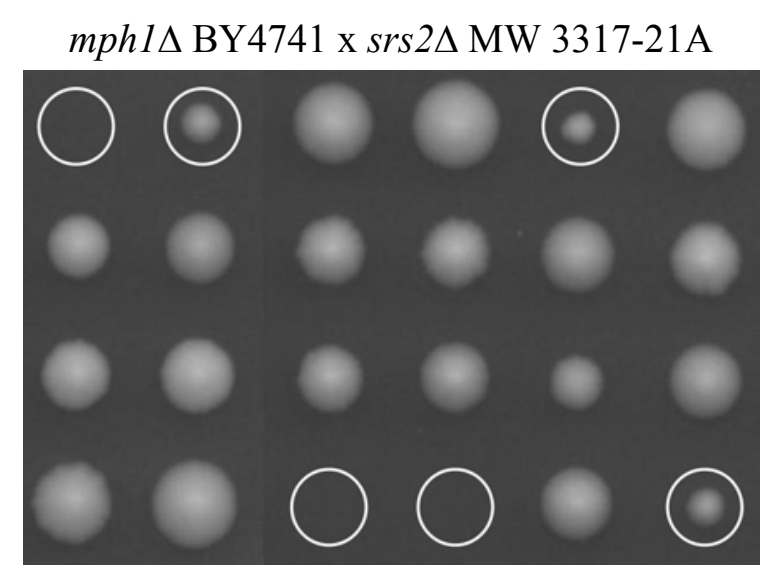

Figure 8. Analysis of the $m p h 1 \Delta \operatorname{srs} 2 \Delta$ synthetic interaction in spores obtained from the cross between the BY4741 mph1::KanMX4 null mutant and the MW 3317-21A srs $2: \because H I S M X 6$ null mutant. The mph1 $\operatorname{srs} 2 \Delta$ double mutants are indicated with circles; three of them were unviable and they were inferred.

Furthermore, an $m p h 1$ null mutant ( $m p h 1:: K a n M X 4$ deletion), isogenic derivative of the $S$. cerevisiae strain DF5, was crossed with the srs2 null mutant ( $\operatorname{srs} 2:: H I S 3 M X 6$ deletion) isogenic derivative of the S. cerevisiae strain MW3317- 
21A (Kramer et al 1989). 9 tetrads, obtained from this cross, were dissected and the 31 spores forming colonies were replica plated onto selective media. The number of mph 1 srs 2 spores was 7, 5 were viable whereas 2 resulted to be unviable and they were inferred. As can be seen in figure 9 , the size of the colonies formed by $m p h 1$ srs 2 single spores, when compared to the other colonies, was also reduced in this strain backgrounds.

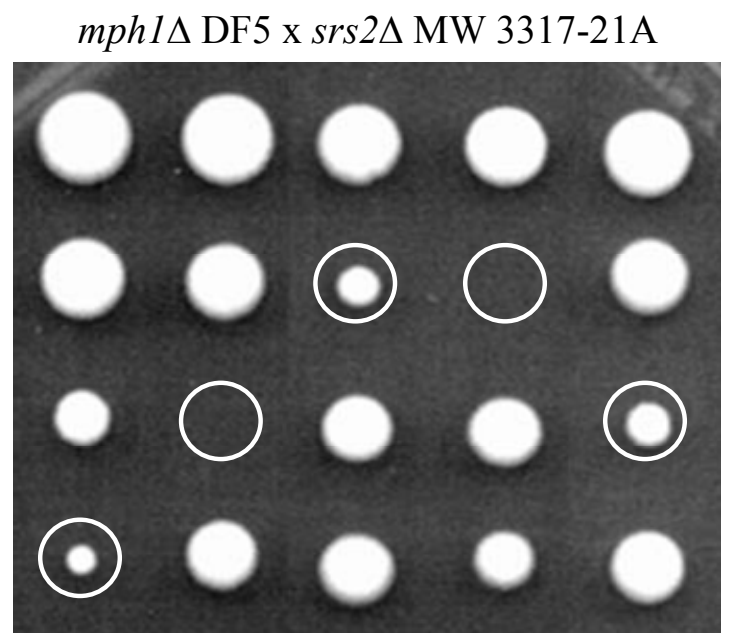

Figure 9. Analysis of the mph1 $1 \Delta r s 2 \Delta$ synthetic interaction in spores obtained from the cross between the DF5 mph1::KanMX4 null mutant and the MW 3317-21A srs $2:: H I S M X 6$ null mutant. The mph $1 \Delta$ srs $2 \Delta$ double mutants are indicated with circles; two of them were unviable and they were inferred.

Taken together these data suggest that the synthetic growth defect observed in spores carring the $m p h 1$ and srs 2 deletions is milder when compared to the synthetic growth defect that the two combined deletions produce in the CEN.PK2 yeast strain. The number of dissected tetrads is probably not enough to judge whether a suppressor of the severe synthetic growth defect, observed in the CEN.PK2 strain, is present or not in one of the other $S$. cerevisiae strains. However, a 1:1 distribution of viable and unviable $m p h 1$ srs 2 spores would be expected if a suppressor was present. A distribution 10:5 and 5:2 in favour of the viable spores was observed in the two crosses previously described. On the other hand, a mutation carried by the CEN.PK2 strain and causing the severe synthetic growth defect could also account for the observed phenotypic differences.

Further investigation were made to determine whether the CEN.PK2 genetic background is dominant or recessive over the BY4741/MW3317-21A background 
with respect to the $m p h 1$ srs 2 synthetic lethality. An $m p h 1$ srs 2 double mutant and an srs 2 single mutant (recovered from the cross between the mphl BY4741 strain and the srs2 MW3317-21A strain) were crossed with the mph1 srs2 MPH1 CEN.PK2 strain (containing the ectopic MPH1 gene integrated between the two alleles URA3 and URA3-52, as described previously). Three $m p h 1 / m p h 1 s r s 2 / s r s 2 M P H 1$ and three mph1/MPH1 srs $2 /$ srs 2 MPH1 zygotes were isolated from this cross. To compare them for the ability of loosing the integrated MPHI gene, which capability, as previously described and illustrated in figure 6 can be selected on 5-FOA plates, six over night cultures of the six zygotes were used to inoculate six fresh cultures that were grown for four hours. For each culture serial dilution were made and they were plated on 5-FOA plates and SC plates for determination of the viable titer. The number of 5-FOA resistant colonies was divided by the total number of living cells (viable titer) in order to calculate the frequencies of 5-FOA resistant colonies. As shown in table 7, the three zygotes $m p h 1 / m p h 1$ srs $2 / s r s 2 M P H 1$ showed in all the three independent experiments a markedly reduced frequency of 5-FOA resistant colonies if compared to the three mph1/MPH1 srs $2 / s r s 2 ~ M P H 1$ zygotes. This results indicate that the CEN.PK2 genetic background exerts a dominant effect on the $m p h 1$ srs 2 synthetic growth defect.

Table 7. Frequencies of forming 5-FOA resistant colonies. The numbers were calculated dividing the number of 5-FOA resistant colonies by the total number of living cells (viable titer).

\begin{tabular}{cccc}
\hline Strain (Diploids) & \multicolumn{3}{c}{ Experiments } \\
\hline & I & II & III \\
\hline$m p h 1 / m p h 1 s r s 2 / s r s 2 M P H 1$ & $4,6 \times 10^{-6}$ & $8,9 \times 10^{-9}$ & $3,6 \times 10^{-7}$ \\
\hline$m p h 1 / M P H 1 \mathrm{srs} 2 / s r s 2 \mathrm{MPH1}$ & $1,3 \times 10^{-3}$ & $5,5 \times 10^{-5}$ & $6,2 \times 10^{-4}$ \\
\hline
\end{tabular}




\section{HOMOLOGOUS RECOMBINATION CAUSES LETHALITY IN THE DOUBLE MUTANT mph1 srs2}

The involvement of Mph1 in a recombinogenic pathway for the error-free bypass of DNA lesions (Schürer et al. 2004), the Srs2 ability to inhibit the recombination reaction (Krejci et al. 2003), the srs 2 null mutant hyper-recombination phenotype (Klein 2001) lead to the hypothesis that the srs 2 deletion, combined with the $m p h 1$ deletion, gives rise to toxic recombination intermediates causing cell death or extreme sickness. Moreover, similar hypothesis were formulated to explain the lethality or poor growth of srs 2 rad54 and $s r s 2 s g s 1$ double mutants (Klein 2001; Gangloff et al 2000). Deletion of genes involved in early steps of homologous recombination were tested for the ability to suppress the $m p h 1$ srs 2 lethality in the CEN.PK2 genetic background. The marker replacing each deleted gene will be indicated in parenthesis in this section.

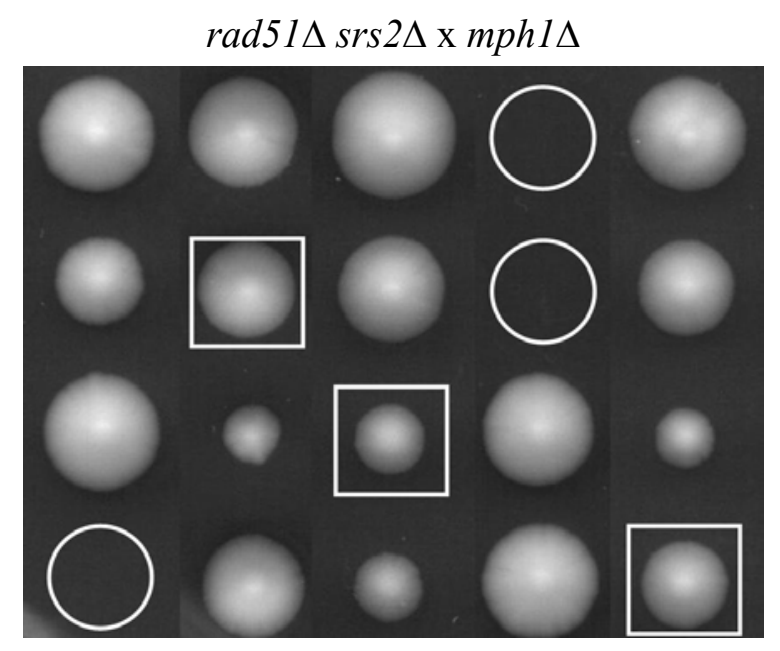

Figure 10. Suppression of $m p h 1 \Delta$ srs $2 \Delta$ lethality by deletion of the RAD51 gene. Unviable $m p h 1$ srs 2 spores are marked by circles and viable rad51 $\mathrm{mph} 1 \mathrm{srs} 2$ spores by squares.

As shown in figure 10, after the cross between the rad51 (LEU2) srs2 (HIS3) double mutant and the mphl (URA3) single mutant, zygotes isolation and tetrad analysis, viable rad51 $\mathrm{mph} 1 \mathrm{srs} 2$ triple mutants were recovered. It should be pointed out that requirement of the $R A D 51$ gene can be distinguished by the requirement of $R A D 52$ in the different homologous recombination mechanisms. Gene conversion 
and repair of DSBs in mitotic cells requires the RAD51 gene. However, in the rad51 mutants, recombination can still be detected suggesting the existence of an alternate pathway for the strand invasion process that requires the RAD52 and to some extent the RAD59 genes (Paques and Haber 1999; Symington 2002; Krogh and Sygmington 2004). rad52 mutants show severe defect in gene conversion and recombination between inverted repeats and they are also defective in BIR and SSA mechanisms (see also Introduction section for homologous recombination mechanisms, Symington 2002, Krogh and Sygmington 2004). On the contrary, the rad51 mutant does not show defect in SSA mechanism and a much lower reduction of recombination between inverted repeats (Rattray and Sygminton 1994; Ivanov et al 1996). The Rad51 protein seems to have a greater influence on intermolecular strand invasion events compared to the Rad52 protein that seems to efficiently promote intramolecular recombination events (Bartsch et al 2000; Davis and Symington 2004). Despite the different roles that Rad51 and Rad52 may play in homologous recombination, the suppression of the mph1 srs 2 synthetic lethality introducing the rad52 deletion was also obtained. As shown in figure 11, the rad52 (kanMX4) srs 2 (HIS3) double mutant was crossed with the mph1 (URA3) single mutant and after tetrad analysis viable rad52 $\mathrm{mph} 1 \mathrm{srs} 2$ triple mutants were recovered.

$\operatorname{rad} 52 \Delta \operatorname{srs} 2 \Delta \mathrm{x} \Delta m p h 1$

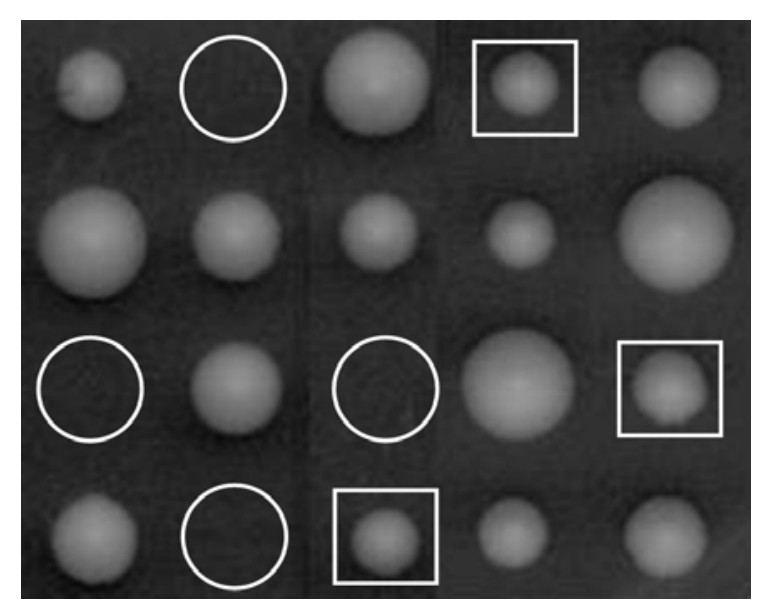

Figure 11. Suppression of $m p h 1 \Delta \operatorname{srs} 2 \Delta$ lethality by deletion of the RAD52 gene. Unviable $m p h 1$ srs 2 spores are marked by circles and viable rad52 $\mathrm{mph} 1 \mathrm{srs} 2$ spores by squares. 
The rad55 and rad57 deletions were also tested for the ability to rescue the mph1 srs2 lethality. The rad55 (LEU2) srs2 (HIS3) double mutant was crossed to the mph1 (URA3) single mutant. As shown in figure 12 a, tetrad analysis revealed the presence of viable rad55 mph1 srs 2 triple mutants. Furthermore, the rad57(LEU2) mphl(URA3) double mutant crossed to the srs2(HIS3) single mutant allowed recovery of viable rad57 mph1 srs 2 triple mutants (figure $12 \mathrm{~b}$ ).

a. $\operatorname{rad} 55 \Delta \operatorname{srs} 2 \Delta \mathrm{x} m p h 1 \Delta$

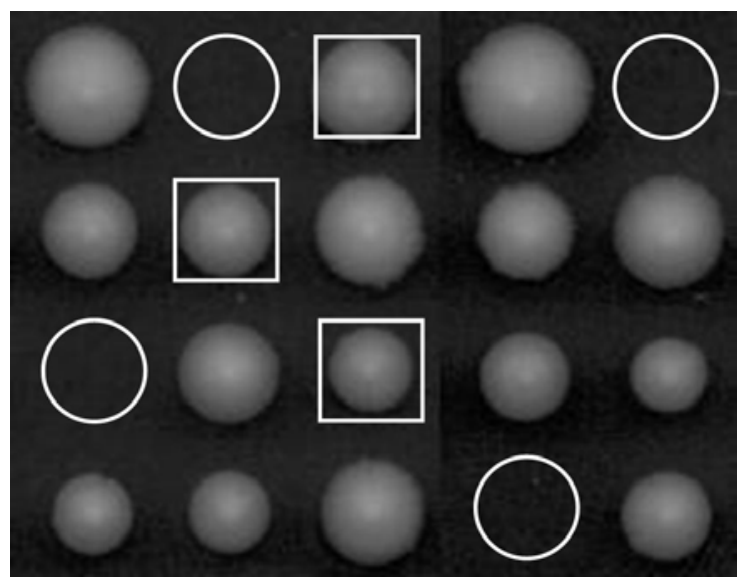

b. $\operatorname{rad} 57 \Delta m p h 1 \Delta \mathrm{x} \operatorname{srs} 2 \Delta$

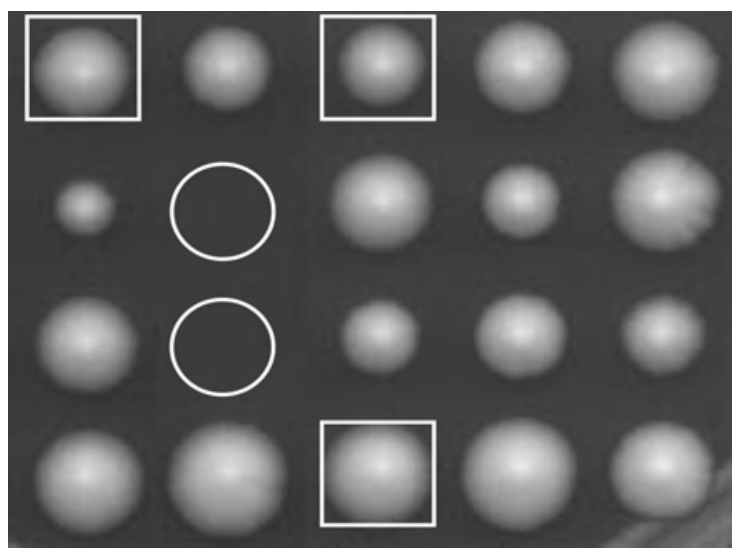

Figure 12. Suppression of $m p h 1 \Delta s r s 2 \Delta$ lethality by deletion of the RAD55 and RAD57 genes. Unviable $m p h 1$ $s r s 2$ spores are marked by circles in figure a and b. Viable rad55 mph1 srs 2 and rad57 mph1 srs 2 spores are marked by squares in a and $b$ respectively.

These results sustain the hypothesis that simultaneous deletion of the MPH1 and SRS2 genes produces toxic recombination intermediates causing cell death or extreme sickness in the CEN.PK2 yeast strain. In fact, inhibition of the Rad51- 
nucleoprotein filament formation, an early step in the homologous recombination processes, can rescue the mph1 srs 2 synthetic lethality.

The crosses and tetrads analysis presented in this study were repeated several times using also different deletions combinations. For instance, when the rad52 deletion was investigated for the ability of rescuing the mph1 srs 2 synthetic lethality the rad52 (KanMX4) mph1 (mph1::hisG deletion) double mutant was crossed to the srs2 (HIS3) single mutant. A tetrad analysis with selective media (G418 and SC-HIS plates) and PCR screen, for the $m p h 1:: h i s G$ deletion, allowed detection of viable rad52 mph1 srs 2 triple mutants. The mating type of the triple mutants was determined and two of them, one a and one $\alpha$, were further verified by PCR for each deletion. Furthermore, double mutants rad52(KanMX4) srs2(HIS3), recovered from the previous cross, were mated with the mphl (mph1::URA3 deletion) single mutant and tetrad analysis was again repeated. A complete list of all the deletions tested in this study for the ability to suppress the synthetic lethality and the results obtained can be found at page 56. The PCR analysis on the rad52 mphl srs 2 triple mutant (mating type a, list number 19) is described in figures 13 and 14 (see also table 3, page 27 for primer combinations). 


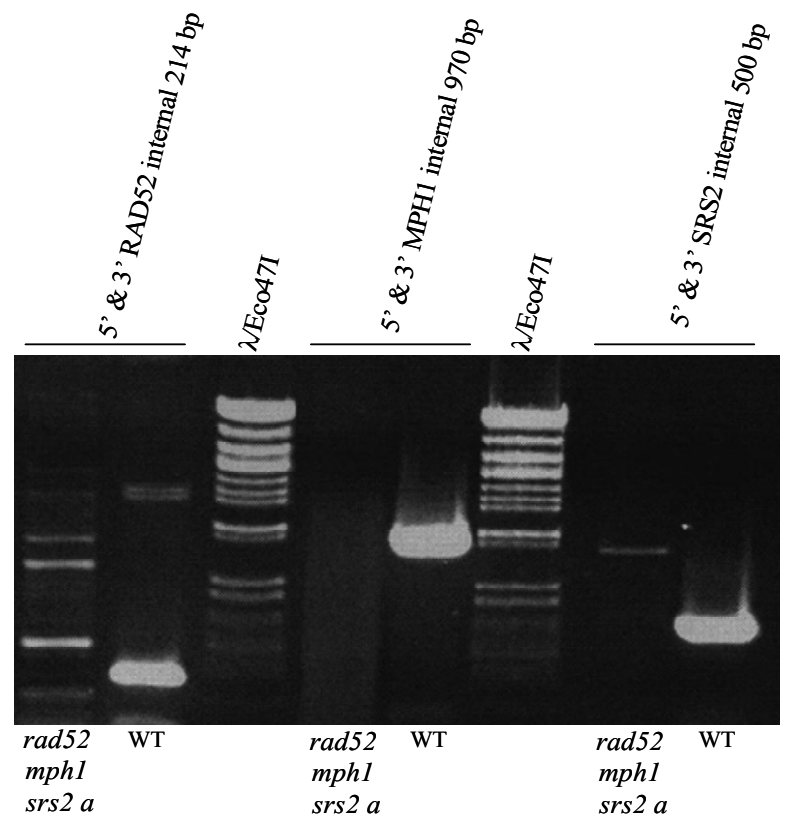

Figure 13. PCR analysis of the chromosomal DNA extracted from the rad52 $\mathrm{mph} 1 \mathrm{srs} 2$ triple mutant and wt strain. The internal combination of primers detecting the RAD51 MPH1 and SRS2 genes were tested in three independent PCR reactions on the triple mutant and the wt as control. As it is possible to observe in the picture the expected DNA fragment was obtained only in the wt control but no fragments or aspecific products were obtained in the case of the triple mutant rad51 mph1 srs 2 . The $\lambda /$ Eco47I (MBI Fermentas) marker was used where the size of the DNA fragments range from $8126 \mathrm{bp}$ to $23 \mathrm{bp}$.

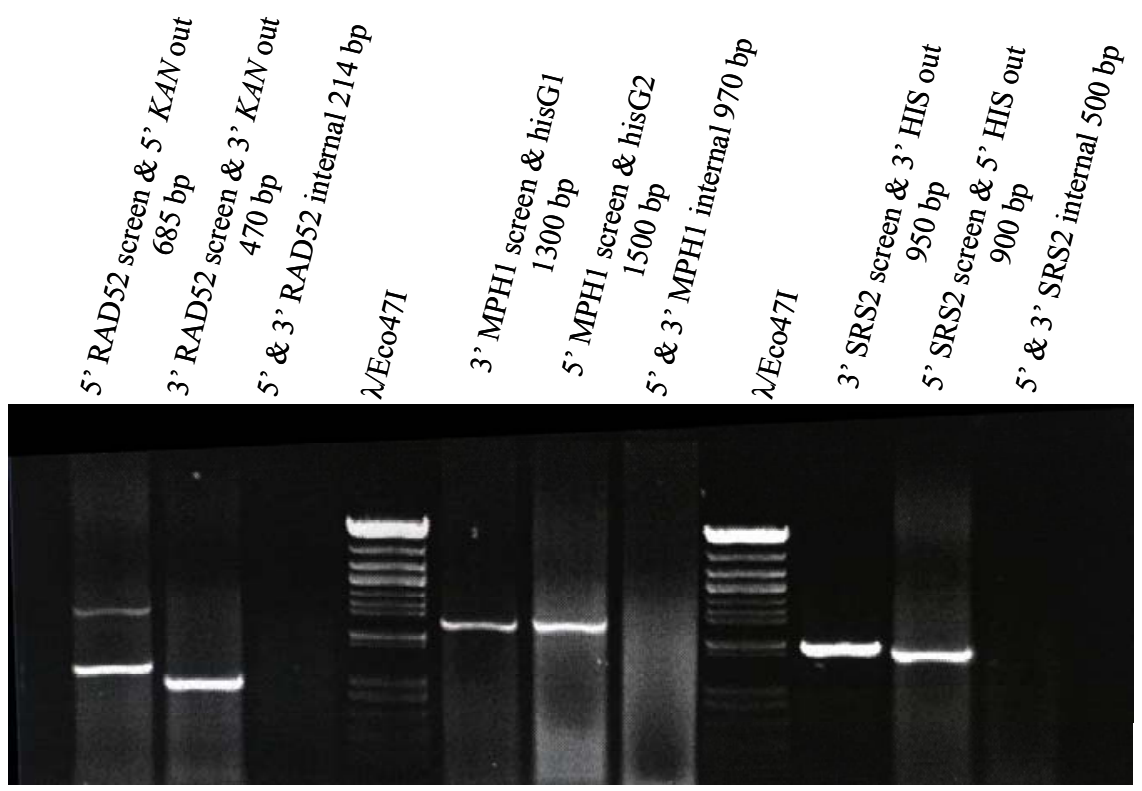

Figure 14. PCR analysis of the chromosomal DNA extracted from the rad52 mphl srs 2 triple mutant. The structure of the deletions $\operatorname{rad} 52:: \operatorname{Kanmx} 4, \operatorname{mph} 1:: h i s G$ and $\operatorname{srs} 2:: H I S 3 M X 6$ were verified with the primers combinations indicated in the picture. The PCR with internal combination of primers for detection of the RAD51 $M P H 1$ and SRS2 genes was also repeated. The $\lambda /$ Eco47I (MBI Fermentas) marker was used where the size of the DNA fragments range from $8126 \mathrm{bp}$ to $23 \mathrm{bp}$. 


\section{DELETION OF GENES INVOLVED IN THE DNA DAMAGE CHECKPOINT PATHWAY SUPRESSES THE $m p h 1$ srs 2 SYNTHETIC LETHALITY}

The previous results indicate that in mphl srs 2 double mutants a functional homologous recombination pathway is responsible for the lethal phenotype. It is conceivable that the simultaneous absence of the Mph1 and Srs2 proteins generate a defect in the processing of recombination intermediates, leading thus to accumulation of aberrant DNA structures. Such structures might be sensed by the DNA damage checkpoint proteins. They may induce a permanent cell cycle arrest that would explain the mph1 srs 2 phenotype in the CEN.PK2 yeast strain. To test this hypothesis the same genetic approach previously described was used and mutations, in genes with a role in the DNA damage checkpoint pathways, were tested for the ability to suppress the synthetic lethality. Deletions of the MEC1, RAD53, TEL1, RAD17, $R A D 24$ and $R A D 9$ genes were tested.

MEC1 and RAD53 are two essential genes central transducers of the DNA damage checkpoint pathways. Suppression of late origin firing, stabilization of slowed or stalled replication forks, prevention of cell cycle progression until conditions are appropriate for the resumption of DNA replication show dependence on these two genes (Elledge 1996). However, the essentiality of MEC1 and RAD53 genes is not due to their role in DNA damage checkpoint but rather to the inactivation of Sml1, an inhibitor of the ribonucleotide reductase Rnr1, which regulate the dNTP pool in the cells. Thus generation of mecl or rad53 null mutants requires the deletion of the SML1 gene (Zhao et al 1998; Zhao et al 2000). The MECl gene codes for a phosphatidyl-inositol 3-kinase-like protein (PIKK) that functions in a partially redundant manner with the Tel1 protein, another PIKK family member (Greenwell et al 1995; Morrow et al 1995). In particular, TEL1 seems to be involved in telomere length maintenance (Greenwell et al 1995). It is recruited to DSBs via Xrs2 (Nakada et al 2003) and phosphorylates Mre11 and Xrs2 in the MRX complex, as well as Rad9 (Usui et al 2001, Grenon et al 2001; D'Amours and Jackson 2002). It exhibits also functional redundancy and structural homology with $M E C 1$. Overexpression of TEL1 can suppress some defects in the mecl mutants. However a tell mutant is not checkpoint defective, although mecl tell double mutants are more sensitive to DNA 
damage than mecl single mutants. (Morrow et al 1995). Mec1 exists in complex with the Ddc2 protein that is required for all known function of Mec1. Ddc2 binds DNA independently of $\mathrm{Mec} 1$, and recruitment of Mec1 to DNA requires Ddc2 (Paciotti et al 2000; Rouse and Jackson 2002). The recruitment of Mec1 to DNA lesions by Ddc2 is crucial for Mec1-dependent phosphorylation and subsequent activation of several other proteins responsible for a proper DNA damage response (Lowndes and Murguia 2000; Abraham 2001). The RAD53 gene codes for a protein kinase that is phosphorylated and activated in response to DNA damage. Rad53 contains two forkhead-associated domains (FHA) that flank the catalytic domain. Each FHA domain contains a cluster of PIKK phosphorylation sites required for full checkpointdependent phosphorylation of Rad53 and associated biological functions (Sanchez et al 1999).

When the sml1 rad53 and smll mecl double deletions were tested for the ability of rescuing the synthetic lethality of the $m p h 1$ srs 2 double mutant, viable quadruple mutants were recovered. In particular, the sml1 (HIS3) rad53 (KanMX4) mph1 (mph1::hisG deletion) triple mutant was crossed to the srs2 (HIS3) single mutant. Zygotes were isolated by micromanipulation and 25 tetrads were dissected. Tetrad analysis with selective media and PCR screen for the $m p h 1:: h i s G$ deletion allowed detection of two viable smll rad53 mphl srs2 quadruple mutants. The same procedure was also followed when the sml1 (HIS3) mecl (TRPl) mphl (mph1::hisG deletion) triple mutant was crossed to the $\operatorname{srs} 2$ (HIS3) single mutant and 25 tetrads were dissected. One viable quadruple mutant smll mecl mphl srs 2 was recovered in this case. When the tell deletion was tested for the ability to suppress the synthetic lethality an unexpected result was obtained. In this case the tell(KanMX4) mph1 (mph1::hisG deletion) double mutant was crossed to the srs2 (HIS3) single mutant and 24 tetrads were dissected. From the analysis of 34 spore colonies neither tel1 srs 2 double mutant nor tell $\mathrm{mph} 1$ srs 2 triple mutants were recovered. This result can be ascribed to a probable tell srs 2 synthetic lethality that has not been further investigated.

Rad53 is activated in a Mec1-dependent manner and this activation requires additional factors. They are two protein complexes and the Rad9 protein (Rouse and Jackson $2002 \mathrm{~b}$ ). The first of these complexes resembles the pentameric replication factor C (RFC) except that the Rad24 protein replaces the Rfc1 large subunit. Rad24 forms a complex with the four small RFC subunits Rfc2-5 (Griffiths et al 1995). The 
second complex is formed by the protein Rad17, Ddc1 and Mec3 and shows similarity to the PCNA sliding clamp (Venclovas and Thelen 2000). RAD9 is the first checkpoint gene described (Weinert and Hartwell 1989). It codes for a serine/threonine-rich polypeptide of $148,4 \mathrm{kDa}$ (Schiestl et al 1989). The C-terminal region of the protein shows sequence identity with the mammalian tumor suppressor protein BRCA1 (breast cancer associated 1) which contains a tandem repeat of the BRCT (BRCA1 C-terminus) motif. This motif, required for Rad9 function, mediates also its oligomerization after DNA damage (Soulier and Lowndes 1999). Rad9 is phosphorylated during normal cell-cycle progression and the presence of DNA damage induces Mec1/Tel1-dependent hyperphosphorylation of Rad9. This form of Rad9 interacts with Rad53 in vivo (Sun et al 1998; Emili 1998; Vialard et al 1998). This hyperphosphorylation leads to association of $\operatorname{Rad} 9$ with the kinase $\operatorname{Rad} 53$. The association is mediated by interaction between the two FHA domains of Rad53 and phosphorylated residues in Rad9 (Durocher et al 1999).

Mec1/Tel1 hyperphosphorylation of Rad9 following DNA damage determine the recruitment and activation of Rad53 molecules. Rad9 may act as a scaffold bringing Rad53 molecules into close proximity and facilitating their in trans autophosphorylation (Gilbert et al 2001). The Rad17 protein together with Ddc1 and $\mathrm{Mec} 3$ is responsible for formation of a heterotrimeric PCNA-like structure. This structure is loaded onto DNA in case of damage by a RFC-like complex (where the Rfc1 subunit is substituted by Rad24, Longhese et al 1998, Melo et al. 2001). The recruitment of this PCNA-like structure to sites of DNA damage is dependent on Rad24 but not on Mec1/Dcd2 complex (Kondo et al 2001; Melo et al 2001; Rouse and Jackson 2002 a). In spite of this independent recruitment onto sites of DNA damage Mec1-dependent activation of Rad53, in response to DNA damage, is severely reduced in the absence of the RFC-like and PCNA-like complexes indicating that they play a role in this process (De la Torre-Ruiz et al 1998). RAD9 and $R A D 24 / R A D 17 / M E C 3$ are thought to define two additive, interacting branches of the DNA damage checkpoint pathway. They are believed to function upstream of $R A D 53$ in signalling the presence of DNA damage. Deletion of any one of these genes reduces the normal G1/S and G2/M checkpoint delays after UV irradiation. In rad9 $\mathrm{rad} 24$ double mutants $\mathrm{G} 1 / \mathrm{S}$ checkpoint activity is undetectable, although there is a residual G2/M checkpoint activity (de la Torre-Ruiz et al 1998). Taking into account these findings deletions of the $R A D 9, R A D 17$ and $R A D 24$ genes were also 
tested for the ability to rescue the mph1 srs 2 lethal phenotype. In particular, as shown in figure 15, when the rad9 (KanMX4) mph1 (URA3) double mutant was crossed to the srs2 (HIS3) single mutant viable rad9 mph1 srs2 triple mutant spores were recovered indicating that deletion of the $R A D 9$ gene rescues the $m p h 1$ srs 2 synthetic lethality.

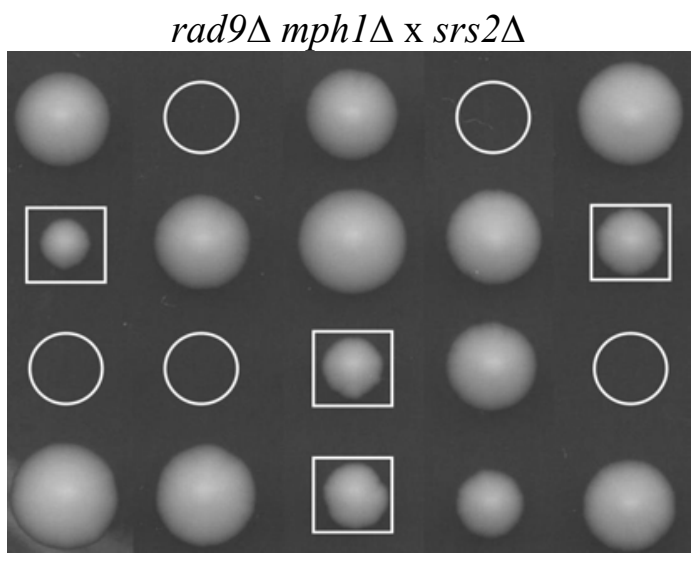

Figure 15. Suppression of $m p h 1 \Delta s r s 2 \Delta$ lethality by deletion of the $R A D 9$ gene. Unviable $m p h 1 s r s 2$ spores are marked by circles and viable rad $9 \mathrm{mph} 1 \mathrm{srs} 2$ spores by squares.

As an example, the PCR analysis made on the rad9 mph1 srs 2 triple mutant (mating type $\alpha$, list number 43) is described in figures 16 .

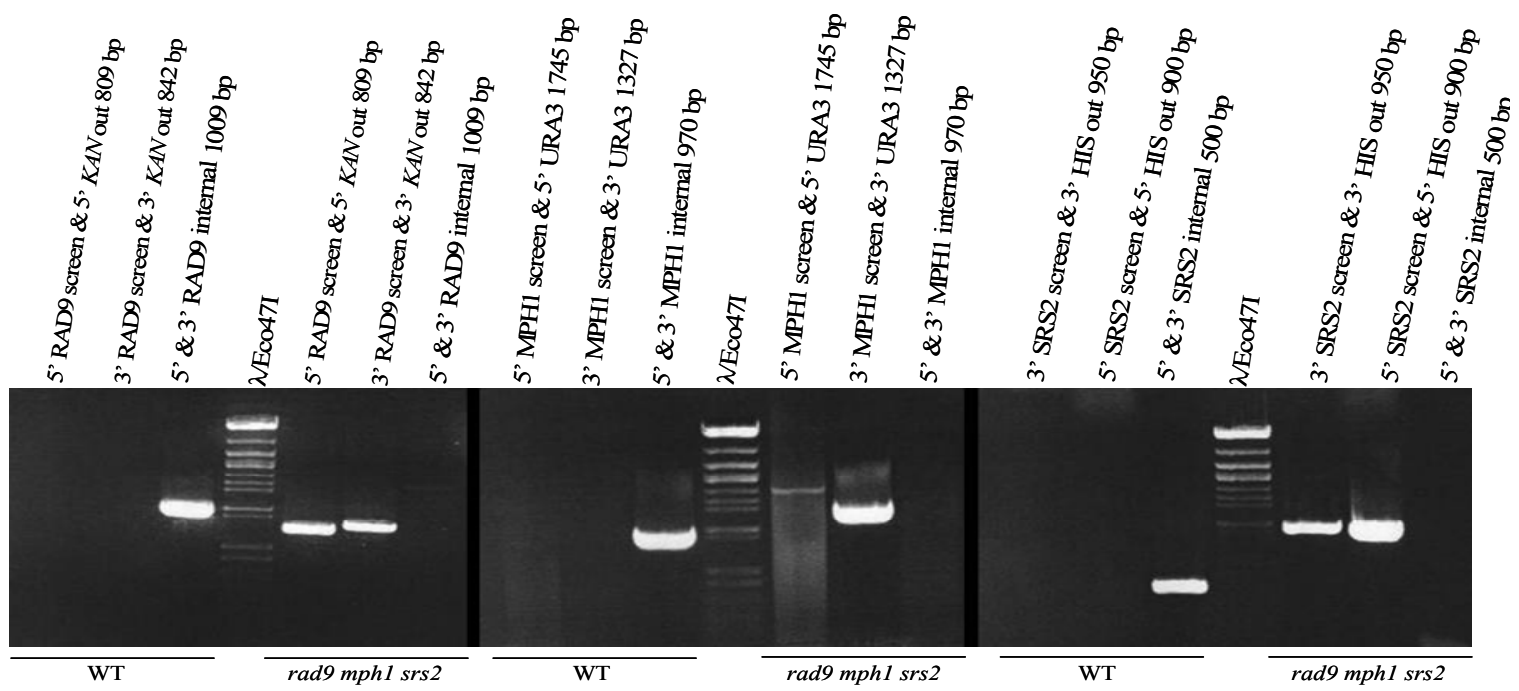

Figure 16. PCR analysis of the chromosomal DNA extracted from the rad 9 mph1 srs 2 triple mutant. The structure of the deletions $\operatorname{rad} 9:: \operatorname{Kanmx} 4, \operatorname{mph} 1:: U R A 3$ and $s r s 2:: H I S 3 M X 6$ were verified with the primers combinations indicated in the picture. The PCR with internal combination of primers for detection of the RAD9 MPH1 and SRS2 genes was also used. All the PCR reactions were also performed on chromosomal DNA extracted from a wt strain as control. The $\lambda /$ Eco47I (MBI Fermentas) marker was used where the size of the DNA fragments range from $8126 \mathrm{bp}$ to $23 \mathrm{bp}$ 
Results

Furthermore, the rad17 and $\mathrm{rad} 24$ deletions were also found to rescue the $m p h 1$ srs2 synthetic lethality. In the genetic assay where the $\operatorname{rad17}$ (URA3) $m p h 1$ (mph1::hisG deletion) double mutant was crossed to a srs2 (HIS3) single mutant the tetrad and PCR analysis revealed the presence of viable triple mutants rad17 mph1 $s r s 2$, as shown in figure 17. In figure 18 the suppressor effect exerted by the rad24 deletion is illustrated. In this case a rad24 (KanMX4) mph1 (mph1::hisG deletion) was crossed to an srs2 (HIS3) single mutant and after tetrad and PCR analysis rad24 mph1 srs2 viable triple mutants were recovered.

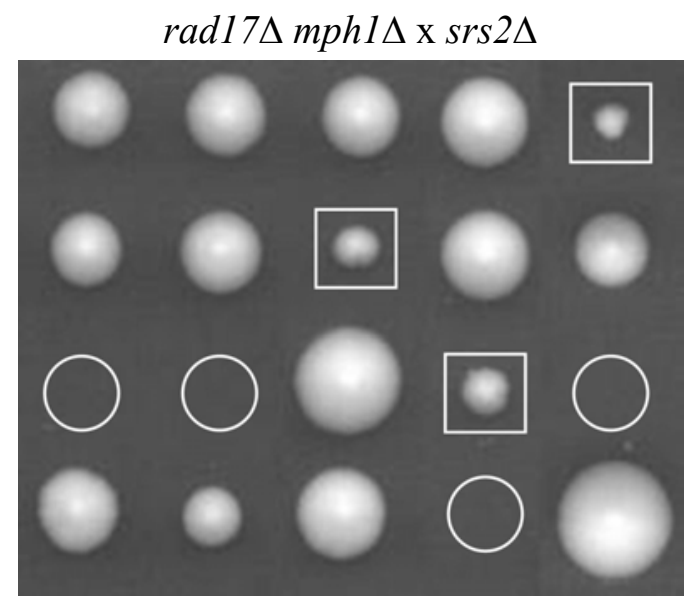

Figure 17. Suppression of $m p h 1 \Delta s r s 2 \Delta$ lethality by deletion of the $R A D 17$ gene. Unviable $m p h 1 s r s 2$ spores are marked by circles and viable rad17 $m p h 1 \operatorname{srs} 2$ spores by squares.

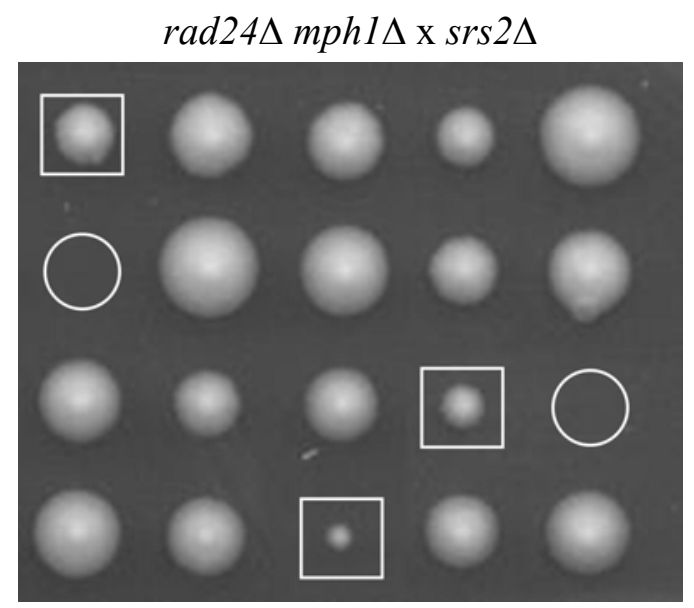

Figure 18. Suppression of $m p h 1 \Delta s r s 2 \Delta$ lethality by deletion of the RAD24 gene. Unviable $m p h 1 s r s 2$ spores are marked by circles and viable rad $24 \mathrm{mph} 1 \mathrm{srs} 2$ spores by squares. 
Taken together this results suggest that DNA damage, probably due to improper processing of recombinogenic DNA structures, is sensed by proteins involved in the DNA damage checkpoint response and cause the permanent cell cycle arrest observed in the mph1 srs 2 double mutant.

Although an involvement of Mph1 in the post replicative repair pathway has already been largely excluded since double mutants of $m p h 1$ with $\mathrm{rad} 6$, rad18 and rad5, mutants in PRR, are considerably more sensitive to DNA damage than the respective single mutants (Schürer et al 2004), deletion of RAD6 and RAD5 genes, involved in the PRR pathway and its error-free sub branch respectively, were tested for the ability to rescue the synthetic lethality of the mph 1 srs 2 double mutant. The result was that no triple mutant rad6 $m p h 1$ srs 2 and rad5 $m p h 1$ srs 2 were recovered after tetrad analysis.

In table 8 all the deletions, tested during this study for the ability to suppress the mph1 srs 2 phenotype, are summarized and the number of recovered triple or quadruple mutants were suppression was observed is also indicated.

Table 8. Deletions tested for the ability to suppress the lethal phenotype of the double mutant $m p h 1$ srs 2 observed in the CEN.PK2 genetic background. Percentage of recovered triple or quadruple mutants is indicated and calculated from the number of viable mutant recovered and number of surviving spores. The tetrads were obtained after sporulation of the respective triply or quadruply heterozygous hybrids.

\begin{tabular}{|c|c|c|c|c|c|}
\hline Deletion & $\begin{array}{l}\text { Expected \% of } \\
\text { mutants }\end{array}$ & $\begin{array}{c}\text { Number of } \\
\text { dissected } \\
\text { tetrads }\end{array}$ & $\begin{array}{c}\text { Surviving } \\
\text { spores }\end{array}$ & $\begin{array}{l}\text { Triple/quadruple } \\
\text { mutant recovered }\end{array}$ & $\%$ observed \\
\hline $\operatorname{rad} 51$ & $12,5 \%$ & 17 & 46 & 7 & $10,2 \%$ \\
\hline $\operatorname{rad} 52$ & $12,5 \%$ & 43 & 109 & 18 & $10,4 \%$ \\
\hline rad55 & $12,5 \%$ & 62 & 143 & 27 & $10,8 \%$ \\
\hline $\operatorname{rad} 57$ & $12,5 \%$ & 51 & 148 & 24 & $11,8 \%$ \\
\hline tell & $12,5 \%$ & 24 & 34 & - & - \\
\hline sml1 mec1 & $6,25 \%$ & 25 & 29 & 1 & $1 \%$ \\
\hline sml1 rad53 & $6,25 \%$ & 25 & 28 & 2 & $2 \%$ \\
\hline rad9 & $12,5 \%$ & 82 & 213 & 8 & $2,4 \%$ \\
\hline $\operatorname{rad17}$ & $12,5 \%$ & 56 & 134 & 5 & $2,2 \%$ \\
\hline $\operatorname{rad} 24$ & $12,5 \%$ & 7 & 25 & 3 & $12 \%$ \\
\hline rad6 & $12,5 \%$ & 36 & 93 & - & - \\
\hline $\operatorname{rad5}$ & $12,5 \%$ & 36 & 91 & - & - \\
\hline
\end{tabular}




\section{MPH1 AND THE RAD54 GENE}

Deletion of the RAD54 gene is synthetically lethal with the $s r s 2$ deletion (Palladino and Klein 1992). The rad54 srs 2 synthetic lethality, as observed for the mph1 srs 2 double mutant, can be suppressed by mutations in the RAD51, RAD52, RAD55 and $R A D 57$ genes and by mutations in the DNA damage checkpoint functions $R A D 9$, RAD17, RAD24 and MEC3 (Klein 2001).

In a previous work, where the MPH1 gene was implicated in an error-free DNA damage bypass pathway, requiring genes from homologous recombination, the rad51, rad52, rad55 mutations were found to be epistatic to $m p h 1$ with respect to spontaneous mutator phenotype and DNA damage sensitivity (Schürer et al 2004).

As for the other members of the homologous recombination pathway the rad54 mutation is epistatic to $m p h l$ with respect to DNA damage sensitivity. Indeed, as illustrated in figure 19, the rad54 single mutant and rad54 mphl double mutant show the same DNA damage sensitivity to the DNA damging agents MMS, 4-NQO and Camptothecin.

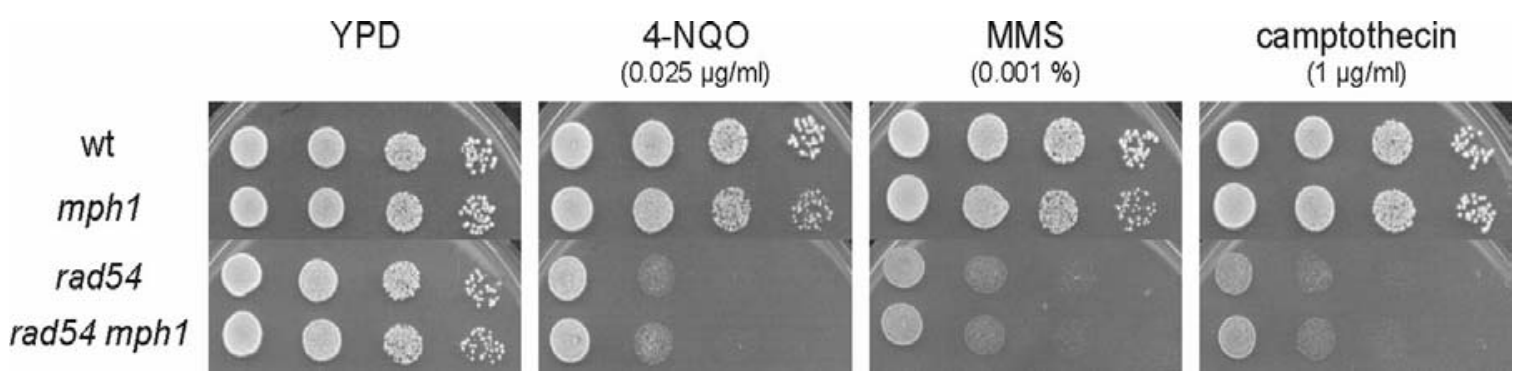

Figure 19. Drop dilution assay for DNA damage sensitivities. The mphl, rad54 and mphl rad54 mutants are compared for the sensitivity toward 4-NQO, MMS and Camptothecin. The rad54 single mutant and the rad54 mph1 double mutant show the same sensitivity to the different chemical compounds indicating thus an epistatic effect of the $m p h 1$ deletion on the sensitivity of the rad54 mutant. The wild type strain and the assay on YPD plate without genotoxic agents are used as controls (Schürer, unpublished observations).

However, the rad54 deletion shows an incomplete epistasis to $m p h 1$ since, in terms of spontaneous mutator phenotype, rad54 behaves differently compared to the other members of the homologous recombination pathway. The results of three independent spontaneous mutation rates determinations are indicated in table 9. In all the experiments the spontaneous DNA damage was increased in rad54 mphl double mutants compared to rad54 and mphl single mutants indicating that the two deletion, 
when combined together, have a sub-additive effect on the spontaneous mutator phenotype.

\begin{tabular}{ccc}
\hline Strains & Mutation rate $\mathbf{~ 1 0} \mathbf{7 0}^{\mathbf{7}}$ & Relative rate \\
\hline \multirow{2}{*}{ Wild type } & $2,2 \pm 0,3(1)$ & 1 \\
& $3,6 \pm 0,5(2)$ & 1 \\
mph1 & $2,5 \pm 0,3(3)$ & 1 \\
& $18,6 \pm 2,2(1)$ & 8,5 \\
rad54 & $24,8 \pm 2,9(2)$ & 6,9 \\
& $17,4 \pm 1,1(3)$ & 7,0 \\
& $20,7 \pm 2,5(1)$ & 9,4 \\
rad54 mph1 & $22 \pm 2,6(2)$ & 6,1 \\
& $23,2 \pm 2,7(3)$ & 9,2 \\
& $29,8 \pm 3,5(1)$ & 13,5 \\
& $36,9 \pm 4,4(2)$ & 10,3 \\
\end{tabular}

Table 9. Spontaneous mutation rates to canavanine resistance (Lea and Coulson 1948) for the mphl, rad54 and mph1 rad54 mutants. Relative rates are calculated by normalizing mutant mutation rates to the wild-type rate. The rad54 deletion, combined with the $m p h l$ deletion, has a sub-additive effect on the spontaneous mutator phenotype (Kramer, unpublished observations).

\section{SRS2 AND PCNA SUMOYLATION}

In the light of recent findings indicating that post-translational modifications of the proliferating cell nuclear antigen (PCNA) exhibit a regulatory effect on the homologous recombination pathway via the Srs2 protein (Pfander et al 2005), a possible involvement of the MPHI gene in this process was investigated. PCNA, encoded by the POL30 gene, is a homotrimeric DNA clamp functioning at multiple levels in directing DNA metabolic pathways. When bound to DNA, PCNA organizes various proteins involved in DNA replication, repair, modification and chromatin remodeling. PCNA encircles dsDNA and slides spontaneously across it. Loading of PCNA onto DNA template-primer junctions is performed in an ATP-dependent process by the replication factor C (RFC) (Tsurimoto 1999, Jónsson and Hübscher 1997; Majka et al 2004).

Modification of PCNA by ubiquitin involves enzymes of the RAD6 post replicative repair pathway (see also page 11). In particular, monoubiquitination of PCNA requires Rad6 and Rad18 and multiubiquitination requires the heterodimer Ubc13Mms2/Rad5. Mono and multi-ubiquitination of PCNA regulate the error-prone and error-free DNA damage bypasses of lesions stalling replication forks respectively (Ulrich 2005). 
PCNA is also subject to posttranslational modification by the small ubiquitin-like modifier SUMO. PCNA is SUMOylated at the residue K164, also subject to monoand multiubiquitination and, to a lesser extent, at the residue K127. In contrast to ubiquitination of PCNA appearing during S-phase in the presence of exogenous DNA-damaging agents, PCNA SUMOylation is also limited to the S-phase but occurs even in the absence of exogenous damage. Furthermore, cells exposed to high amounts of the DNA damaging agents show a marked induction of SUMO conjugation of PCNA, in particular at the residue K164 (Hoege et al 2002). SUMOylation depends on the Ubc9 SUMO-conjugating enzyme and the SUMO ligase Siz1 (Johnson and Gupta 2001; Pfander et al 2005). The sizl mutation abolishes PCNA sumoylation at K164 leaving ubiquitination unaffected. This mutation is found to partially suppress the hypersensitivity to UV light and MMS of rad6, rad18, rad5 and mms 2 mutants defective in the PRR pathway (Stelter and Ulrich 2003). This suppression is strictly linked to a deficiency in PCNA SUMOylation since the same effect has been observed using, instead of sizl, the pol30-K164R mutant lacking the K164 residue. Furthermore, a PCNA mutant lacking both residues subject to SUMO modification (pol30-K164/K127R) has been found to suppress the rad6 and rad18 sensitivities to a greater extent (Pfander et al 2005). Suppression of the rad6 and rad 18 sensitivities by sizl or PCNA mutations at the K164 and/or K127 residues requires a functional RAD52 pathway. In fact the effect is not observed in rad52 rad51 rad55 or rad57 mutants. This finding clearly indicate that PCNA SUMOylation specifically blocks a recombination pathway (Pfander et al 2005). Two hybrid and pull down experiments have shown that Srs2 binds PCNA. This interaction is strongly enhanced by PCNA SUMOylation. The interaction is due to a specific carboxy-terminal binding site of the Srs2 protein distinct from the domain interacting with Rad51 (Pfander et al 2005). Moreover, rad18 srs2, rad18 siz1, rad18 srs 2 siz 1 and rad18 srs 2 pol30-K164/K127R mutants show nearly identical suppression of the DNA damage sensitivities of the rad18 single mutant. srs $2 \Delta C$ mutant allele, expressing a truncated protein defective in binding to SUMOylated PCNA, can suppress the damage sensitivity of rad18 to the same extent of sizl mutant defective in PCNA SUMOylation. When considering the rad6 DNA damage sensitivities, the srs 2 deletion shows a greater suppressing effect compared to mutants in PCNA SUMOylation. The srs $2 \Delta C$ mutant, expressing the protein defective in binding SUMOylated PCNA, can rescue the rad6 phenotype 
only partially and precisely to the level of the sizl mutant. These observations underline that $s r s 2$ suppresses rad6 in a PCNA-SUMO-dependent and -independent mode meaning that other functions of Srs2 are probably left unaffected in the srs $2 \Delta C$ mutant (Pfander et al 2005). All these findings indicate that PCNA SUMOylation and Srs2 may function in the same pathway where Srs2 is recruited to the replication fork, even in the absence of exogenous DNA damaging agents, as a guarding mechanism that prevents unwanted recombination during replication (Pfander et al 2005). On the other hand, it should be pointed out, that the same findings also indicate an Srs2 antirecombinogenic function not directly connected with PCNA SUMOlyation. This function could be explained by the abilities of Srs 2 protein to directly interact with Rad51 (Krejci et al 2003) and to disrupt the Rad51 nucleoprotein filament in vitro (Krejci et al 2003; Veaute et al 2003).

To investigate whether the synthetic lethality of $m p h 1$ srs 2 double mutants is due to the lack of an Srs2 function exerted when the protein is recruited to SUMOylated PCNA, the sizl (HIS3) single mutant was crossed to the mphl (URA3) single mutant. Zygotes were isolated and after sporulation and tetrad analysis viable double mutant sizl $\mathrm{mphl}$ were recovered, as indicated in figure 20. The deletions of two $\mathrm{mph} 1 \mathrm{siz} 1$ double mutants (a and $\alpha$ ) were verified by PCR (data not shown).

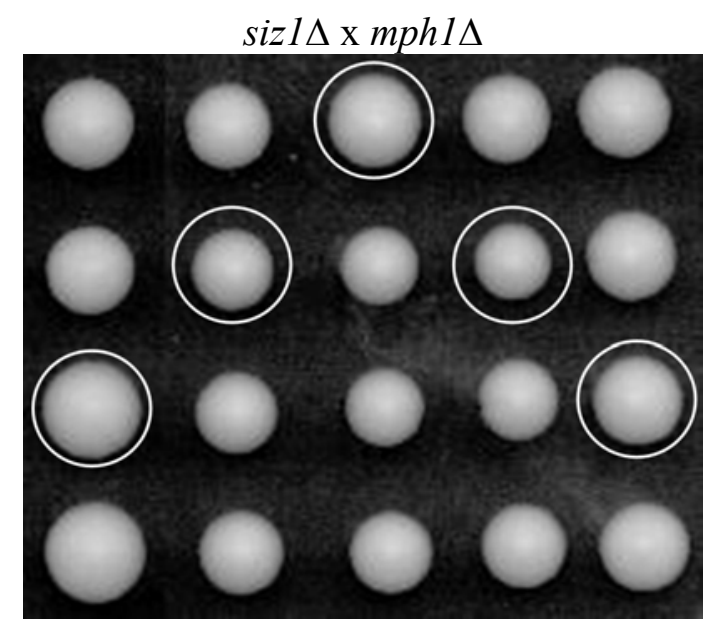

Figure 20. Five dissected tetrads obtained from the cross of mph1::URA3 mutants to siz1::HISMX6 mutants are shown. The viable $m p h 1 \Delta$ siz $1 \Delta$ double null mutant are marked with circles. 
Results

\section{INVESTIGATIONS ON THE VIABLE mph1 srs2 SPORES}

If for E.coli nearly all laboratories study descendants of a single progenitor strain, many different strains of $S$. cerevisiae are in circulation, some of them may carry weak mutations in genes regulating recombination (Pasques and Haber 1999). The results presented so far indicate that the synthetic lethality of the mph1 srs 2 double mutant, in the CEN.PK2 yeast strain, is probably due to unscheduled recombination events triggering the DNA damage response. The milder phenotype of mph1 srs 2 double mutant spores, recovered from the cross of single mutants $m p h 1$ and srs 2 constructed in other yeast strains, could be explained by allelic variants of the genes regulating homologous recombination or the DNA damage checkpoint responses. Such allelic variants may results in up/down regulation of the two cellular processes producing thus the phenotypic differences. On the other hand, the dominant effect exerted by the CEN.PK2 genetic background on the mph1 srs 2 synthetic lethal phenotype, largely exclude a recessive mutation in the CEN.PK2 strain causing the $m p h 1$ srs 2 synthetic lethality. The availability of viable $m p h 1$ srs 2 double mutants was an opportunity to further characterize the consequences produced by the simultaneous deletion of the MPH1 and SRS2 genes.

From the cross of mphl mutants (BY4741 strain) to the srs2 mutants (MW 331721 A strain, Kramer et al 1989) two viable $m p h 1$ srs 2 double mutants, one $m p h 1$ single mutant, one srs 2 single mutant and a wt spore were recovered. In particular, the two mph1 srs 2 spores, recovered from two different dissected tetrads, were compared to the srs 2 and the $m p h 1$ single mutants for the DNA damage sensitivity to the DNA damaging agents MMS, 4-NQO and camptothecin. Previous studies reported that haploid $m p h 1$ mutants are sensitive to MMS, 4-NQO and camptothecin, but not to UV light and X-rays (Scheller et al 2000). Haploid srs 2 mutants are also sensitive to MMS, 4-NQO, camptothecin and other genotoxic compounds (Mankouri et al 2002).

In accordance with previous observations (Scheller et al 2000; Mankouri et al 2002) the $m p h 1$ and srs 2 single mutants were sensitive to MMS, 4-NQO and camptothecin as it can be observed in figure 21 . The mphl mutant showed an appreciable sensitivity to camptothecin at high dose concentration $(150 \mu \mathrm{g} / \mathrm{ml})$. 


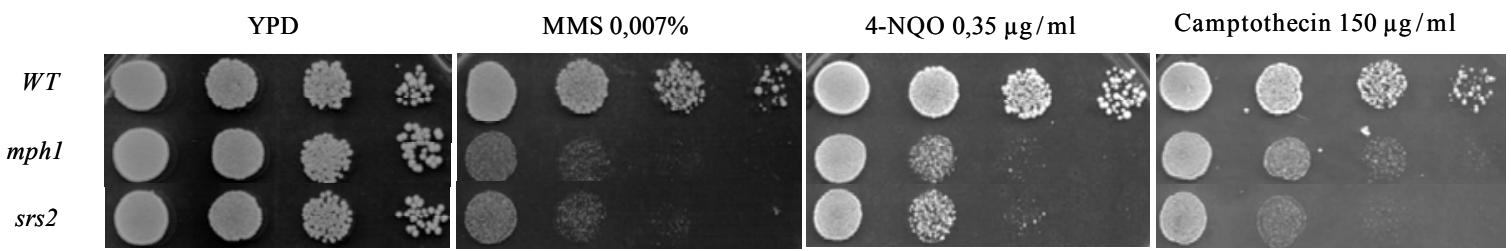

Figure 21. Drop dilution assay for analysis of DNA damage sensitivities. The mphland srs 2 single mutants were compared for the sensitivity toward 4-NQO, MMS and Camptothecin. The wild type strain and the assay on YPD plate without genotoxic agents were used as controls.

When the genotoxic sensitivities of the two double mutants mph1 srs2 was investigated it was found that the two double mutant have an increased sensitivity to the genotoxic agents compared to the $m p h 1$ and srs 2 single mutants as shown in figure 22. It should be pointed out that suppressors of the DNA damage sensitivity is likely to accumulate in the two mph1 srs 2 double mutants. In fact, formation of same DNA damage resistant colonies can be observed in figure 22.

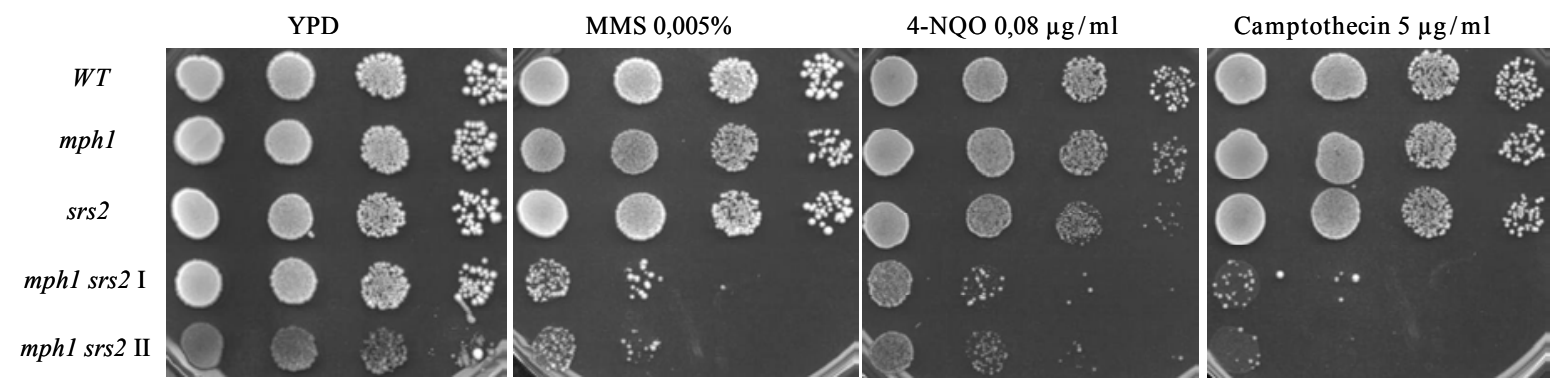

Figure 22. Drop dilution assay for analysis of DNA damage sensitivities. The $m p h 1$, srs 2 single mutants and two mph1 srs 2 double mutants were compared for the sensitivity toward 4-NQO, MMS and Camptothecin. The wild type strain and the assay on YPD plate without genotoxic agents were used as controls.

The increased sensitivity of the mph1 srs 2 double mutants to the genotoxic agents was very pronounced for camptothecin. The two mph1 srs 2 double mutants were already sensitive to a concentration of $5 \mu \mathrm{g} / \mathrm{ml}$. Camptothecin is thought to produce DNA double strand ends during replication (Liu et al 2000; Pommier et al 1998). DNA damage induced by camptothecin can only be repaired by homologous recombination. The DNA ends need to be processed to form a 3'-ssDNA tail and a strand invasion process, with the homologous duplex, has to take place in order to restart replication. The results from the DNA damage sensitivities of viable $m p h 1$ srs2 spores could indicate that, in the absence of Mph1 and Srs2 proteins, 
recombination processes take place in an uncoordinated way producing aberrant DNA structures not easily solvable by the cell. The presence of DNA damaging agents, in particular of camptothecin, is particularly deleterious for the mph 1 srs 2 double mutants. An explanation to these findings could be that the absence of the Mph1 and Srs2 proteins results in a severe defect in the repair of DNA damage requiring homologous recombination.

\section{EXTENTION OF THE GENETIC ANALYSIS TO THE S. CEREVISIAE SGS1 GENE}

\section{THE Sgs1 HELICASE AND ITS ACTIVITIES IN DNA METHABOLISM}

In order to verify the previous hypothesis the Sgs1 protein, thought to prevent illegitimate recombination events after stalling or collapsing of replication forks, (Gangloff et al 1994; Myung et al 2001) was included in the genetic analysis. The Sgs1 protein, like Mph1 and Srs2, is an helicase unwinding DNA with 3'-5' polarity (Rong and Klein 1993; Lu et al 1996; Prakash et al 2005). Sgs1 belongs to the RecQtype helicase family and has several homologs in mammalian cells which confer genetic instability when mutated (see also page 19, Mohaghegh and Hickson 2001). In yeast cells lacking the Sgs1 helicase high levels of mitotic homologous recombination and illegitimate recombination have been observed (Gangloff et al 1994; Watt et al 1996; Yamagata et al 1998). sgs 1 mutants are mildly sensitive to MMS, hydroxyurea and UV light (Yamagata et al 1998; Onoda et al 2000; Miyajima et al 2000; Mullen et al 2000). One function of Sgs1 is suppression of homeologous recombination (between similar but not identical sequences) (Myung et al 2001). Furthermore, the sgs $1 \mathrm{mphl}$ double mutant displays a strong increase in spontaneous mitotic heteroallelic recombination rates compared to the sgs 1 and $m p h 1$ single mutants (Schürer et al 2004). Sgs1 interacts with topoisomerases Top3 and Top2 (Gangloff et al 1994; Watt et al 1995). Top1, Top2 and Top3 topoisomerases are enzymes responsible for resolutions of topological problems of DNA. In particular, they can remove DNA negative supercoils allowing DNA strands to pass through each other (Wang et al 2002). In vitro experiments show that Top3 has the weakest activity compared to Top1 and Top2 (Kim and Wang 1992). S. cerevisiae top3 
mutants show a multifaceted phenotype including a severe growth defect, recombination defects, sporulation defects due to the role of the protein in meiotic recombination, sensitivity to genotoxic agents and a partial intra-S checkpoint defect (Gangloff et al 1994; Gangloff et al 1999; Chakraverty et al 2001). The phenotype of top3 mutants can be almost completely suppressed by mutation of the SGS1 gene (Chakraverty et al 2001; Gangloff et al 1994). It has been suggested that Sgs1, in conjunction with Top3, might act as an anti-recombination protein in disrupting recombination intermediates. In particular, Sgs1 may generate DNA structures which have to be resolved by Top3. If Top3 is missing those DNA structures can not be resolved and they are toxic to the cells. The simultaneous deletion of SGS1 and TOP3 genes can reproduce a phenotype similar to wild type since, in this case, recombination intermediates would not be formed and Top3 would not be needed for their resolution (Gangloff et al 1994; Watt et al 1996; Myung et al 2001; Wu et al 2001). The interaction of Sgs1 with Top2 is required for proper chromosome segregation. It has been proposed that they might act to separate linked DNA intermediates forming during DNA replication to ensure proper sister-chromatid separation (Watt et al 1995). SGS1 and TOP3 transcripts levels peak in S-phase (Cho et al 1998; Chakraverty et al 2001) and Sgs1 has been found to associate with the replication forks both in the presence and absence of DNA damage (Cobb et al 2003). sgs 1 mutants are partially defective in the checkpoint response to DNA damage during S-phase. In particular, Sgs1 is required for activation of Rad53. The helicase function of Sgs1 in checkpoint activation is not required. In fact an helicasedead version of the protein can still efficiently activate Rad53. The last finding can be explained by the fact that Sgs1 strongly interacts with Rad53 via its FHA domains. Being bound to the stalled fork Sgs1 may recruit Rad53 facilitating its activation (Bjergbaek et al 2005). On the other and, the Sgs1 helicase activity together with Top3 and Rad51, with which Sgs1 has also shown to interact, is needed for a recovery process that can be largely distinguished from the checkpoint activation function (Wu et al 2001; Bjergbaek et al 2005). A model for Sgs1 action during S-phase might be proposed where it may act both as a sensor for damage during replication and as a resolvase for recombinogenic DNA structures. Such structures arise at paused forks and their formation is due to $\operatorname{Rad} 51$ and the other members of the HR pathway (Bjergbaek et al 2005). 
sgs 1 srs 2 double mutants are synthetically lethal and can be rescued by eliminating Rad51. This finding indicates that the two helicases are involved in the suppression of the same deleterious recombination events albeit at different steps (Gangloff et al 2000). Furthermore, multicopy SGS1 can suppress the MMS and hydroxyurea sensitivity of the Srs 2 mutant giving support to a functional overlap between the two DNA helicases (Mankouri et al 2002).

\section{MULTICOPY SGS1 CAN PARTIALLY RESCUE THE GENOTOXIC SENSITIVITIES OF $m p h 1$ AND srs 2 SINGLE MUTANTS AND $m p h 1 s r s 2$ DOUBLE MUTANTS}

From the findings presented so far a collaboration between the three DNA helicases Mph1, Srs2 and Sgs1 in processing common recombination intermediates toxic to cells could be hypothesized. Further investigations were made to determine the effect of the $S G S 1$ overexpression on the DNA damage sensitivities of the $m p h 1$ and srs 2 single mutants and viable mph1 srs 2 double mutants. The idea was that multicopy SGS1 could alleviate such DNA damage sensitivities if they are due to unproper recombinogenic processes.

To investigate the effect of $S G S 1$ overexpression on the DNA damage sensitivities of the two viable mph1 srs 2 double mutants, the two strains were transformed with the multicopy pYES SGS1 plasmid and the multicopy pYES empty vector as control. The results, illustrated in figure 23 , indicate that SGS1 overexpression alleviate the DNA damage sensitivities to MMS, 4-NQO and camptothecin of the two double mutants $m p h 1$ srs 2 . The effect is evident by comparing the mph1 srs 2 double mutants harbouring the pYES empty vector and the mph1 srs 2 double mutants harbouring the pYES SGS1 plasmid. To largely exclude the possibility that the observed results are due to suppressors of the DNA damage sensitivity accumulating in mph1 srs 2 mutants (possibility mentioned at page 62), for each transformation a large number of transformant colonies were included in the same culture utilized for the assays presented here. 

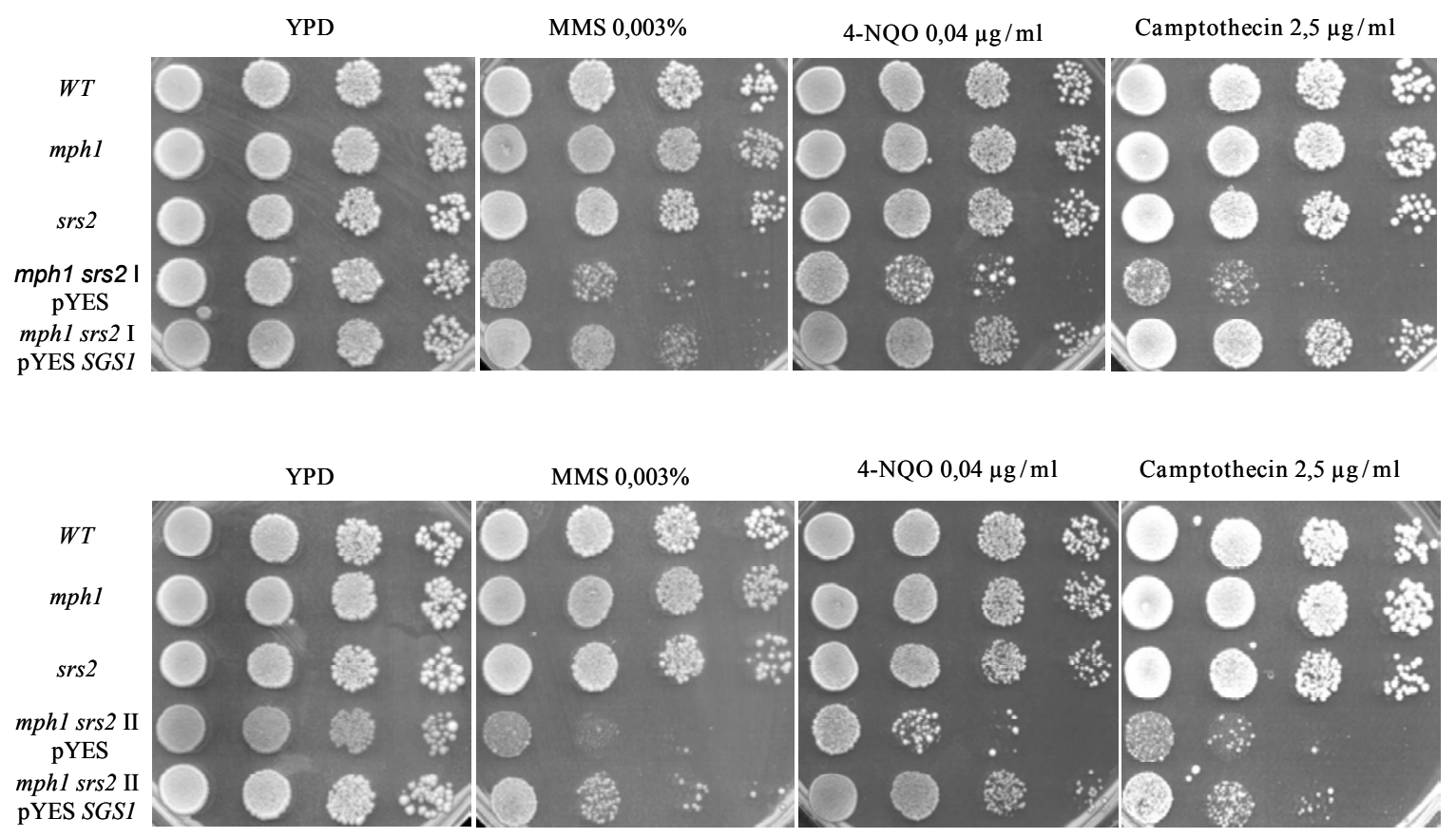

Figure 23. Drop dilution assays for analysis of DNA damage sensitivities. Complementation of the $m p h 1 s r s 2$ double mutants sensitivities to genotoxic agents by $S G S 1$ overexpression can be observed. The two independent mph1 srs 2 double mutants (I and II) recovered from different tatrads have been transformed with the pYES empty vector and the pYES SGS1 plasmid and have been compared for the DNA damage resistance to MMS, 4-NQO and camptothecin. The wild type strain the single mutants $m p h 1$ and srs 2 and the assay on YPD plate without genotoxic agents were used as controls.

To evaluate the effect of SGS1 overexpression on the DNA damage sensitivities of the single mutants $m p h l$ and $s r s 2$, the drop dilution assay was repeated comparing, this time, the mphl and srs 2 single mutants transformed with the plasmid pYES $S G S 1$ to the mph1 and srs 2 single mutants transformed the empty vector pYES used as control. As already reported (Mankouri et al 2002) and illustrated in figure 24, multicopy SGS1 could suppress the MMS sensitivity of the srs 2 mutant and to a very low extent also MMS sensitivity of $m p h 1$ mutants. In the assay for the 4-NQO sensitivity no appreciable effect on both mutants could be observed. More interestingly, the assay for the sensitivity to camptothecin revealed that sensitivity of both $m p h 1$ and $s r s 2$ single mutants is quite efficiently rescued by the overexpression of $S G S 1$. 


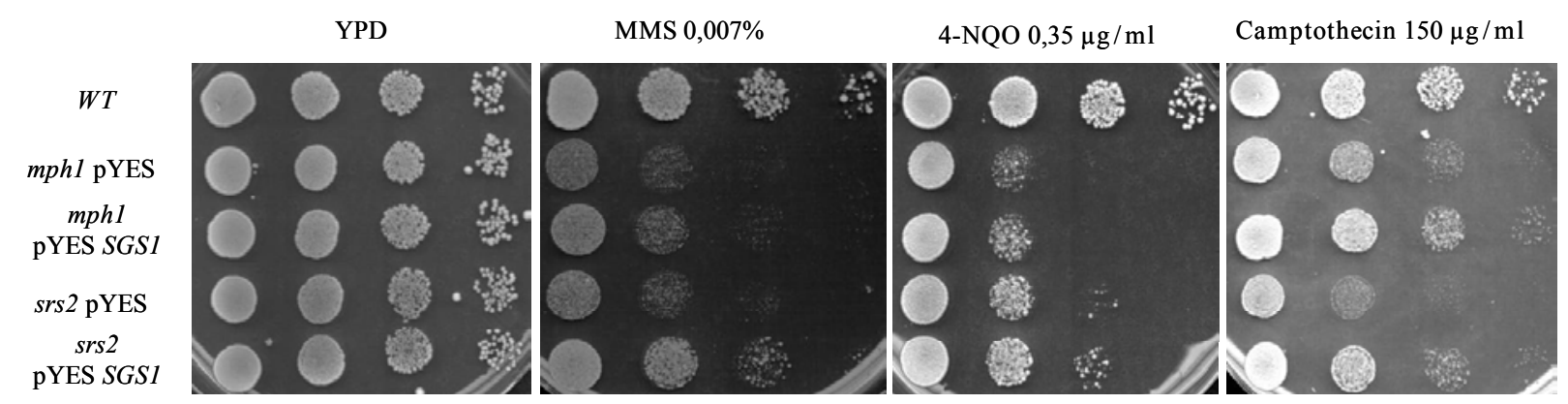

Figure 24. Drop dilution assays for analysis of genotoxic sensitivities. The effect of $S G S 1$ overexpression on the sensitivities of $m p h 1$ and srs 2 single mutants has been tested. The two single mutants have been both transformed with the pYES empty vector and the pYES SGS1 plasmid and have been compared for the DNA damage resistance to MMS, 4-NQO and camptothecin. The wild type strain and the assay on YPD plate without genotoxic agents were used as controls.

In order to demonstrate that the DNA damage sensitivity of the double mutants mph1 srs 2 is actually due to the absence of the MPH1 gene in the srs 2 null mutant genetic background, the two double mutants $m p h 1$ srs2, utilized in all these assays, were transformed with the integrating vector YIplac211 MPH1. The integration of the MPH1 gene should restore the situation of an srs 2 single mutant. Several transformants have been compared to the srs 2 single mutant for the DNA damage sensitivity to MMS, 4-NQO and camptothecin. As indicated in figure 25, where two example are shown, the transformants showed an increased DNA damage resistance comparable to the level of the srs 2 single mutant.

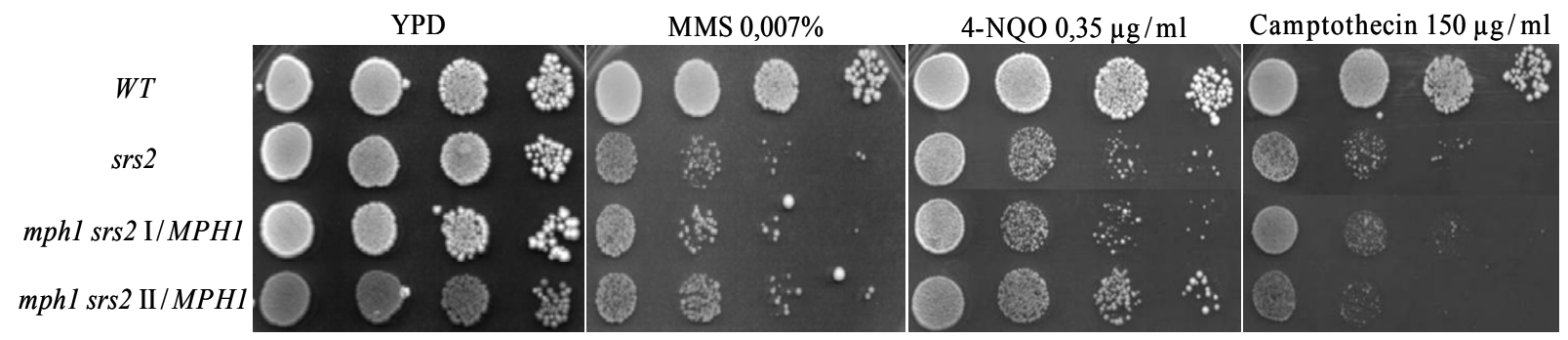

Figure 25. Drop dilution assays for analysis of genotoxic sensitivities. The effect of $M P H 1$ gene integration on the sensitivities of the two mph1 srs 2 double mutants has been tested. The wild type strain and the assay on YPD plate without genotoxic agents were used as controls. 


\section{REV3 DEPENDENCE OF THE sgs 1 MUTATOR PHENOTYPE}

The mutator phenotype observed in many DNA repair mutants is due to the channelling of DNA lesions into the error-prone branch of post replicative repair pathway. This results in a mutagenic bypass of these DNA lesions by the translesion polymerase Pol $\zeta$ consisting of the two subunits Rev3 and Rev7 (Nelson et al 1996). mphl mutants were found to have an increased spontaneous mutation rate in a forward mutation assay to canavanine resistance. The $m p h l$ spontaneous mutator phenotype was found to be REV3 dependent. Indeed it is abolished by the introduction of a rev3 mutation (Scheller et al 2000). Spontaneous mutation rates were determined using the forward mutation assay to canavanine resistance for the mph1, sgs 1, mph1 sgs 1 and sgs 1 rev3 mutants. Two independent rates are indicated for $m p h 1$ sgs 1 and sgs 1 rev3 double mutants since they were included in duplicate in the assay. As can be seen in table 10, the $\operatorname{sgs} 1$ mutants shown a lower mutator phenotype compared to mphl mutants. The $s g s l$ mutator phenotype was REV3 dependent since it was abolished by the rev3 deletion. Interestingly, the spontaneous mutation rates of $\mathrm{mphl} \mathrm{sgs} 1$ double mutants were found to be quite below additivity since the values were comprised between the $m p h 1$ and $s g s 1$ rates.

\begin{tabular}{ccc}
\hline Strains & Mutation rate $\mathbf{~ 1 0 ^ { 7 }}$ & $\begin{array}{c}\text { Relative } \\
\text { rate }\end{array}$ \\
\hline Wild type & $1,76 \pm 0,3$ & $\mathbf{1}$ \\
mph1 & $19 \pm 0,5$ & $\mathbf{1 0 , 8}$ \\
sgs1 & $5,7 \pm 0,3$ & $\mathbf{3 , 2}$ \\
mph1 sgs1 & $14,4 \pm 1,2$ & $\mathbf{8 , 1}$ \\
& $10,3 \pm 1,9$ & $\mathbf{6}$ \\
sgs1 rev3 & $1,9 \pm 0,2$ & $\mathbf{1 , 1}$ \\
& $2,3 \pm 0,1$ & $\mathbf{1 , 3}$ \\
\hline
\end{tabular}

Table 10. Spontaneous mutation rates to canavanine resistance (Lea and Coulson 1948) for the mphl, sgs 1 mph1 sgs 1 and mph1 rev3 mutants. Relative rates are calculated by normalizing mutant mutation rates to the wild-type rate. 


\section{DISCUSSION}

\section{A LIKELY FUNCTION FOR Mph1 IS D-LOOP FORMATION OR PROCESSING}

The MPH1 gene has been implicated in a pathway for error-free bypass of DNA lesions arresting replication which requires, in addition, homologous recombination functions (Schürer et al 2004). The current hypothesis assigns a function to Mph1 at the formation or processing of the D-loop structure arising after recombinationmediated invasion of the arrested strand into the sister chromatid, as depicted in figure 2 ( $\mathrm{i}$ a). Two evidences support this idea. The first evidence is the reduction of sister chromatid interactions in $m p h 1$ mutants described in a previous work (Rudolph 2004). The second evidence comes from the genetic interaction between $m p h 1$ and rad54 presented in this study. As shown in figure 19, the rad54 deletion is epistatic to mph1 for DNA damage sensitivity but, in terms of spontaneous mutator phenotype, a sub-additive effect is observed and illustrated in table 9. This finding could indicate that the two proteins play a role at the same phase of the Rad51mediated strand invasion process and, if they are simultaneously absent, the cell is less efficient to process DNA damage in an error-free manner via sister chromatid interaction. The primary function of Rad54 during the strand invasion process is probably postsynaptic. In particular, Rad54 ability to translocate on duplex DNA thus remodelling its structure is thought to favour the strand exchange reaction and the extension of the paired region.

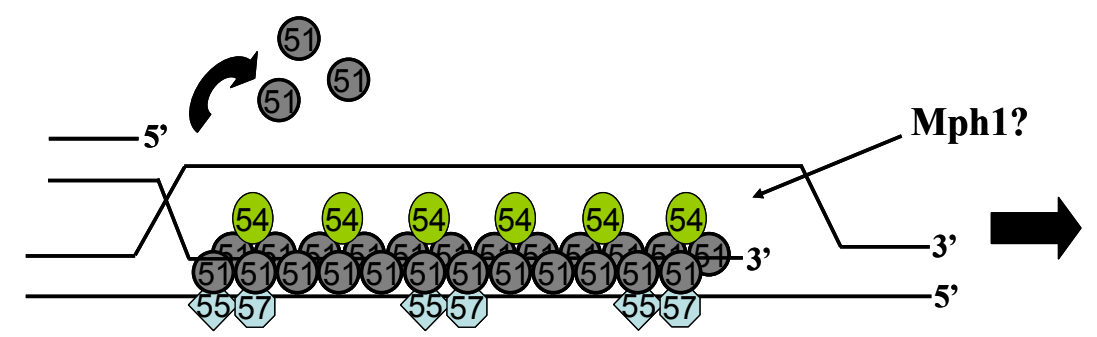

Figure 25. Rad54 abilities to translocate on duplex DNA, to remodel its structure and to displace the Rad51 protein from the nucleoprotein filament are thought to favourite the strand exchange reaction and the extension of the D-loop. Evidences support the hypothesis that Mph1 is also involved in D-loop formation or processing. 
Moreover, its ability to displace the Rad51 protein might be important for the turnover of Rad51 and also for facilitating the movement of the D-loop structure (Van Komen et al 2000; Solinger et al 2001; Solinger et al 2002). As depicted in figure 25, if Mph1 function is also placed at the synaptic or postsynaptic phase of the strand invasion process in order to favour D-loop formation, this would explain the sub-additive effect observed in the spontaneous mutator phenotype of rad54 $\mathrm{mph} 1$ double mutants and the reduction of sister chromatid interactions observed in $m p h 1$ mutants (Rudolph 2004).

\section{mph1 srs 2 SYNTHETIC GROWTH DEFECT}

The genetic analysis carried out during this study in the yeast strain CEN.PK2 revealed that the $m p h 1$ deletion combined with the $s r s 2$ deletion results in a severe synthetic growth defect. This synthetic defect could be rescued after deletion of the $R A D 51, R A D 52, R A D 55$ and $R A D 57$ genes responsible for early steps of homologous recombination and, in particular, for the formation of the Rad51 nucleoprotein filament mediating the strand invasion process with an homologous DNA duplex. These findings indicate that the mph1 srs 2 combination leads to accumulation of unsolved recombinogenic DNA structures which are toxic for the cell. Moreover, deletion of $M E C 1, R A D 53, R A D 9, R A D 17$ and $R A D 24$ genes involved in the DNA damage checkpoint responses were also able to rescue the synthetic lethality of $m p h 1$ srs 2 double mutants. These results support the hypothesis that aberrant DNA structures accumulating in the double mutant $m p h 1$ srs 2 are sensed by the DNA damage checkpoint functions which may ultimately trigger a permanent cell cycle arrest. However, the percentage of rescued $m p h 1$ srs 2 double mutants by deletion of DNA damage checkpoint genes is below the expectance as indicated in table 8 . This observation suggests that the unresolved DNA structures postulated above are still present and may often be processed into a lethal secondary damage.

The mph1 srs 2 synthetic defect is severe in the CEN.PK2 yeast strain where spores containing the double deletion could very rarely form a visible colony. However, from microscopic inspection they show the ability to divide a few times and to form microcolonies (see table 6). The cross between mphl mutants in the BY 4741 background and srs 2 mutants in the MW 3317 21A background produced haploid mph 1 srs 2 spores with a less severe synthetic defect. They formed visible colonies in 
about $70 \%$ of the cases but they were smaller than the other spores. Similar results were obtained when $m p h l$ mutants constructed in the DF5 yeast strain were crossed to srs2 mutants in the MW 3317 21A yeast strain. The DNA damage sensitivity of these viable $m p h 1$ srs 2 spores to MMS, 4-NQO and camptothecin was higher if compared to single mutants $m p h 1$ and srs 2 . The effect was stronger for camptothecin. Camptothecin is thought to produce DNA double strand ends during replication (Liu et al 2000; Pommier et al 1998). This type of DNA damage can only be repaired via homologous recombination. In particular the DNA end need to be processed to form a 3'-ssDNA tail and a strand invasion process with the homologous duplex has to take place to restart replication. The pronounced sensitivity to camptothecin of viable mph1 srs 2 double mutants could indicate that Srs2 and Mph1 proteins are required for the repair of DNA ends arising during replication.

The phenotypic differences of $m p h 1$ srs 2 double mutants recovered in different yeast genetic backgrounds could be due to allelic variants of the genes responsible for homologous recombination or the DNA damage checkpoint response.

For example it has been reported that some of the several yeast strains in circulation may carry weak mutations in genes playing a role in recombination (Paques and Haber 1999).

\section{THE IMPORTANCE OF Srs2, Sgs1, Rad54 AND Mph1 PROTEINS DURING REPLICATION}

It is known that the srs 2 deletion combined with deletions of genes affecting DNA metabolism results in synthetic lethality or severe growth defect. For instance, srs 2 interacts negatively with rad54 and also sgs 1 . As for the double mutant $m p h 1$ srs 2 the rad54 srs 2 and $s g s 1$ srs 2 synthetic lethality or severe growth defect can be rescued by eliminating homologous recombination or DNA damage checkpoints functions (Palladino and Klein 1992; Gangloff, 2000; Klein 2001). Although each of the proteins mediating the strand exchange reaction is not essential in vegetatively growing yeast cells, implying that replication can also proceed in the absence of them, the synthetic defect observed in mph1 srs 2 , rad54 srs 2 and sgs 1 srs 2 double mutants can be ascribed to recombination probably associated with replication. The different roles that Srs2, Sgs1, Rad54 and Mph1 proteins play in recombination may 
explain why deletions in the genes coding for these proteins produce a synthetic growth defect if they are combined. The Srs2 protein belongs to the SF1 family of nucleic acid helicases (Aboussekhra et al 1989). srs 2 mutants have a complex recombination phenotype since they favour recombination in some contexts (Ira et al 2003, Aylon et 2003) and discourage it in others (Aboussekhra et al 1989; Rong et al 1991). Genetic observations placed SRS2 at an initial stage where it is thought to counteract recombination (Chanet et al 1996; Rong et al 1991) and SGS1 downstream of $S R S 2$ at a resolution step of recombination intermediates (Fabre et al 2002; Ira et al 2003). These data are also supported by recent findings suggesting that Sgs1, together with Top3, promotes resolution of recombination-dependent cruciform structures accumulating at damaged replication forks while Srs2 prevents their accumulation. In particular, if formation of these recombination intermediates was induced with MMS, they were Rad51 dependent and probably resulting from recombination-dependent intermediates originating from sister chromatid junctions (Liberi et al 2005). The role of Srs2 in preventing formation of recombination intermediates and the one of $\mathrm{Sgs} 1$ at their resolution reflects also their in vitro activities. Biochemical experiments show that Srs2 works not only as a DNA helicase, but also as a DNA translocase that disrupts Rad51 nucleoprotein filaments (Krejci et al 2003; Veaute et al 2003). In contrast, Sgs 1 and other RecQ helicases catalyze the branch migration of synthetic Holliday junctions (Bennett et al 1998; Constantinou et al 2000; Karow et al 2000) and BLM, the human Sgs1 homolog, dissolves double Holliday junctions in concert with topoisomerase III $\alpha$ (Wu et al 2003). Furthermore, recent studies indicate that Srs 2 is directly recruited at the replication fork by means of a direct interaction with the SUMOylated form of PCNA. The recruitment of Srs2 at the replication fork was suggested to counteract unwanted recombination events during replication. The same study also revealed that Srs2 can still counteract recombination even if not directly recruited by SUMOylated PCNA. In fact it has been shown that suppression of rad6 or rad18 sensitivities by a truncated form of the Srs2 protein $(\operatorname{srs} 2 \Delta C)$, unable to bind SUMOylated PCNA, was lower than the suppressor effect obtained with a deletion of the SRS2 gene (Pfander et al 2005). This finding explains the observation that viable mphl sizl spores were recovered in the genetic assay described in this study. Since SUMOlyation of PCNA requires the Siz1 SUMO ligase the sizl deletion, combined with the mphl deletion, might have reproduced the $m p h 1$ srs 2 lethal phenotype if the missing recruitment of 
Srs2 at the replication fork was corresponding to the lack of Srs2 function in the mph1 srs 2 double mutant. This was not the case demostarting thus that Srs2 may still exert its functions even in the absence of SUMOylated PCNA. In particular, the Srs2 abilities to directly interact with Rad51 (Krejci et al 2003) and to dismantle the preformed Rad51 nucleoprotein filament in vitro (Krejci et al 2003; Veaute et al 2003) could explain this finding.

Nevertheless it should be pointed out and it will be discussed below that Srs2 may also play different functions, from those discussed here, during recombination.

\section{REPLICATION FORK ARREST AS ONE OF THE CAUSES OF THE $m p h l$ srs2 SYNTHETIC GROWTH DEFECT}

The findings discussed above and those presented in this study suggest a mutual involvement of Mph1, Srs2, Sgs1 and Rad54 proteins in processing of common recombination intermediates arising after replication fork arrest or collapse.

The mph1 srs2 synthetic growth defect observed in the CEN.PK2 strain, the increased sensitivity to MMS and 4-NQO of the viable mph1 srs2 spores could indicate that replication fork arrest is deleterious in the absence of the Mph1 and Srs2 proteins. In figure 26 a model is proposed in order to explain this hypothesis. In a wt situation a DNA lesion on the leading strand template arrests the replication fork. The DNA lesion may be repaired via translesion synthesis or, if the leading strand invades the sister chromatid, the D-loop structure is formed and the Rad54 protein and probably also Mph1 contribute to D-loop formation and extension. The 3'-end of the leading strand can thus be elongated beyond the lesion on the lagging strand as template. If during D-loop formation the displaced strand hybridizes with the complementary strand a single Holliday junction would be formed. Sgs1 could branch migrate the Holliday junction restoring the replication fork. Another possibility would be that the homologous recombination functions hybridizes the 3 'end of the elongated leading strand with the parental strand forming a double Holliday junction. The combined activity of Sgs1 and Top3 could resolve this structure restoring the replication fork. As result the DNA lesion is bypassed in an error-free manner, the DNA damage is still present on the parental strand and could 
be repaired at a later time using the right information from the newly synthesized strand.
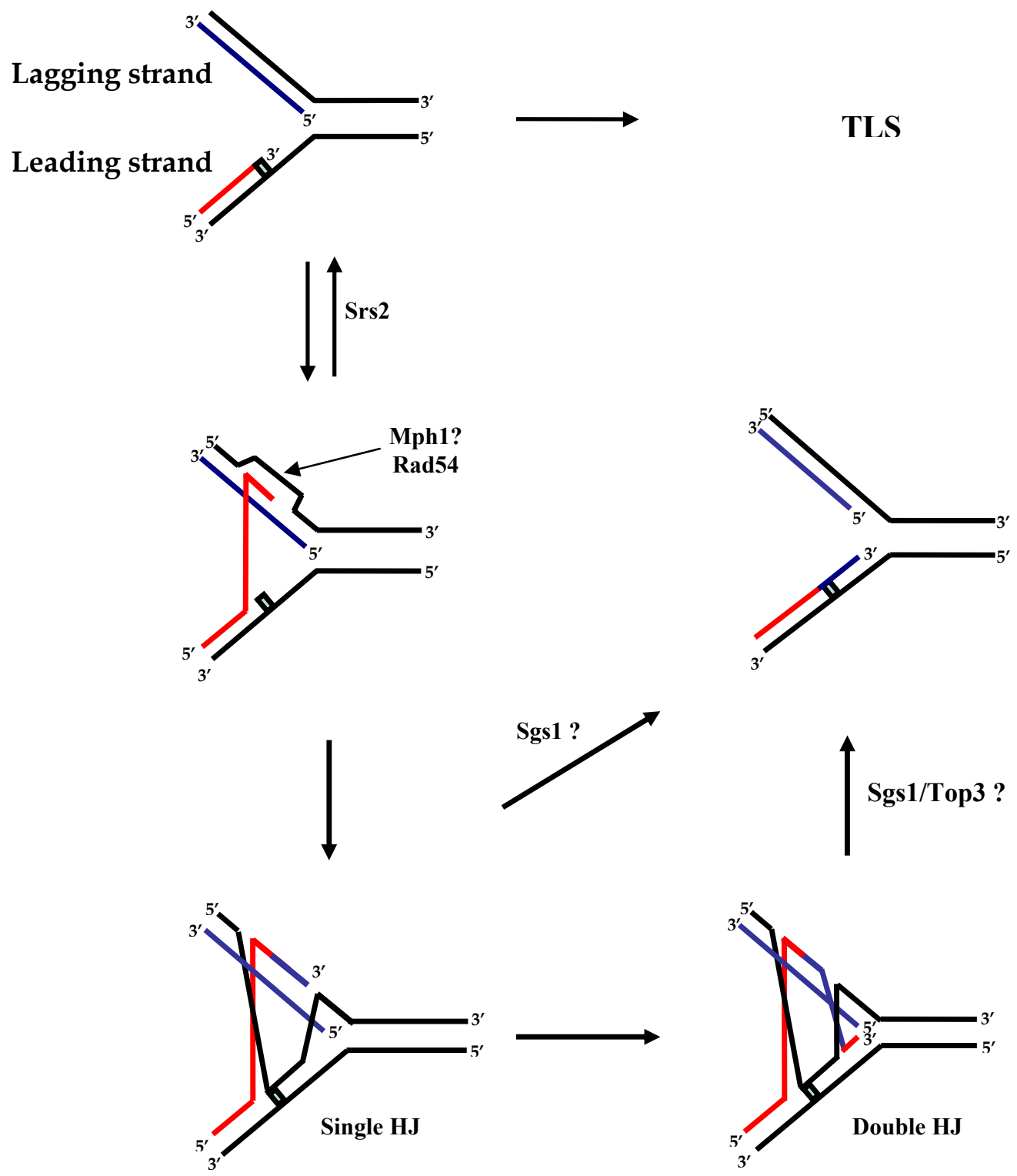

Figure 26. Model describing how Mph1, Srs2, Sgs1 and Rad54 proteins collaborate for reinitiation of stalled replication forks. In a wt situation a DNA lesion on the leading strand template arrests the replication fork. One possibility would be to bypass the lesion via translesion synthesis. An alternative is the strand invasion into the sister chromatid by the arrested leading strand with the formation of the D-loop. The D-loop would by formed and stabilized by Rad54 and probably also Mph1. The 3'-end of the leading strand could be elongated beyond the lesion on the lagging strand as template. If during D-loop extension the displaced strand hybridizes with the complementary strand a single Holliday junction could be formed. Sgs1 might branch migrate it restoring the replication fork. As an alternative, the 3'-end of the leading strand could also hybridize with the parental strand forming thus a double Holliday junction. The combined activity of Sgs1 and Top3 could resolve this structure restoring the replication fork. 
In the mph 1 srs 2 double mutant strand invasion after replication fork arrest takes place probably with higher frequency because the formation of the $\operatorname{Rad} 51$ nucleoprotein filament is not counteracted by Srs2. In such circumstances the absence of Mph1 would be deleterious since the D-loop structure can not be efficiently processed even in the presence of Rad54. Accumulation of such unprocessed structures may account for the synthetic lethality of the mph1 srs2 double mutant observed in the CEN.PK2 strain. This hypothesis is supported by the restoration of viability by introducing $\mathrm{rad} 51$, rad52 and $\mathrm{rad} 55 / \mathrm{rad} 57$ deletions or deletions in the DNA damage checkpoint functions which may sense arrested replication forks and induce permanent cell cycle arrest.

The increased sensitivity to MMS and 4-NQO of viable mph1 srs 2 double mutants compared to $m p h 1$ and $s r s 2$ single mutants, the ability of $S G S 1$, if overexpressed, to partially suppress such sensitivities is supporting the model depicted in figure 26 and also the Sgs1 function in processing of recombinogenic structures arising after replication fork arrest.

\section{REPLICATION FORK RESTART AFTER COLLAPSE IS DEFECTIVE IN THE $m p h 1$ srs2 DOUBLE MUTANT}

During replication the DNA damage produced by camptothecin induces replication fork collapse with formation of a double strand end (Pommier et al 1998; Strumberg et al 2000; Lin et al 2000). The only possible way to restart replication in this case is via homologous recombination. The $m p h 1$ and srs 2 single mutants, as already reported (Scheller et al 2000; Mankouri et al 2002), show a very moderate sensitivity to camptothecin. A synergistic effect, in terms of sensitivity to camptothecin, is observed in the viable mph1 srs 2 double mutants. $S G S 1$ overexpression could rescue the sensitivity of these mutants to camptothecin and also the milder sensitivity of mph1 and srs 2 single mutants. The models proposed in figure 27 could account for this observations. The DNA double strand end produced after fork collapse is processed in order to have a 3' protruding end which can invade the sister chromatid with formation of a D-loop structure. Two alternatives for resolution of the D-loop structure and replication restart may be proposed: 
1. Mph1 could function at the processing of the D-loop structure in order to create a substrate recognized by the heterodimeric endonuclease Mms4/Mus81 which was shown to cleave three branched DNA structures (Kaliraman et al 2001, Osman et al 2003). Mph1 is supposed to stimulate the endonuclease Mms4/Mus81 and this hypothesis is supported by the epistatic relation between $m p h 1$ and mus 81 in terms of sensitivity to camptothecin (W. Kramer personal comunication) and also by the finding that in the archaeal homolog of Mph1, called Hef, which has an N-terminal helicase domain and an additional C-terminal domain with homologies to the Mus81 endonuclease, it was shown that the N-terminal helicase stimulates the endonucleolytic activity of the C-terminal domain (Komori et al 2002). A proper resolution of the D-loop via Mms4/Mus81-Mph1, as shown in figure 27, would allow replication to restart.

2. In the absence of Mph1 the Mms4/Mus81-Mph1 pathway could be slower and a different DNA substrate could be formed. In particular, extension of the D-loop in the direction of the invading strand would allow the formation of a single Holliday junction. At this point replication could restart with mechanisms similar to those proposed for the break induced replication model invoked to explain the repair of double strand breaks (see also figure 2). Sgs1 could participate in this process by branch migrating the Holliday junction. This would favour the movement of the Dloop in the direction of DNA synthesis which could continue like a normal DNA replication until the end of the chromosome unless the Holliday junction is resolved at some point. Resolution of the Holliday junction by Sgs1 would recreate the DNA substrate for the Mms4/Mus81-Mph1 pathway as depicted in figure 27.

This would explain why SGS1 overexpression can suppress the camptothecin sensitivity of $m p h 1$ mutants and also $m p h 1$ srs 2 double mutants.

The function of Srs 2 in this context would be to favour the first alternative and this would explain the sensitivity of $s r s 2$ and $m p h 1 s r s 2$ mutants to camptothecin and the ability of $S G S 1$, if overexpressed, to partially rescue these sensitivities. Srs2 would probably discourage formation of an $\mathrm{HJ}$ and resolution via Sgs1. It has been shown that during the repair of a DSB Srs2 promotes the SDSA pathway (see also figure 1) and discourages resolution via formation of a double HJ (Ira et al 2003) as proposed in the DSBR model (see also figure 1). Probably repair of the DNA damage induced by camptothecin requires this function of Srs 2 and could also require an alternate pathway to Rad51 for the strand invasion process. 


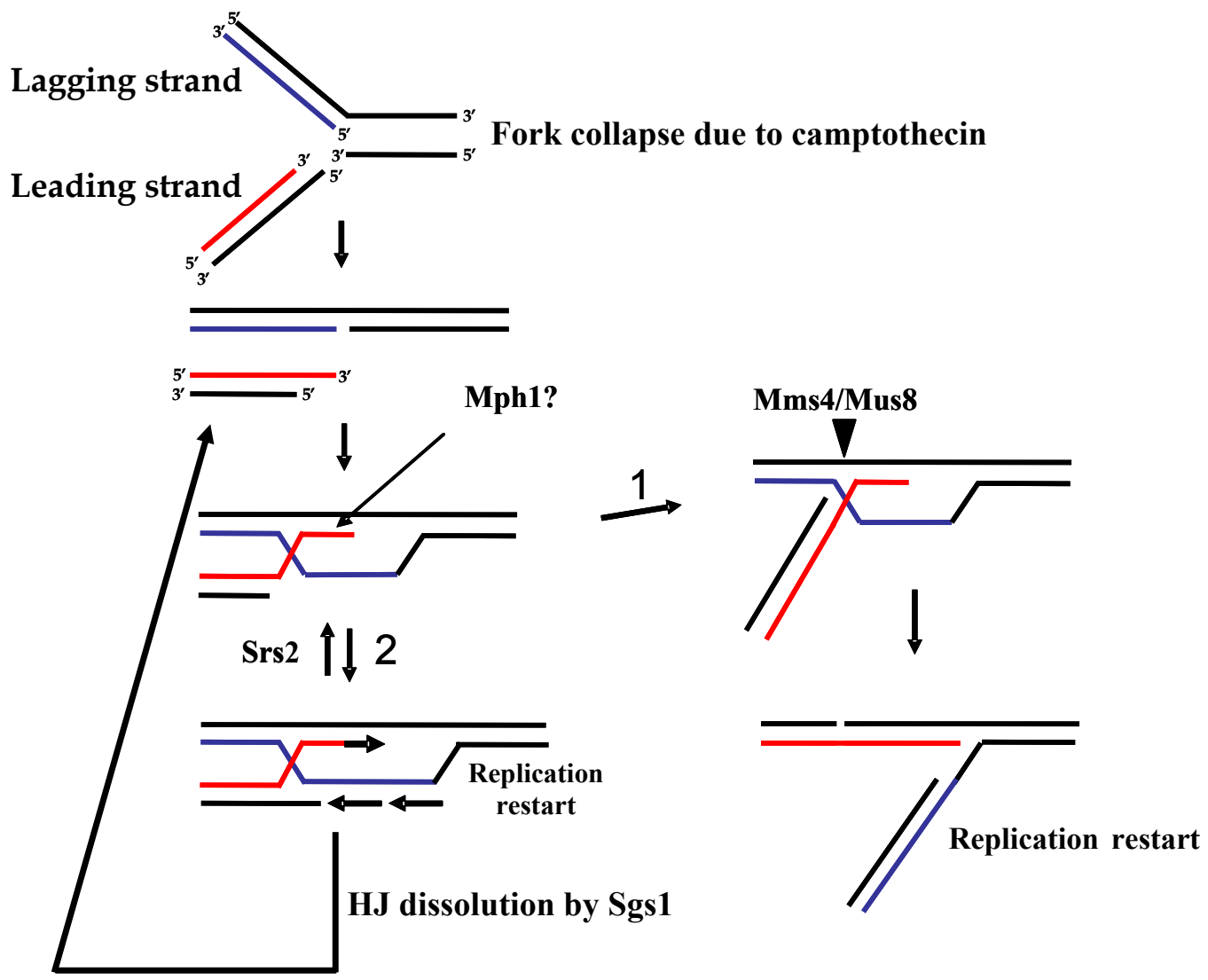

Figure 27. Model describing how Mph1, Srs2 and Sgs1 proteins collaborate for reinitiation of collapsed replication forks. The DNA double strand end generated after fork collapse is processed in a 3' protruding end which can invade the sister chromatid with formation of the D-loop. In the first alternative Mph1 is thought to stimulate the activity of the endonuclease Mms4/Mus81 which could cleave the D-loop restoring the replication fork. However, in the absence of Mph1, this process may slow down and a DNA substrate, like a single HJ, could be formed. Sgs 1 could participate in this process by branch migrating the Holliday junction. This would favour the movement of the D-loop in the direction of DNA synthesis which could continue like a normal DNA replication. Resolution of the Holliday junction by Sgs1 would recreate the DNA substrate for the Mms4/Mus81Mph1 pathway. The function of Srs2, in this context, would be to prevent resolution via Sgs1 favouring thus resolution via the Mms4/Mus81-Mph1 pathway. 


\section{REFERENCES}

Aboussekhra, A., Chanet, R., Adjiri, A. and F. Fabre (1992). Semidominant suppressors of Srs2 helicase mutations of Saccharomyces cerevisiae map in the RAD51 gene, whose sequence predicts a protein with similarities to procaryotic RecA proteins. Mol Cell Biol 12(7): 3224-34.

Aboussekhra, A., Chanet, R., Zgaga, Z., Cassier-Chauvat, C., et al. (1989). RADH, a gene of Saccharomyces cerevisiae encoding a putative DNA helicase involved in DNA repair. Characteristics of radH mutants and sequence of the gene. Nucleic Acids Res 17(18): 7211-9.

Abraham, R. T. (2001). Cell cycle checkpoint signaling through the ATM and ATR kinases. Genes Dev 15(17): 2177-96.

Aguilera, A. and H. L. Klein (1988). Genetic control of intrachromosomal recombination in Saccharomyces cerevisiae. I. Isolation and genetic characterization of hyper- recombination mutations. Genetics 119(4): 779-90.

Alani, E., Cao, L. and N. Kleckner (1987). A method for gene disruption that allows repeated use of URA3 selection in the construction of multiply disrupted yeast strains. Genetics 116(4): 541-5.

Alexeev, A., Mazin, A. and S. C. Kowalczykowski (2003). Rad54 protein possesses chromatin-remodeling activity stimulated by the Rad51-ssDNA nucleoprotein filament. Nat Struct Biol 10(3): 182-6.

Aylon, Y., Liefshitz, B., Bitan-Banin, G. and M. Kupiec (2003). Molecular dissection of mitotic recombination in the yeast Saccharomyces cerevisiae. Mol Cell Biol 23(4): 1403-17.

Bailly, V., Lamb, J., Sung, P., Prakash, S. and L. Prakash (1994). Specific complex formation between yeast RAD6 and RAD18 proteins: a potential mechanism for targeting RAD6 ubiquitin-conjugating activity to DNA damage sites. Genes Dev 8(7): 811-20.

Bailly, V., Lauder, S., Prakash, S. and L. Prakash (1997). Yeast DNA repair proteins Rad6 and Rad18 form a heterodimer that has ubiquitin conjugating, DNA binding, and ATP hydrolytic activities. J Biol Chem 272(37): 23360-5.

Bao, S., Lu, T., Wang, X., Zheng, H., Wang, L. E., et al. (2004). Disruption of the Rad9/Rad1/Hus 1 (9-1-1) complex leads to checkpoint signaling and replication defects. Oncogene 23(33): 5586-93.

Bao, S., Tibbetts, R. S., Brumbaugh, K. M., Fang, Y., et al.(2001). "ATR/ATMmediated phosphorylation of human Rad17 is required for genotoxic stress responses." Nature 411(6840): 969-74.

Bartsch, S., Kang, L. E. and L. S. Symington (2000). RAD51 is required for the repair of plasmid double-stranded DNA gaps from either plasmid or chromosomal templates. Mol Cell Biol 20(4): 1194-205.

Basile, G., Aker, M. and R. K. Mortimer (1992). Nucleotide sequence and transcriptional regulation of the yeast recombinational repair gene RAD51. Mol Cell Biol 12(7): 3235-46. 
Bennett, R. J., Sharp, J. A. and J. C.Wang (1998). Purification and characterization of the Sgs1 DNA helicase activity of Saccharomyces cerevisiae. J Biol Chem 273(16): 9644-50.

Bermudez, V. P., Lindsey-Boltz, L. A., Cesare, A. J., Maniwa, Y., et al. (2003). Loading of the human 9-1-1 checkpoint complex onto DNA by the checkpoint clamp loader hRad17-replication factor C complex in vitro. Proc Natl Acad Sci U S A 100(4): 1633-8.

Bjergbaek, L., Cobb, J. A., Tsai-Pflugfelder, M. and S. M.Gasser (2005). Mechanistically distinct roles for Sgs1p in checkpoint activation and replication fork maintenance. Embo J 24(2): 405-17.

Branzei, D. and M. Foiani (2005). The DNA damage response during DNA replication. Curr Opin Cell Biol 17(6): 568-75.

Broomfield, S., Chow, B. L. and W. Xiao (1998). MMS2, encoding a ubiquitinconjugating-enzyme-like protein, is a member of the yeast error-free postreplication repair pathway. Proc Natl Acad Sci U S A 95(10): 5678-83.

Cassier-Chauvat, C. and F. Fabre (1991). A similar defect in UV-induced mutagenesis conferred by the rad6 and rad18 mutations of Saccharomyces cerevisiae. Mutat Res 254(3): 247-53.

Chaganti, R. S., Schonberg, S. and J. German (1974). A manyfold increase in sister chromatid exchanges in Bloom's syndrome lymphocytes. Proc Natl Acad Sci U S A 71(11): 4508-12.

Chakraverty, R. K. and I. D. Hickson (1999). Defending genome integrity during DNA replication: a proposed role for RecQ family helicases. Bioessays 21(4): 286-94.

Chakraverty, R. K., Kearsey, J. M., Oakley, T. J., Grenon, M., et al. (2001). Topoisomerase III acts upstream of Rad53p in the S-phase DNA damage checkpoint. Mol Cell Biol 21(21): 7150-62.

Chanet, R., Heude, M., Adjiri, A., Maloisel, L. and F. Fabre (1996). Semidominant mutations in the yeast Rad51 protein and their relationships with the Srs2 helicase. Mol Cell Biol 16(9): 4782-9.

Cho, R. J., Campbell, M. J., Winzeler, E. A., Steinmetz, L., Conway, A., Wodicka, L., et al. (1998). A genome-wide transcriptional analysis of the mitotic cell cycle. Mol Cell 2(1): 65-73.

Clever, B., Interthal, H., Schmuckli-Maurer, J., King, J., Sigrist, M. and W. D.Heyer (1997). Recombinational repair in yeast: functional interactions between Rad51 and Rad54 proteins. Embo J 16(9): 2535-44.

Cobb, J. A., Bjergbaek, L. and S. M. Gasser (2002). RecQ helicases: at the heart of genetic stability. FEBS Lett 529(1): 43-8.

Cobb, J. A., Bjergbaek, L., Shimada, K., Frei, C. and S. M.Gasser (2003). DNA polymerase stabilization at stalled replication forks requires Mec1 and the RecQ helicase Sgs1. Embo J 22(16): 4325-36.

Constantinou, A., Tarsounas, M., Karow, J. K., Brosh, R. M., et al. (2000). Werner's syndrome protein (WRN) migrates Holliday junctions and co-localizes with RPA upon replication arrest. EMBO Rep 1(1): 80-4. 
Cordeiro-Stone, M., Makhov, A. M., Zaritskaya, L. S. and J. D. Griffith (1999). Analysis of DNA replication forks encountering a pyrimidine dimer in the template to the leading strand. J Mol Biol 289(5): 1207-18.

Cortez, D., Guntuku, S., Qin, J. and S. J. Elledge (2001). ATR and ATRIP: partners in checkpoint signaling. Science 294(5547): 1713-6.

Costanzo, V. and J. Gautier (2003). Single-strand DNA gaps trigger an ATR- and Cdc7-dependent checkpoint. Cell Cycle 2(1): 17.

D'Amours, D. and S. P. Jackson (2002). The Mre11 complex: at the crossroads of dna repair and checkpoint signalling. Nat Rev Mol Cell Biol 3(5): 317-27.

D'Andrea, A. D. and M. Grompe (2003). The Fanconi anaemia/BRCA pathway. Nat Rev Cancer 3(1): 23-34.

Davis, A. P. and L. S. Symington (2004). RAD51-dependent break-induced replication in yeast. Mol Cell Biol 24(6): 2344-51.

De la Torre-Ruiz, M. A., Green, C. M. and N. F. Lowndes (1998). RAD9 and RAD24 define two additive, interacting branches of the DNA damage checkpoint pathway in budding yeast normally required for Rad53 modification and activation. Embo J 17(9): 2687-98.

Durocher, D., Henckel, J., Fersht, A. R. and S. P. Jackson (1999). The FHA domain is a modular phosphopeptide recognition motif. Mol Cell 4(3): 387-94.

Elledge, S. J. (1996). Cell cycle checkpoints: preventing an identity crisis. Science 274(5293): 1664-72.

Ellis, N. A., Groden, J., Ye, T. Z., Straughen, J., Lennon, D. J., Ciocci, S., et al. (1995). The Bloom's syndrome gene product is homologous to RecQ helicases. Cell 83(4): 655-66.

Emili, A. (1998). MEC1-dependent phosphorylation of Rad9p in response to DNA damage. Mol Cell 2(2): 183-9.

Entian, K. D., Schuster, T., Hegemann, J. H., Becher, D., et al. (1999). Functional analysis of 150 deletion mutants in Saccharomyces cerevisiae by a systematic approach. Mol Gen Genet 262(4-5): 683-702.

Fabre, F., Chan, A., Heyer, W. D and S. Gangloff (2002). Alternate pathways involving Sgs1/Top3, Mus81/Mms4, and Srs2 prevent formation of toxic recombination intermediates from single-stranded gaps created by DNA replication. Proc Natl Acad Sci U S A 99(26): 16887-92.

Ferguson, D. O. and W. K. Holloman (1996). Recombinational repair of gaps in DNA is asymmetric in Ustilago maydis and can be explained by a migrating Dloop model. Proc Natl Acad Sci U S A 93(11): 5419-24.

Fishman-Lobell, J., Rudin, N. and J. E. Haber (1992). Two alternative pathways of double-strand break repair that are kinetically separable and independently modulated. Mol Cell Biol 12(3): 1292-303.

Fogel, S. and R. K. Mortimer (1969). Informational transfer in meiotic gene conversion. Proc Natl Acad Sci U S A 62(1): 96-103.

Foray, N., Marot, D., Gabriel, A., Randrianarison, V., Carr, A. M., et al. (2003). A subset of ATM- and ATR-dependent phosphorylation events requires the BRCA1 protein. Embo J 22(11): 2860-71. 
Friedberg, E. C. (2003). DNA damage and repair. Nature 421(6921): 436-40.

Friedberg, E. C., Fischhaber, P. L. and C. Kisker (2001). Error-prone DNA polymerases: novel structures and the benefits of infidelity. Cell 107(1): 9-12.

Game, J. C. and R. K. Mortimer (1974). A genetic study of X-ray sensitive mutants in yeast. Mutat Res 24(3): 281-92.

Gangloff, S., de Massy, B., Arthur, L., Rothstein, R. and F. Fabre (1999). The essential role of yeast topoisomerase III in meiosis depends on recombination. Embo J 18(6): 1701-11.

Gangloff, S., McDonald, J. P., Bendixen, C., Arthur, L., and R. Rothstein (1994). The yeast type I topoisomerase Top3 interacts with Sgs1, a DNA helicase homolog: a potential eukaryotic reverse gyrase. Mol Cell Biol 14(12): 8391-8.

Gangloff, S., Soustelle, C. and F. Fabre (2000). Homologous recombination is responsible for cell death in the absence of the Sgs1 and Srs2 helicases. Nat Genet 25(2): 192-4.

Garcia-Higuera, I., Taniguchi, T., Ganesan, S., Meyn, M. S., et al. (2001). Interaction of the Fanconi anemia proteins and BRCA1 in a common pathway. Mol Cell 7(2): 249-62.

Gatei, M., Scott, S. P., Filippovitch, I., Soronika, N., et al. (2000). Role for ATM in DNA damage-induced phosphorylation of BRCA1. Cancer Res 60(12): 3299304.

Gietz, D., St Jean, A., Woods, R. A. and R. H. Schiestl (1992). Improved method for high efficiency transformation of intact yeast cells. Nucleic Acids Res 20(6): 1425.

Gietz, R. D. and A. Sugino (1988). New yeast-Escherichia coli shuttle vectors constructed with in vitro mutagenized yeast genes lacking six-base pair restriction sites. Gene 74(2): 527-34.

Gilbert, C. S., Green, C. M. and N. F. (2001). Budding yeast Rad9 is an ATPdependent Rad53 activating machine. Mol Cell 8(1): 129-36.

Golin, J. E. and M. S. Esposito (1984). Coincident gene conversion during mitosis in saccharomyces. Genetics 107(3): 355-65.

Golin, J. E. and H. Tampe (1988). Coincident recombination during mitosis in saccharomyces: distance-dependent and -independent components. Genetics 119(3): 541-7.

Gottifredi, V. and C. Prives (2005). The S phase checkpoint: when the crowd meets at the fork. Semin Cell Dev Biol 16(3): 355-68.

Green, C. M., Erdjument-Bromage, H., Tempst, P. and N. F. Lowndes (2000). A novel $\operatorname{Rad} 24$ checkpoint protein complex closely related to replication factor $\mathrm{C}$. Curr Biol 10(1): 39-42.

Greenwell, P. W., Kronmal, S. L., Porter, S. E., Gassenhuber, J., Obermaier, B. And T. D. Petes (1995). TEL1, a gene involved in controlling telomere length in $\mathrm{S}$. cerevisiae, is homologous to the human ataxia telangiectasia gene. Cell 82(5): 823-9.

Gregory, R. C., Taniguchi, T. and A. D. D'Andrea (2003). Regulation of the Fanconi anemia pathway by monoubiquitination. Semin Cancer Biol 13(1): 77-82. 
Grenon, M., Gilbert, C. and N. F. Lowndes (2001). Checkpoint activation in response to double-strand breaks requires the Mre11/Rad50/Xrs2 complex. Nat Cell Biol 3(9): 844-7.

Griffiths, D. J., Barbet, N. C., McCready, S., Lehmann, A. R. and A. M. Carr (1995). Fission yeast rad17: a homologue of budding yeast RAD24 that shares regions of sequence similarity with DNA polymerase accessory proteins. Embo J 14(23): 5812-23.

Haracska, L., Torres-Ramos, C. A., Johnson, R. E., Prakash, S. and L. Prakash (2004). Opposing effects of ubiquitin conjugation and SUMO modification of PCNA on replicational bypass of DNA lesions in Saccharomyces cerevisiae. Mol Cell Biol 24(10): 4267-74.

Hays, S. L., Firmenich, A. A. and P. Berg (1995). Complex formation in yeast double-strand break repair: participation of $\operatorname{Rad} 51, \operatorname{Rad} 52$, $\operatorname{Rad} 55$, and $\operatorname{Rad} 57$ proteins. Proc Natl Acad Sci U S A 92(15): 6925-9.

Higgins, N. P., Kato, K. And B. Strauss (1976). A model for replication repair in mammalian cells. J Mol Biol 101(3): 417-25.

Higuchi, K., Katayama, T., Iwai, S., Hidaka, M., Horiuchi, T. and H. Maki (2003). Fate of DNA replication fork encountering a single DNA lesion during oriC plasmid DNA replication in vitro. Genes Cells 8(5): 437-49.

Hoege, C., Pfander, B., Moldovan, G. L., Pyrowolakis, G. and S. Jentsch (2002). RAD6-dependent DNA repair is linked to modification of PCNA by ubiquitin and SUMO. Nature 419(6903): 135-41.

Hofmann, R. M. and C. M. Pickart (1999). Noncanonical MMS2-encoded ubiquitin-conjugating enzyme functions in assembly of novel polyubiquitin chains for DNA repair. Cell 96(5): 645-53.

Hurst, D. D., Fogel, S. and R. K. Mortimer (1972). Conversion-associated recombination in yeast (hybrids-meiosis-tetrads-marker loci-models). Proc Natl Acad Sci U S A 69(1): 101-5.

Hussain, S., Wilson, J. B., Medhurst, A. L., Hejna, J., Witt, E., et al. (2004). Direct interaction of FANCD2 with BRCA2 in DNA damage response pathways. Hum Mol Genet 13(12): 1241-8.

Ira, G., Malkova, A., Liberi, G., Foiani, M. and J. E. Haber (2003). Srs2 and Sgs1-Top3 suppress crossovers during double-strand break repair in yeast. Cell 115(4): 401-11.

Ivanov, E. L., Sugawara, N., Fishman-Lobell, J. and J. E. Haber (1996). Genetic requirements for the single-strand annealing pathway of double-strand break repair in Saccharomyces cerevisiae. Genetics 142(3): 693-704.

Jaskelioff, M., Van Komen, S., Krebs, J. E., Sung, P. and C. L. Peterson (2003). $\operatorname{Rad} 54 \mathrm{p}$ is a chromatin remodeling enzyme required for heteroduplex DNA joint formation with chromatin. J Biol Chem 278(11): 9212-8.

Jentsch, S., McGrath, J. P. and A. Varshavsky (1987). The yeast DNA repair gene RAD6 encodes a ubiquitin-conjugating enzyme. Nature 329(6135): 131-4. 
Jiang, H., Xie, Y., Houston, P., Stemke-Hale, K., Mortensen, U. H., et al. (1996). Direct association between the yeast Rad51 and Rad54 recombination proteins. J Biol Chem 271(52): 33181-6.

Joenje, H. and K. J. Patel (2001). The emerging genetic and molecular basis of Fanconi anaemia. Nat Rev Genet 2(6): 446-57.

Johnson, E. S. and A. A. Gupta (2001). An E3-like factor that promotes SUMO conjugation to the yeast septins. Cell 106(6): 735-44.

Johnson, R. D. and L. S. Symington (1995). Functional differences and interactions among the putative RecA homologs Rad51, Rad55, and Rad57. Mol Cell Biol 15(9): 4843-50.

Johnson, R. E., Prakash, S. and L. Prakash (1994). Yeast DNA repair protein RAD5 that promotes instability of simple repetitive sequences is a DNAdependent ATPase. J Biol Chem 269(45): 28259-62.

Johzuka, K. and H. Ogawa (1995). Interaction of Mre11 and Rad50: two proteins required for DNA repair and meiosis-specific double-strand break formation in Saccharomyces cerevisiae. Genetics 139(4): 1521-32.

Jonsson, Z. O. and U. Hubscher (1997). Proliferating cell nuclear antigen: more than a clamp for DNA polymerases. Bioessays 19(11): 967-75.

Kaliraman, V., Mullen, J. R., Fricke, W. M., Bastin-Shanower, S. A. and S. J. Brill (2001). Functional overlap between Sgs1-Top3 and the Mms4-Mus81 endonuclease. Genes Dev 15(20): 2730-40.

Kans, J. A. and R. K. Mortimer (1991). Nucleotide sequence of the RAD57 gene of Saccharomyces cerevisiae. Gene 105(1): 139-40.

Karow, J. K., Constantinou, A., Li, J. L., West, S. C. and I. D. Hickson (2000). The Bloom's syndrome gene product promotes branch migration of holliday junctions. Proc Natl Acad Sci U S A 97(12): 6504-8.

Kennedy, R. D. and A. D. D'Andrea (2005). The Fanconi Anemia/BRCA pathway: new faces in the crowd. Genes Dev 19(24): 2925-40.

Kim, R. A. and J. C. Wang (1992). Identification of the yeast TOP3 gene product as a single strand-specific DNA topoisomerase. J Biol Chem 267(24): 17178-85.

Klein, H. L. (2001). Mutations in recombinational repair and in checkpoint control genes suppress the lethal combination of srs2Delta with other DNA repair genes in Saccharomyces cerevisiae. Genetics 157(2): 557-65.

Komori, K., Fujikane, R., Shinagawa, H. and Y. Ishino (2002). Novel endonuclease in Archaea cleaving DNA with various branched structure. Genes Genet Syst 77(4): 227-41.

Kondo, T., Wakayama, T., Naiki, T., Matsumoto, K. and K. Sugimoto (2001). Recruitment of Mec1 and Ddc1 checkpoint proteins to double-strand breaks through distinct mechanisms. Science 294(5543): 867-70.

Kool, E. T. (2002). Active site tightness and substrate fit in DNA replication. Annu Rev Biochem 71: 191-219.

Kramer, B., Kramer, W., Williamson M. S. And S. Fogel (1989). Eteroduplex DNA correction in Saccharomyces cerevisiae is mismatch specific and requires functional PMS genes. Mol. Cell. Biol. 9: 4432-4440 
Krejci, L., Macris, M., Li, Y., Van Komen, S., Villemain, J. Ellenberger, T., et al. (2004). Role of ATP hydrolysis in the antirecombinase function of Saccharomyces cerevisiae Srs2 protein. J Biol Chem 279(22): 23193-9.

Krejci, L., Van Komen, S., Li, Y., Villemain, J., Reddy, M. S., et al. (2003). DNA helicase Srs2 disrupts the Rad51 presynaptic filament. Nature 423(6937): 305-9.

Krogh, B. O. and L. S. Symington (2004). Recombination proteins in yeast. Annu Rev Genet 38: 233-71.

Kuzminov, A. (1995). Collapse and repair of replication forks in Escherichia coli. Mol Microbiol 16(3): 373-84.

Lawrence, C. W. and R. Christensen (1976). UV mutagenesis in radiationsensitive strains of yeast. Genetics 82(2): 207-32.

Lawrence, C. W. and R. B. Christensen (1979). Metabolic suppressors of trimethoprim and ultraviolet light sensitivities of Saccharomyces cerevisiae rad6 mutants. J Bacteriol 139(3): 866-76.

Lea, D. E. and C. A. Coulson (1948). The distribution of mutants in bacterial populations. J Genet 49: 248-264.

Lee, S. K., Johnson, R. E., Yu, S. L., Prakash, L. and S. Prakash (1999). Requirement of yeast SGS1 and SRS2 genes for replication and transcription. Science 286(5448): 2339-42.

Levitus, M., Waisfisz, Q., Godthelp, B. C., de Vries, Y., Hussain, S., et al. (2005). The DNA helicase BRIP1 is defective in Fanconi anemia complementation group J. Nat Genet 37(9): 934-5.

Li, Z., Xiao, W., McCormick, J. J. and V. M. Maher (2002). Identification of a protein essential for a major pathway used by human cells to avoid UV-induced DNA damage. Proc Natl Acad Sci U S A 99(7): 4459-64.

Liberi, G., Chiolo, I., Pellicioli, A., Lopes, M., Plevani P., et al. (2000). Srs2 DNA helicase is involved in checkpoint response and its regulation requires a functional Mec1-dependent pathway and Cdk1 activity. EMBO J 19(18): 5027-38.

Liberi, G., Maffioletti, G., Lucca, C., Chiolo, I., Baryshnikova, A., et al. (2005). Rad51-dependent DNA structures accumulate at damaged replication forks in sgs1 mutants defective in the yeast ortholog of BLM RecQ helicase. Genes Dev 19(3): 339-50.

Lin, S. Y., Li, K., Stewart, G. S. and S. J. Elledge (2000). Mechanism of action of camptothecin. Ann N Y Acad Sci 922: 1-10.

Lin, S. Y., Li, K., Stewart, G. S., and S. J. Elledge (2004). Human Claspin works with BRCA1 to both positively and negatively regulate cell proliferation. Proc Natl Acad Sci U S A 101(17): 6484-9.

Longhese, M. P., Foiani, M., Muzi-Falconi, M., Lucchini, G. and P. Plevani (1998). DNA damage checkpoint in budding yeast. Embo J 17(19): 5525-8.

Lopes, M., Cotta-Ramusino, C., Pellicioli, A., Liberi, G., Plevani, P., et al. (2001). The DNA replication checkpoint response stabilizes stalled replication forks. Nature 412(6846): 557-61. 
Lovett, S. T. (1994). Sequence of the RAD55 gene of Saccharomyces cerevisiae: similarity of RAD55 to prokaryotic RecA and other RecA-like proteins. Gene 142(1): 103-6.

Lowndes, N. F. and J. R. Murguia (2000). Sensing and responding to DNA damage. Curr Opin Genet Dev 10(1): 17-25.

Lu, J., Mullen, J. R., Brill, S. J., Kleff, S., Romeo, A. M. and R. Sternglanz (1996). Human homologues of yeast helicase. Nature 383(6602): 678-9.

Majka, J. and P. M. Burgers (2004). The PCNA-RFC families of DNA clamps and clamp loaders. Prog Nucleic Acid Res Mol Biol 78: 227-60.

Malkova, A., Ivanov, E. L. and J. E. Haber (1996). Double-strand break repair in the absence of RAD51 in yeast: a possible role for break-induced DNA replication. Proc Natl Acad Sci U S A 93(14): 7131-6.

Mankouri, H. W., Craig, T. J. and A. Morgan (2002). SGS1 is a multicopy suppressor of srs2: functional overlap between DNA helicases. Nucleic Acids Res 30(5): 1103-13.

Maryon, E. and D. Carroll (1991). Characterization of recombination intermediates from DNA injected into Xenopus laevis oocytes: evidence for a nonconservative mechanism of homologous recombination. Mol Cell Biol 11(6): 3278-87.

Masutani, C., Araki, M., Yamada, A., Kusumoto, R., Nogimori, T., et al. (1999). Xeroderma pigmentosum variant (XP-V) correcting protein from HeLa cells has a thymine dimer bypass DNA polymerase activity. Embo J 18(12): 3491-501.

Masutani, C., Kusumoto, R., Iwai, S. and F. Hanaoka (2000). Mechanisms of accurate translesion synthesis by human DNA polymerase eta. Embo J 19(12): 3100-9.

Mazin, A. V., Alexeev, A. A. and S. C. Kowalczykowski (2003). A novel function of Rad54 protein. Stabilization of the Rad51 nucleoprotein filament. J Biol Chem 278(16): 14029-36.

Mazin, A. V., Zaitseva, E., Sung, P. and S. C. Kowalczykowski (2000). Tailed duplex DNA is the preferred substrate for Rad51 protein-mediated homologous pairing. Embo J 19(5): 1148-56.

McIlwraith, M. J., Van Dyck, E., Masson, J. Y., Stasiak, A. Z., Stasiak, A. and S. C. West (2000). Reconstitution of the strand invasion step of double-strand break repair using human Rad51 Rad52 and RPA proteins. J Mol Biol 304(2): 151-64.

Meetei, A. R., de Winter J. P., et al. (2003). A novel ubiquitin ligase is deficient in Fanconi anemia. Nat Genet 35(2): 165-70.

Meetei, A. R., de Winter, J. P., Medhurst, A. L., Wallisch, M., et al. (2005). A human ortholog of archaeal DNA repair protein Hef is defective in Fanconi anemia complementation group M. Nat Genet 37(9): 958-63.

Melo, J. A., Cohen, J. and D. P.Toczyski (2001). Two checkpoint complexes are independently recruited to sites of DNA damage in vivo. Genes Dev 15(21): 2809-21.

Miyajima, A., Seki, M., Onoda, F., Shiratori, M., Odagiri, N., et al. (2000). Sgs1 helicase activity is required for mitotic but apparently not for meiotic functions. Mol Cell Biol 20(17): 6399-409. 
Mohaghegh, P. and I. D. Hickson (2001). DNA helicase deficiencies associated with cancer predisposition and premature ageing disorders. Hum Mol Genet 10(7): 741-6.

Montelone, B. A., Prakash, S. and L. Prakash (1981). Recombination and mutagenesis in rad6 mutants of Saccharomyces cerevisiae: evidence for multiple functions of the RAD6 gene. Mol Gen Genet 184(3): 410-5.

Morgan, E. A., Shah, N. and L. S. Symington (2002). The requirement for ATP hydrolysis by Saccharomyces cerevisiae Rad51 is bypassed by mating-type heterozygosity or RAD54 in high copy. Mol Cell Biol 22(18): 6336-43.

Morrison, A., Christensen, R. B., Alley, J., Beck, A. K., et al. (1989). REV3, a Saccharomyces cerevisiae gene whose function is required for induced mutagenesis, is predicted to encode a nonessential DNA polymerase. J Bacteriol 171(10): 5659-67.

Morrow, D. M., Connelly, C. and P. Hieter (1997). Break copy duplication: a model for chromosome fragment formation in Saccharomyces cerevisiae. Genetics 147(2): 371-82.

Morrow, D. M., Tagle, D. A., Shiloh, Y., Collins, F. S. and P. Hieter (1995). TEL1, an S. cerevisiae homolog of the human gene mutated in ataxia telangiectasia, is functionally related to the yeast checkpoint gene MEC1. Cell 82(5): 831-40.

Mosedale, G., Niedzwiedz, W., Alpi, A., Perrina, F., et al. (2005). The vertebrate Hef ortholog is a component of the Fanconi anemia tumor-suppressor pathway. Nat Struct Mol Biol 12(9): 763-71.

Mullen, J. R., Kaliraman, V. and S. J. Brill (2000). Bipartite structure of the SGS1 DNA helicase in Saccharomyces cerevisiae. Genetics 154(3): 1101-14.

Myung, K., Datta, A., Chen, C. and R. D. Kolodner (2001). SGS1, the Saccharomyces cerevisiae homologue of BLM and WRN, suppresses genome instability and homeologous recombination. Nat Genet 27(1): 113-6.

Nakada, D., Matsumoto, K. and K. Sugimoto (2003). ATM-related Tel1 associates with double-strand breaks through an Xrs2-dependent mechanism. Genes Dev 17(16): 1957-62.

Nakanishi, K., Taniguchi, T., Ranganathan, V., New, H. V., et al. (2002). Interaction of FANCD2 and NBS1 in the DNA damage response. Nat Cell Biol 4(12): 913-20.

Nassif, N., Penney, J., Pal, S., Engels, W. R. and G. B. Gloor (1994). Efficient copying of nonhomologous sequences from ectopic sites via P-element-induced gap repair. Mol Cell Biol 14(3): 1613-25.

Nelson, J. R., Lawrence, C. W. and D. C.Hinkle (1996). Deoxycytidyl transferase activity of yeast REV1 protein. Nature 382(6593): 729-31.

New, J. H., Sugiyama, T., Zaitseva, E. and S. C. Kowalczykowski (1998). Rad52 protein stimulates DNA strand exchange by Rad51 and replication protein A. Nature 391(6665): 407-10. 
Nyberg, K. A., Michelson, R. J., Putnam, C. W. and T. A. Weinert (2002).

Toward maintaining the genome: DNA damage and replication checkpoints. Annu Rev Genet 36: 617-56.

Oakley, T. J. and I. D. Hickson (2002). Defending genome integrity during Sphase: putative roles for RecQ helicases and topoisomerase III. DNA Repair (Amst) 1(3): 175-207.

Ogawa, T., Yu, X., Shinohara, A. and E. H. Egelman (1993). Similarity of the yeast RAD51 filament to the bacterial RecA filament. Science 259(5103): 1896-9.

Onoda, F., Seki, M., Miyajima, A. and T. Enomoto (2000). Elevation of sister chromatid exchange in Saccharomyces cerevisiae sgs 1 disruptants and the relevance of the disruptants as a system to evaluate mutations in Bloom's syndrome gene. Mutat Res 459(3): 203-9.

Orr-Weaver, T. L. and J. W. Szostak (1983). Yeast recombination: the association between double-strand gap repair and crossing-over. Proc Natl Acad Sci U S A 80(14): 4417-21.

Orr-Weaver, T. L., Szostak, J. W. and R. T. Rothstein (1981). Yeast transformation: a model system for the study of recombination. Proc Natl Acad Sci U S A 78(10): 6354-8.

Osman, F., Dixon, J., Doe, C. L. and M. C. Whitby (2003). Generating crossovers by resolution of nicked Holliday junctions: a role for Mus81-Eme1 in meiosis. Mol Cell 12(3): 761-74.

Paciotti, V., Clerici, M., Lucchini, G. and M. P. Longhese (2000). The checkpoint protein Ddc2, functionally related to S. pombe Rad26, interacts with Mec1 and is regulated by Mec1-dependent phosphorylation in budding yeast. Genes Dev 14(16): 2046-59.

Pagés, V. and R. P. Fuchs (2003). Uncoupling of leading- and lagging-strand DNA replication during lesion bypass in vivo. Science 300(5623): 1300-3.

Palladino, F. and H. L. Klein (1992). Analysis of mitotic and meiotic defects in Saccharomyces cerevisiae SRS2 DNA helicase mutants. Genetics 132(1): 23-37.

Papouli, E., Chen, S., Davies, A. A., Huttner, D., et al. (2005). Crosstalk between SUMO and ubiquitin on PCNA is mediated by recruitment of the helicase Srs $2 p$. Mol Cell 19(1): 123-33.

Paques, F. and J. E. Haber (1999). Multiple pathways of recombination induced by double-strand breaks in Saccharomyces cerevisiae. Microbiol Mol Biol Rev 63(2): 349-404.

Paull, T. T. and M. Gellert (1998). The 3' to 5' exonuclease activity of Mre 11 facilitates repair of DNA double-strand breaks. Mol Cell 1(7): 969-79.

Pegg, A. E. (1984). Methylation of the O6 position of guanine in DNA is the most likely initiating event in carcinogenesis by methylating agents. Cancer Invest 2(3): 223-31.

Petukhova, G., Stratton, S. and P. Sung (1998). Catalysis of homologous DNA pairing by yeast Rad51 and Rad54 proteins. Nature 393(6680): 91-4.

Petukhova, G., Van Komen, S., Vergano, S., Klein, H. and P. Sung (1999 a). Yeast Rad54 promotes Rad51-dependent homologous DNA pairing via ATP 
hydrolysis-driven change in DNA double helix conformation. J Biol Chem 274(41): 29453-62.

Petukhova, G., Stratton, S. A. and P. Sung (1999 b). Single strand DNA binding and annealing activities in the yeast recombination factor Rad59. J Biol Chem 274(48): 33839-42.

Pfander, B., Moldovan, G. L., Sacher, M., Hoege, C. and S. Jentsch (2005). SUMO-modified PCNA recruits Srs2 to prevent recombination during S phase. Nature 436(7049): 428-33.

Pommier, Y., Pourquier, P., Fan, Y. and D. Strumberg (1998). Mechanism of action of eukaryotic DNA topoisomerase I and drugs targeted to the enzyme. Biochim Biophys Acta 1400(1-3): 83-105.

Postow, L., Crisona, N. J., Peter, B. J., Hardy, C. D. and N. R. Cozzarelli (2001 b). Topological challenges to DNA replication: conformations at the fork. Proc Natl Acad Sci U S A 98(15): 8219-26.

Postow, L., Ullsperger, C., Keller, R. W., Bustamante, C., et al. (2001 a). Positive torsional strain causes the formation of a four-way junction at replication forks. $\mathrm{J}$ Biol Chem 276(4): 2790-6.

Prakash, L. (1974). Lack of chemically induced mutation in repair-deficient mutants of yeast. Genetics 78(4): 1101-18.

Prakash, R., Krejci, L., Van Komen, S. Schürer, K. A. Kramer, W. and P. Sung (2005) Saccharomyces cerevisiae MPH1 Gene, Required for Homologous Recombination-mediated Mutation Avoidance, Encodes a 3' to 5' DNA Helicase. J Biol Chem 280(9): 7854-7860.

Prakash, S., Johnson, R. E. and L. Prakash (2004). Eukaryotic Translesion Synthesis DNA Polymerases: Specificity of Structure and Function. Annu Rev Biochem.

Praash, S. and L. Prakash (2002). Translesion DNA synthesis in eukaryotes: a oneor two-polymerase affair. Genes Dev 16(15): 1872-83.

Quah, S. K., von Borstel, R. C. and P. J. Hastings (1980). The origin of spontaneous mutation in Saccharomyces cerevisiae. Genetics 96(4): 819-39.

Ramotar, D., Belanger, E., Brodeur, I., Masson, J. Y. and E. A. Drobetsky (1998). A yeast homologue of the human phosphotyrosyl phosphatase activator PTPA is implicated in protection against oxidative DNA damage induced by the model carcinogen 4-nitroquinoline 1-oxide. J Biol Chem 273(34): 21489-96.

Rattray, A. J. and L. S. Symington (1994). Use of a chromosomal inverted repeat to demonstrate that the RAD51 and RAD52 genes of Saccharomyces cerevisiae have different roles in mitotic recombination. Genetics 138(3): 587-95.

Roche, H., Gietz, R. D. and B. A. Kunz (1995). Specificities of the Saccharomyces cerevisiae rad6, rad18, and rad52 mutators exhibit different degrees of dependence on the REV3 gene product, a putative nonessential DNA polymerase. Genetics 140(2): 443-56.

Rong, L. and H. L. Klein (1993). Purification and characterization of the SRS2 DNA helicase of the yeast Saccharomyces cerevisiae. J Biol Chem 268(2): 1252. 
Rong, L., Palladino, F., Aguilera, A. and H. L. Klein (1991). The hyper-gene conversion hpr5-1 mutation of Saccharomyces cerevisiae is an allele of the SRS2/RADH gene. Genetics 127(1): 75-85.

Rouse, J. and S. P. Jackson (2002 a). Lcd1p recruits Mec1p to DNA lesions in vitro and in vivo. Mol Cell 9(4): 857-69.

Rouse, J. and S. P. Jackson (2002 b). Interfaces between the detection, signaling, and repair of DNA damage. Science 297(5581): 547-51.

Rudolph, C. (2004). Untersuchungen zur Entstehung und Reparatur von DNASchäden in mph1-Mutanten von Saccharomyces cerevisiae. Göttingen, Von der Universität Göttingen angenommene Diplomarbeit.

Rudolph, C., Schürer, A. and W. Kramer (2006). Facing stalled replicaton forks: The intricacies of doing the right thing. Genome Dynamics and Stability. D. H. Lankenau. Heidelberg, Springer.

Sanchez, Y., Bachant, J., Wang, H., Hu, F., et al. (1999). Control of the DNA damage checkpoint by chk1 and rad53 protein kinases through distinct mechanisms. Science 286(5442): 1166-71.

Santocanale, C. and J. F. Diffley (1998). A Mec1- and Rad53-dependent checkpoint controls late-firing origins of DNA replication. Nature 395(6702): 615-8.

Scheller, J., Schürer, A., Rudolph, C., Hettwer, S. and W. Kramer (2000). MPH1, a yeast gene encoding a DEAH protein, plays a role in protection of the genome from spontaneous and chemically induced damage. Genetics 155(3): 1069-81.

Schiestl, R. H., Prakash, S. and L. Prakash (1990). The SRS2 suppressor of rad6 mutations of Saccharomyces cerevisiae acts by channeling DNA lesions into the RAD52 DNA repair pathway. Genetics 124(4): 817-31.

Schiestl, R. H., Reynolds, P., Prakash, S. And L. Prakash (1989). Cloning and sequence analysis of the Saccharomyces cerevisiae RAD9 gene and further evidence that its product is required for cell cycle arrest induced by DNA damage. Mol Cell Biol 9(5): 1882-96.

Schürer, K. A. (2003). Zur Function des Mph1-Gens von Saccharomyces cerevisiae bei der rekombinativen Umgehung von replikationsarretierended DNA-Schäden. Göttingen, Von der Universität Göttingen angenommene Diplomarbeit.

Schürer, K. A., Rudolph, C., Ulrich, H. D. And W. Kramer (2004). Yeast MPH1 gene functions in an error-free DNA damage bypass pathway that requires genes from Homologous recombination, but not from postreplicative repair. Genetics 166(4): 1673-86.

Shen, J. C. and L. A. Loeb (2000). The Werner syndrome gene: the molecular basis of RecQ helicase-deficiency diseases. Trends Genet 16(5): 213-20.

Shiloh, Y. (2003). ATM and related protein kinases: safeguarding genome integrity. Nat Rev Cancer 3(3): 155-68.

Shinohara, A., Ogawa, H. and T. Ogawa (1992). Rad51 protein involved in repair and recombination in S. cerevisiae is a RecA-like protein. Cell 69(3): 457-70. 
Shinohara, A. and T. Ogawa (1998). Stimulation by Rad52 of yeast Rad51mediated recombination. Nature 391(6665): 404-7.

Sikorski, R. S. and J. D. Boeke (1991). In vitro mutagenesis and plasmid shuffling: from cloned gene to mutant yeast. Methods Enzymol 194: 302-18.

Solinger, J. A. and W. D. Heyer (2001). Rad54 protein stimulates the postsynaptic phase of Rad51 protein-mediated DNA strand exchange. Proc Natl Acad Sci U S A 98(15): 8447-53.

Solinger, J. A., Kiianitsa, K. And W. D. Heyer (2002). Rad54, a Swi2/Snf2-like recombinational repair protein, disassembles Rad51:dsDNA filaments. Mol Cell 10(5): 1175-88.

Song, B. and P. Sung (2000). Functional interactions among yeast Rad51 recombinase, Rad52 mediator, and replication protein A in DNA strand exchange. J Biol Chem 275(21): 15895-904.

Soulier, J. and N. F. Lowndes (1999). The BRCT domain of the S. cerevisiae checkpoint protein Rad9 mediates a Rad9-Rad9 interaction after DNA damage. Curr Biol 9(10): 551-4.

Spell, R. M. and S. Jinks-Robertson (2004). Examination of the roles of Sgs1 and Srs2 helicases in the enforcement of recombination fidelity in Saccharomyces cerevisiae. Genetics 168(4): 1855-65.

Stelter, P. and H. D. Ulrich (2003). Control of spontaneous and damage-induced mutagenesis by SUMO and ubiquitin conjugation. Nature 425(6954): 188-91.

Strumberg, D., Pilon, A. A., Smith, M., Hickey, R., Malkas, L. and Y. Pommier (2000). Conversion of topoisomerase I cleavage complexes on the leading strand of ribosomal DNA into 5'-phosphorylated DNA double-strand breaks by replication runoff. Mol Cell Biol 20(11): 3977-87.

Sugiyama, T. and S. C. Kowalczykowski (2002). Rad52 protein associates with replication protein A (RPA)-single-stranded DNA to accelerate Rad51-mediated displacement of RPA and presynaptic complex formation. J Biol Chem 277(35): 31663-72.

Sun, Z., Hsiao, J., Fay, D. S. and D. F. Stern (1998). Rad53 FHA domain associated with phosphorylated Rad9 in the DNA damage checkpoint. Science 281(5374): 272-4.

Sung, P. (1997). Yeast Rad55 and Rad57 proteins form a heterodimer that functions with replication protein A to promote DNA strand exchange by Rad51 recombinase. Genes Dev 11(9): 1111-21.

Sung, P. and D. L. Robberson (1995). DNA strand exchange mediated by a RAD51-ssDNA nucleoprotein filament with polarity opposite to that of RecA. Cell 82(3): 453-61.

Sung, P. and S. A. Stratton (1996). Yeast Rad51 recombinase mediates polar DNA strand exchange in the absence of ATP hydrolysis. J Biol Chem 271(45): 27983-6.

Svoboda, D. L. and J. M. Vos (1995). Differential replication of a single, UVinduced lesion in the leading or lagging strand by a human cell extract: fork uncoupling or gap formation. Proc Natl Acad Sci U S A 92(26): 11975-9. 
Symington, L. S. (2002). Role of RAD52 epistasis group genes in homologous recombination and double-strand break repair. Microbiol Mol Biol Rev 66(4): 630-70, table of contents.

Szostak, J. W., Orr-Weaver, T. L., Rothstein, R. J. and F. W. Stahl (1983). The double-strand-break repair model for recombination. Cell 33(1): 25-35.

Taniguchi, T., Garcia-Higuera, I., Andreassen, P. R., Gregory, R. C., et al. (2002). S-phase-specific interaction of the Fanconi anemia protein, FANCD2, with BRCA1 and RAD51. Blood 100(7): 2414-20.

Tercero, J. A. and J. F. Diffley (2001). Regulation of DNA replication fork progression through damaged DNA by the Mec1/Rad53 checkpoint. Nature 412(6846): 553-7.

Tibbetts, R. S., Cortez, D., Brumbaugh, K. M., Scully, R., et al. (2000). Functional interactions between BRCA1 and the checkpoint kinase ATR during genotoxic stress. Genes Dev 14(23): 2989-3002.

Trujillo, K. M., Roh, D. H., Chen, L., Van Komen, S., et al. (2003). Yeast xrs2 binds DNA and helps target rad50 and mre11 to DNA ends. J Biol Chem 278(49): 48957-64.

Trujillo, K. M. and P. Sung (2001). DNA structure-specific nuclease activities in the Saccharomyces cerevisiae Rad50/Mre11 complex. J Biol Chem 276(38): 35458-64.

Tsurimoto, T. (1999). PCNA binding proteins. Front Biosci 4: D849-58.

Turesky, R. J. (1994). DNA adducts of heterocyclic aromatic amines, arylazides and 4-nitroquinoline 1-oxide. IARC Sci Publ 125: 217-28.

Ulrich, H. D. (2005). The RAD6 pathway: control of DNA damage bypass and mutagenesis by ubiquitin and SUMO. Chembiochem 6(10): 1735-43.

Ulrich, H. D. and S. Jentsch (2000). Two RING finger proteins mediate cooperation between ubiquitin- conjugating enzymes in DNA repair. Embo J 19(13): 3388-97.

Unsal-Kacmaz, K. and A. Sancar (2004). Quaternary structure of ATR and effects of ATRIP and replication protein A on its DNA binding and kinase activities. Mol Cell Biol 24(3): 1292-300.

Usui, T., Ogawa, H., and J. H. Petrini (2001). A DNA damage response pathway controlled by Tell and the Mre11 complex. Mol Cell 7(6): 1255-66.

Usui, T., Ohta, T., Oshiumi, H., Tomizawa, J., Ogawa, H. and T. Ogawa (1998). Complex formation and functional versatility of Mre11 of budding yeast in recombination. Cell 95(5): 705-16.

Van Komen, S., Petukhova, G., Sigurdsson, S., Stratton, S. and P. Sung (2000). Superhelicity-driven homologous DNA pairing by yeast recombination factors Rad51 and Rad54. Mol Cell 6(3): 563-72.

Van Komen, S., Reddy, M. S., Krejci, L., Klein, H. and P. Sung (2003). ATPase and DNA helicase activities of the Saccharomyces cerevisiae anti-recombinase Srs2. J Biol Chem 278(45): 44331-7. 
Veaute, X., Jeusset, J., Soustelle, C., Kowalczykowski, S. C., Le Cam, E. And F. Fabre (2003). The Srs2 helicase prevents recombination by disrupting Rad51 nucleoprotein filaments. Nature 423(6937): 309-12.

Venclovas, C. and M. P. Thelen (2000). Structure-based predictions of Rad1, $\operatorname{Rad} 9$, Hus1 and Rad17 participation in sliding clamp and clamp-loading complexes. Nucleic Acids Res 28(13): 2481-93.

Venkitaraman, A. R. (2002). Cancer susceptibility and the functions of BRCA1 and BRCA2. Cell 108(2): 171-82.

Vennos, E. M. and W. D. James (1995). Rothmund-Thomson syndrome. Dermatol Clin 13(1): 143-50.

Vialard, J. E., Gilbert, C. S.,Green, C. M. and N. F. Lowndes (1998). The budding yeast Rad9 checkpoint protein is subjected to Mec1/Tel1- dependent hyperphosphorylation and interacts with Rad53 after DNA damage. Embo J 17(19): 5679-88.

Wach, A., Brachat, A., Alberti-Segui, C., Rebischung, C. and P. Philippsen (1997). Heterologous HIS3 marker and GFP reporter modules for PCR-targeting in Saccharomyces cerevisiae. Yeast 13(11): 1065-75.

Wach, A., Brachat, A., PohImann, R. and P. Philippsen (1994). New heterologous modules for classical or PCR-based gene disruptions in Saccharomyces cerevisiae. Yeast 10(13): 1793-808.

Wang, J. C. (2002). Cellular roles of DNA topoisomerases: a molecular perspective. Nat Rev Mol Cell Biol 3(6): 430-40.

Wang, X., Andreassen, P. R. and A. D. D'Andrea (2004). Functional interaction of monoubiquitinated FANCD2 and BRCA2/FANCD1 in chromatin. Mol Cell Biol 24(13): 5850-62.

Washington, M. T., Johnson, R. E., Prakash, S. and L. Prakash (1999). Fidelity and processivity of Saccharomyces cerevisiae DNA polymerase eta. J Biol Chem 274(52): 36835-8.

Washington, M. T., Johnson, R. E., Prakash, S. and L. Prakash (2000). Accuracy of thymine-thymine dimer bypass by Saccharomyces cerevisiae DNA polymerase eta. Proc Natl Acad Sci U S A 97(7): 3094-9.

Watt, P. M., Hickson, I. D., Borts, R. H. and E. J. Louis (1996). SGS1, a homologue of the Bloom's and Werner's syndrome genes, is required for maintenance of genome stability in Saccharomyces cerevisiae. Genetics 144(3): 935-45.

Watt, P. M., Louis, E. J., Borts, R. H. and I. D. Hickson (1995). Sgs1: a eukaryotic homolog of E. coli RecQ that interacts with topoisomerase II in vivo and is required for faithful chromosome segregation. Cell 81(2): 253-60.

Weinert, T. and L. Hartwell (1989). Control of G2 delay by the rad9 gene of Saccharomyces cerevisiae. J Cell Sci Suppl 12: 145-8.

Wu, L., Davies, S. L., Levitt, N. C. and I. D. Hickson (2001). Potential role for the BLM helicase in recombinational repair via a conserved interaction with RAD51. J Biol Chem 276(22): 19375-81. 
Wu, L. and I. D. Hickson (2003). The Bloom's syndrome helicase suppresses crossing over during homologous recombination. Nature 426(6968): 870-4.

Xiao, W., Chow, B. L., Fontanie, T., Ma, L., Bacchetti, S., Hryciw, T. and S. Broomfield (1999). Genetic interactions between error-prone and error-free postreplication repair pathways in Saccharomyces cerevisiae. Mutat Res 435(1): $1-11$.

Yamagata, K., Kato, J., Shimamoto, A., Goto, M., Furuichi, Y. and H Ikeda (1998). Bloom's and Werner's syndrome genes suppress hyperrecombination in yeast sgs 1 mutant: implication for genomic instability in human diseases. Proc Natl Acad Sci U S A 95(15): 8733-8.

Zhao, X., Georgieva, B., Chabes, A., Domkin, V., et al. (2000). Mutational and structural analyses of the ribonucleotide reductase inhibitor Sml1 define its Rnr1 interaction domain whose inactivation allows suppression of mec1 and rad53 lethality. Mol Cell Biol 20(23): 9076-83.

Zhao, X., Muller, E. G. and R. Rothstein (1998). A suppressor of two essential checkpoint genes identifies a novel protein that negatively affects dNTP pools. Mol Cell 2(3): 329-40.

Zou, L., Cortez, D. and S. J. Elledge (2002)."Regulation of ATR substrate selection by Rad17-dependent loading of Rad9 complexes onto chromatin. Genes Dev 16(2): 198-208.

Zou, L. and S. J. Elledge (2003). Sensing DNA damage through ATRIP recognition of RPA-ssDNA complexes. Science 300(5625): 1542-8. 


\section{ABBREVIATIONS}

$\begin{array}{ll}\text { ATM } & \text { Ataxia Telangiectasia mutated } \\ \text { ATR } & \text { Ataxia Telangiectasia and rad-related } \\ \text { BIR } & \text { Break induced replication model } \\ \text { BLM } & \text { Bloom's syndrome } \\ \text { BRCA1/2 } & \text { Breast cancer susceptibility genes } \\ \text { DBS } & \text { Double strand break } \\ \text { DSBR } & \text { Double-strand-break repair model } \\ \text { dsDNA } & \text { Double strand DNA } \\ \text { HJ } & \text { Holliday junction } \\ \text { HR } & \text { Homologous recombination } \\ \text { MMS } & \text { Methyl methane-sulfonate } \\ \text { 4-NQO } & \text { 4-nitroquinoline-1-oxide } \\ \text { PCNA } & \text { Proliferating cell nuclear antigene } \\ \text { PIKK } & \text { Phosphatidyl-inositol 3-kinase-like protein } \\ \text { PRR } & \text { Post replicative repair pathway } \\ \text { RFC } & \text { Replication factor C } \\ \text { RPA } & \text { Replication protein A } \\ \text { RTS } & \text { Rothmund-Thomson syndrome } \\ \text { SsDNA } & \text { Single strand DNA } \\ \text { SDSA } & \text { Synthesis-dependent strand-annealing model } \\ \text { SSA } & \text { Single-strand annealing model } \\ \text { TLS } & \text { Translesion DNA synthesis } \\ \text { WRN } & \text { Werner's syndrome } \\ & \end{array}$


I would like to express my gratitude to Wilfried Kramer for the possibility of being involved in this attractive study on DNA replication and repair and for being a precious advisor. Nevertheless I thank the former and present members of our lab: Anke, Christian Rudolph, Marion, Birgit, Despina, Christopher and Michael.

To Marita an everlasting thank for the support in the bureaucratic steps of my career. To Angelika and Marlies I want to say thank for being so indulgent with me during the preparation of my lab material. I'm also grateful to Bettina for being a very helpful person.

My gratitude is also for the groupleaders Hans Joachim Fritz, Andreas Schwienhorst, Susanne Behrens and Harald Kolmar.

A special thank to Gerrit, Christian Hildmann, Rene, Florian, Stefan, Dennis, Thorsten, Uli, Christiane, Stina, Lars, Helena and Swetlana for sharing with me their knowledge and also funny moments. 


\section{LEBENSLAUF}

Name:

Adresse:

Geburtsdatum:

Geburtsort:

Staatsangehörigkeit:

Schulbildung:

1982-1987

$1987-1990$

1990-1995

\section{Hochschulausbildung:}

1995-2002

2001-2002

2003
Evandro Rocco Panico

Düstere Strasse 14/15 37073 Göttingen, Deutchland oder

via $\mathrm{xx}$ settembre, 3b, 73046 Matino (Lecce), Italia

08 Februar 1977

Casarano (LE), Italia

Italienisch

Scuola elementare Raffaele Gentile Matino (LE), Italia

Istituto di scuola media inferiore Dante Aligheri, Matino (LE), Italia

Istituto Tecnico Commerciale A. De Viti de Marco, Casarano (LE), Italia

Studium der Biologie an der Facoltà di scienze Matematiche Fisiche e Naturali, Università degli studi di Lecce, Italia

Diplomarbeit am Istituto ISPA CNR bei Prof. Luigi De Bellis, Laboratorio di Fisiologia Vegetale, Dipartimento di scienze Biologiche, Università degli studi di Lecce, Italia. Thema: „Caratterizzazione biochimica e molecolare del processo di maturazione della fragola“".

Beginn der Dissertation am Institut für Molekulare Genetik und Präparative Molekularbiologie bei PD Dr. Wilfried Kramer 